Portland State University

PDXScholar

Summer 8-25-2014

\title{
Socio-spatial Transformation and Contested Space at the Street Level in Latin America: The Case of Cali, Colombia
}

Maria Janeth Mosquera Becerra

Portland State University

Follow this and additional works at: https://pdxscholar.library.pdx.edu/open_access_etds

Part of the Transportation Commons, and the Urban Studies Commons Let us know how access to this document benefits you.

\section{Recommended Citation}

Mosquera Becerra, Maria Janeth, "Socio-spatial Transformation and Contested Space at the Street Level in Latin America: The Case of Cali, Colombia" (2014). Dissertations and Theses. Paper 1953.

https://doi.org/10.15760/etd.1952

This Dissertation is brought to you for free and open access. It has been accepted for inclusion in Dissertations and Theses by an authorized administrator of PDXScholar. Please contact us if we can make this document more accessible: pdxscholar@pdx.edu. 
Socio-spatial Transformation and Contested Space at the Street Level in Latin America:

The Case of Cali, Colombia

by

Maria Janeth Mosquera Becerra

A dissertation submitted in partial fulfillment of the requirements for the degree of

Doctor of Philosophy

in

Sociology

Dissertation Committee:

Veronica Dujon, Chair

Amy Lubitow

Margaret Everett

Matthew Carlson

Carlos Crespo

Leopoldo Rodríguez

Portland State University

2014 
(C) 2014 Maria Janeth Mosquera Becerra 


\begin{abstract}
Since 2008 , more than $50 \%$ of the world's population has lived in cities and it is projected that by 2050 around $87 \%$ will do so. Designing infrastructure in urban spaces has become increasingly critical for achieving human well-being. This dissertation examines socio-spatial transformation processes related to urbanization, economic development and the marginalization of utilitarian cycling in Cali, Colombia, as a particular expression of the struggle for transportation space occurring in urban areas. The research analyzes (a) the socio-spatial processes that have restricted the use of bicycles as a means of transportation in the city of Cali, Colombia; and (b) the social, health and economic implications for people who use bicycles as their primary means of transportation in this city.
\end{abstract}

Cali is a major city in Latin America and an excellent case to study the complex dynamic of how social and economic forces are evident in resource distribution at the street level. Informed by Harvey's work (1976; 1978; 2012), combined with an environmental justice perspective (Bullard 2007), this research adopts a conceptual framework that examines the transformation of the built environment as part of capitalist led urbanization. It concludes that the implementation of transportation infrastructure was aimed at enabling productivity and profits, with less emphasis on the comprehensive needs of all citizens, ultimately marginalizing transportation options for those of lower socio-economic status. The experience in Cali can be understood as a case of consolidation of inequality at the street level. 
A historical review of Cali's urbanization process demonstrates that cycling as a mode of transportation has been losing social and physical space. Analysis of the political economy of more recent economic development initiatives suggest that the City, in responding to the demands of globalization, and in conjunction with international financial agencies and national government support has implemented a Bus Rapid Transit system and a set of megaprojects which marginalize bike commuters, particularly those who bike out of economic necessity. Although bike commuters recognize economic and health and time-saving benefits of biking to themselves as individuals they also experience daily travel in Cali as a classed, problematic, stigmatized, and transitory activity. From an environmental justice perspective, the resulting impact on residents, particularly, those of lower socioeconomic stratum, unmasks the uneven distribution of environmental benefits and harms. The marginalization of biking as a means of transportation in urban areas in Latin America may be understood as a social injustice similar to the deprivation of parks, schools, health services, or housing endured by residents of lower socioeconomic status. 


\section{Dedication}

To my mom (Doña María) and Víctor Hugo.

This dissertation is dedicated to the memory of my father (Don Luís Carlos) and Harmony, my dear friend. 


\section{Acknowledgments}

Thanks to my adviser Veronica Dujon. She knows very well what it means to be a professor.

I would like to thank the members of my committee for their contributions to my dissertation.

I am grateful for my dear and incredible friends in the U.S., Colombia and in many cities around the world. All of you are in my heart.

I would like to thank my lovely family. Wherever I am, my family will always be with me. 


\section{Table of Contents}

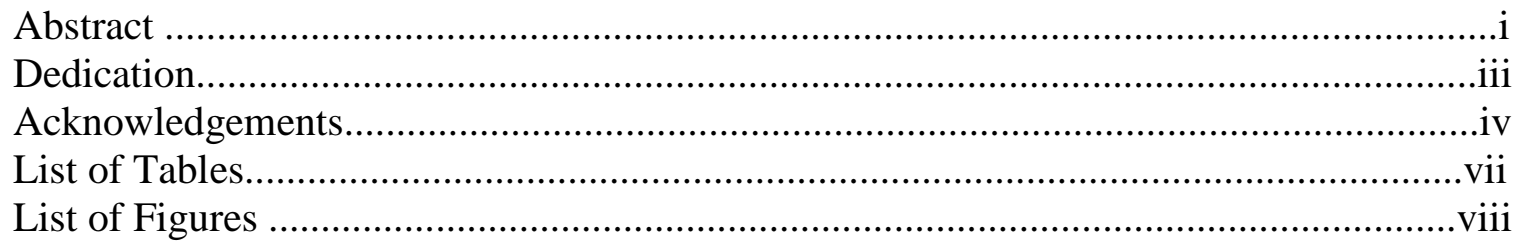

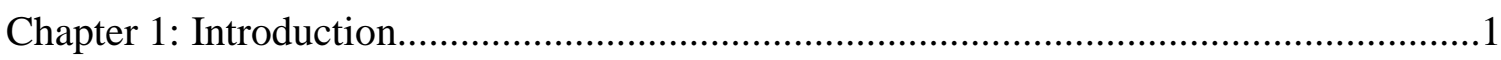

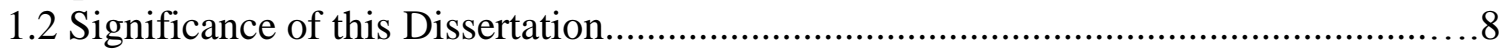

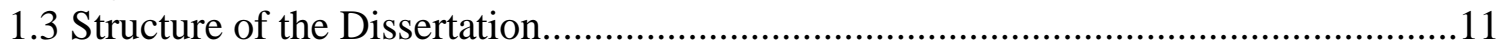

Chapter 2: Review of Literature ........................................................................... 13

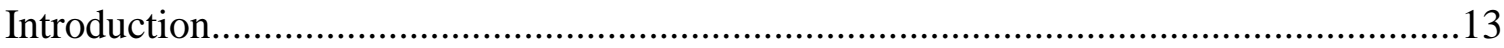

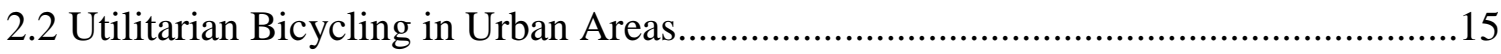

2.3 Theoretical Approaches in Transportation Equity.............................................26

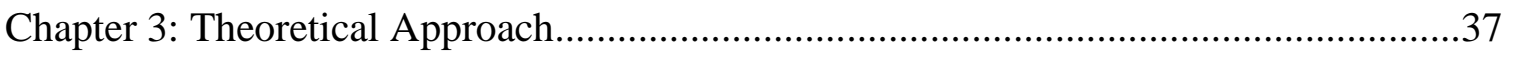

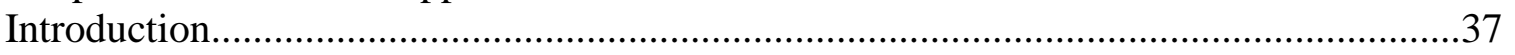

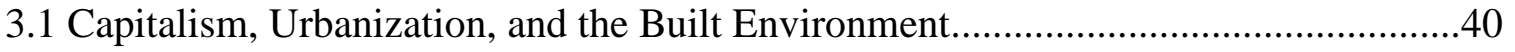

3.2 Environmental Justice Approach..........................................46

Chapter 4:

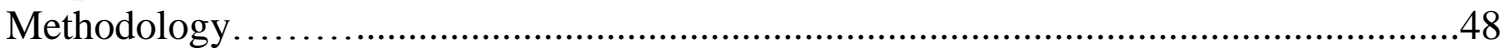

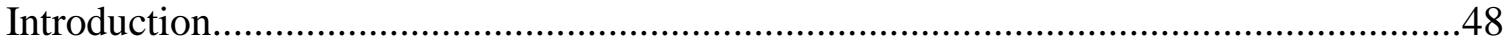

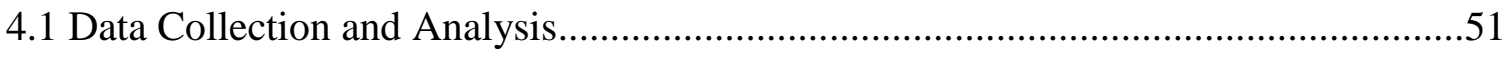

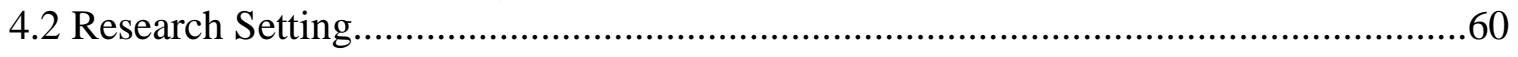

Chapter 5:

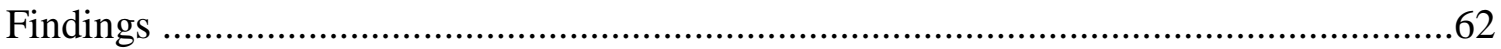

Introduction.............................................................62

5.1. A Chronological Overview of Cali's Urbanization Process........................63

5.1.1 The First Period: Takeoff as an Industrial City $(1945-1958) \ldots \ldots \ldots \ldots \ldots \ldots \ldots 64$

5.1.2 Second Period: Revitalizing the City thought the Pan-American Games

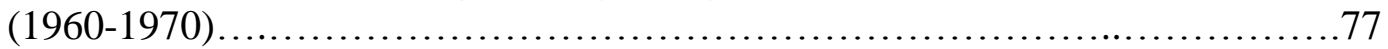

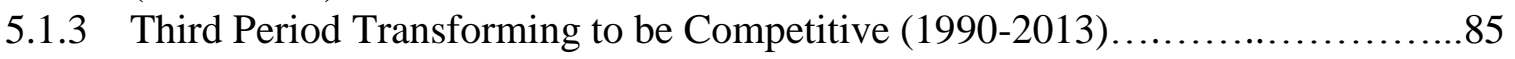

5.2. Current Social and Economic Forces and Processes Limiting Travel by Bike in Cali

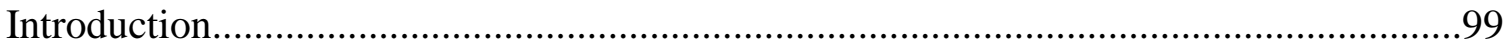

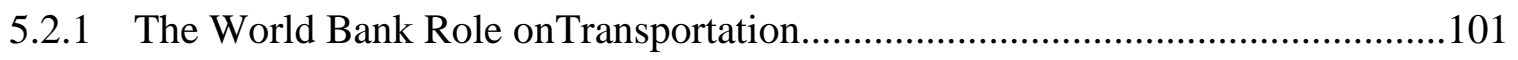

5.2.2 The Strengthening of the Car Industry ............................................................ 112

5.2.3 The Implementation of the Bus Rapid Transit System in Cali............................118

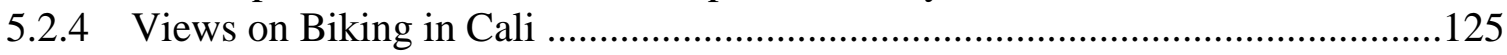


5.2.5 Urban Transportation Planning Sector........................................................ 127

5.2.6 No Counter-hegemonic Processes............................................................. 134

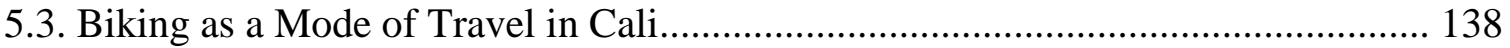

5.3.1 Socioeconomic Conditions of Bikers...................................................................138

5.3.2 Cyclists Experiencing Travel by Bike in Cali.......................................................150

5.2.2.1 Class Conflicts at the Street Level................................................................. 152

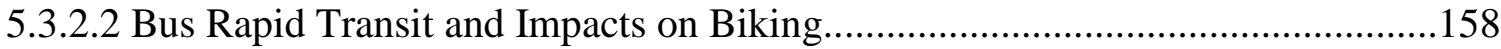

5.3.2.3 Negative Social and Physical Urban Conditions for Biking................................163

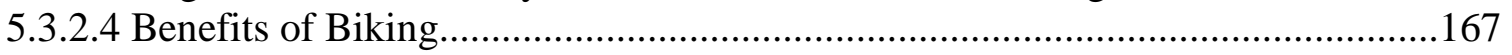

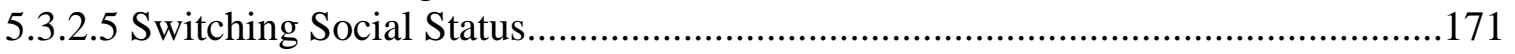

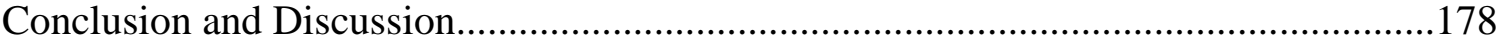

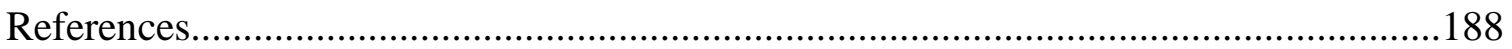

Appendices

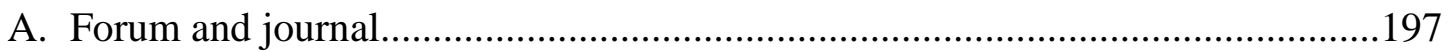

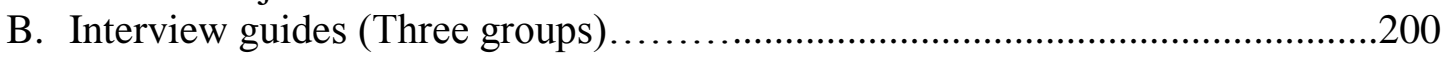

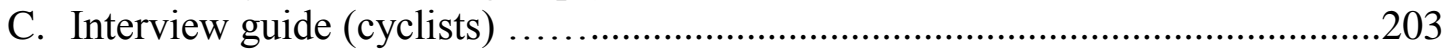




\section{List of Tables}

Table 1- Data reduction steps...............................................58

Table 2 - Constructing the network................................................ 59

Table 3 - Information on interviewed participants ............................. 101

Table 4 - Socio- demographic characteristics of population included in the study.....140

Table 5 - Modes of transportation among population included in the study............142

Table 6 - Participants from the study who reported biking in the last 7 days............143

Table 7 - Time in minutes riding a bike as means of transportation in the last 7 days...144

Table 8 - Socio-environmental perceptions among bikers versus non-bikers............144

Table 9 - Socio-environmental perceptions among bikers........................ 145

Table 10 - Biking use as a means of transportation in Cali..........................148

Table 11 - Contextual information from interviewed participants....................150

Table 12 - Information on interviewed participants.............................151 


\section{List of Figures}

Map 1 - Cali urban area (Neighborhoods by SES).............................61

Map 2 - Routes used by cyclist in Cali, 2011-2012 ..............................131

Map 3 - Current bike paths in Cali, 2011-2013............................... 132

Map 4 - Projected bike paths in Cali, POT 2014-2027...........................133

Picture 1 - The first car with motor in Cali $(1913)$..............................65

Picture 2 - Families using a bike (1928) .....................................66

Picture 3 - Cycling competition $(1927)$.................................... 67

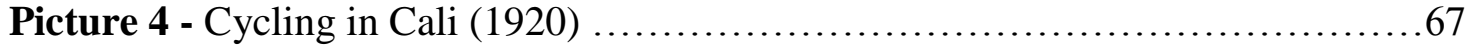

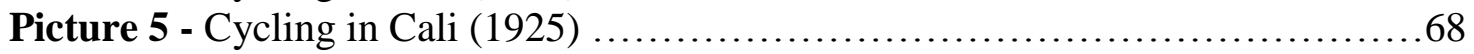

Picture 6 - Motovía in Cali .................................................. 117

Picture 7 - Lacking of physical space...................................... 155

Picture 8 - MIO and Cyclists................................................. 162

Picture 9 - Bike from a father with a boy with disability...................... 170

Figure 1 - Methodological rationale........................................60

Figure 2 - Thematic network for "Class conflict at the street level"................158

Figure 3 - Thematic network for "Bus Rapid Transit and impacts on biking"........163

Figure 4 - Thematic network for "Negative social and physical urban conditions for biking" ............................................................ 167

Figure 5 - Thematic network for "Benefits of biking" ........................ 171

Figure 6 - Thematic network for "Switching social status" ...................... 174 


\section{Chapter 1}

\section{INTRODUCTION}

Since 2008 , more than $50 \%$ of human populations have lived in cities. However, worldwide, there are differences in urbanization processes and levels of urbanization among regions. While currently in Latin America and the Caribbean around $80.3 \%$ of the population already lives in cities, it is expected that by 2025 only $45 \%$ of African populations will be living in urban areas (UN-Habitat 2012). Even though the urbanization process in Latin America and the Caribbean was later than Europe's or that of the U.S, over the last fifty years this region reached $80 \%$ urbanization, a higher proportion than achieved by Europe (73\%) and similar to the U.S (82.3\%) and Canada (80.6\%) (UN-Habitat 2012). Within Latin America itself there are differences between countries and regions in terms of urbanization. By 2010, for example, in the Caribbean region, $75.2 \%$ of the Cuban population lived in urban areas, but in Haiti just $52.1 \%$ of its populace lived in cities (UN-Habitat 2012).

Within urbanization processes, transportation is an important element for urban mobility for both people and commodities, and a key element in accessibility to workplaces, merchandise, services and markets. Indeed, transportation is a strategic factor for economic accumulation because it provides conditions to "accommodate the turnover of capital". As part of the built environment under capitalism, the transportation

system reflects class relations or, more specifically, class struggles. In this 
conceptualization, decisions about what transportation system should be implemented depend on who is designing the city, and for whom the city is being organized. The focus is on the forces and processes that drive urbanization.

This research engages the broad spectrum regarding production and use of built environment in capitalist societies as part of the urbanization process. The project does this in three parts; first, it focuses on Cali's urbanization process in order to identify main historical urban transformations that have neglected the needs of bicycle users. Second, it analyzes recent years when the building of a bike-path network articulated to the Bus Rapid Transit system (BRT) was expected and the built environment is extensively transformed with a new set of constructions called Megaobras. Third, it shows the consequences of constraining biking for people who currently use a bicycle as their principal means of transportation.

The experience with transportation planning and systems in a large Latin American city like Cali, Colombia, is part of a broader process related to the role of urbanization within capitalist development in Latin America. The research seeks to explain the complex set of forces and processes at the global, national and local scales that have influenced the distribution of transportation resources in this large Latin American city. Two theoretical frameworks are particularly useful in elucidating these forces and processes. Harvey's (2012) work on capitalism and urbanization sets struggles in cities over daily life such as transportation or housing, within the distribution of power 
(political and economic) which determines who has the right to the city and who does not. An environmental justice approach complements Harvey's contribution by locating the struggle over resources for environmental well-being within the context of the places where people live, work and play (Bullard 2007; Schweitzer and Valenzuela 2004). An unequal distribution of power and limitations to participating in the decision making processes shaping cities, produces environmental injustice.

According to Harvey (2008), as a kind of human right, the right to the city entails the right to "reshape the process of urbanization" or to shape the city we live in.

"The question of what kind of city we want cannot be divorced from that of what kind of social ties, relationship to nature, lifestyles, technologies and aesthetic values we desire." (p. 23).

Following a critical approach, urbanization in Latin America is understood as part of capitalist accumulation. The first period of urbanization in Latin America is not a consequence of industrialization; on the contrary, industrialization followed urbanization. As Almandoz (2008) explains "Already by the 1920s, parts of Latin America harbored two residents in the cities for each farmer who had remained on the pampas, plains and backlands of its vast geography (...)” (Almandoz, p.66 Cited Beyhaut, 1985, pp. 210211). Indeed, before the 1920s in Latin America, accelerated migration processes corresponded with the interests of imperialist systems fuelled urbanization in this region; circumstances which differed from Europe or the USA where industrialization set the conditions for urbanization (Angotti 1987). 
In fact, scholars explain that urbanization in Latin America was a consequence of the emergence of monopoly capitalism in core capitalist countries (mainly the USA and England) that needed to expand markets to sell their products and invest surplus. They established banks and industries in Latin American cities and promoted the construction of infrastructure for services such as water, transportation and communications, aimed to facilitate conditions to export raw material. As a consequence, migration from rural to urban areas and internal migration were stimulated by dynamics related to monopoly capitalism and promoted the creation of urban centers (metropolises) in Latin America (Angotti 1987).

"The imperialist system, and not early industrial capitalism, set the conditions for urbanization in Latin America. This accounts for the sharp differences between urbanization in Latin America and the developed capitalist countries." (p. 146).

In addition, the second period of urbanization in Latin America, characterized by accelerated and uneven growth, happened during the 1950s and early 60s, as a result of new conditions or requirements for capitalist accumulation. It was only during the fifties and sixties that Latin American countries experienced what was called the Import Substitution Industrialization period (ISI), an economic strategy designed to protect the local industry promoting industrialization and economic growth. ISI was an initiative "to break out of the world division of labor (through) establishing domestic production facilities to manufacture goods which were formerly imported" (Baer 1972; p. 95).

During the ISI period, Latin American countries produced consumer durables for the domestic market, while they continued to import intermediate and capital goods 
necessary for their production. For example, ISI promoted manufacturing industries such as the automobile industry in Chile, Brazil and Argentina. Consequently, industrialization was promoted by ISI strategies creating an extensive urban market and, and in some cases, it was made at the expense of the agricultural sector, which also pushed people from rural to urban areas. Moreover, this ISI process pressed a new "wave" of migration from rural to already established urban areas. However, the rate of urban population growth was higher than the capacity of industries to absorb labor (Baer 1972).

As a consequence, Latin American countries experienced high rate of informal jobs, unemployment, inadequate housing and negative impacts on urban development. The ISI model as applied in Latin America was problematic and showed shortcomings in promoting industrial development. The key failures of this model were related to high costs of local production, limitations to compete with other markets, negative impacts on the agricultural sector, and abandonment of some manufacturing sectors which had been raised before ISI was implemented (Baer 1972; Felix 1989).

More recently, cities, as key sites of activity for the neoliberal economic project of globalization, the new face of capitalist development, have become new locations for promoting competiveness and creating gateways to internationalization. As of the late 1980s and 90s, Latin American countries experienced a "new stage of capitalism" in which new economic, political and social rules were established. Three interrelated 
processes reconfigured the capitalist system: globalization, productive restructuring, and neoliberalism.

Globalization may be understood as both intensive interconnection and increasing exchange of goods, services and people between countries and regions as well as a strategy to create new market niches (McMichael 2012). In this period of capitalism, telecommunications and transportation play a fundamental role in facilitating this process promoted by leading international financial and trade organizations such as the World Bank, International Monetary Fund (IMF) and the World Trade Organization (WTO) in concert with free trade agreements. This period of productive restructuring represented a shift away from Fordism as a production and regulation model to a more flexible production system, referred to by some scholars as post-Fordism, to accommodate reduction in the cost of production. Changes in the organization of labor were implemented as well as changes in spatial distribution of production and mass production. The role of the State was re-conceptualized away from Keynesian Welfare State under the Fordist model to Schumpeterian workfare state under the new model (Jessop 2008). Finally, a neoliberal policy framework, the free market was established as a mechanism to implement the objectives of the new regime. The new role of the State was to enable the functioning of this free market approach by modifying the relationship between private and public sector and promoting a new sociocultural ideology (Sassen 1996). Concomitantly, cities became spaces of competiveness; in fact, scholars report that mega 
projects shaping urban areas in order to be attractive to capital and new international relationships are part of this new capitalist stage (Brenner 2005).

Over the last two decades (from 1990 to 2010) and as a result of socioeconomic transformations driven by neoliberal policies (i.e. free market processes), Latin America experienced an expansion of public modes of transportation, a substantial increase in physical infrastructure for motorized vehicles (UN-Habitat 2012), and an accelerated process of private car usage and motorcycle ownership (Lupano and Sánchez 2009). This tendency toward motorized forms has fuelled an "automotive-based environment" with several social and economic impacts on urban life. These include inequities in physical mobility in the form of limited access to places or services due to financial constraints of private car ownership or fuel costs, and cost of public transportation. There are also inequalities in the impact on public health from air pollution, traffic injuries, and noise. And of key interest to this research are the social inequities associated with constraints to using public streets because of a lack of infrastructure for non-motorized modes of transportation.

In brief, the research focus of this dissertation is the socio-spatial transformations that took place in Cali during the 20st and 21st centuries in order to better understand the conditions and processes that resulted in current conditions for utilitarian cycling in this city. The research questions of this dissertation are: What have been the socio-spatial processes that have contributed to restrict the use of bicycles as transportation in Cali? 
And what are the implications for people who use bicycles as their primary means of transportation in this city, currently? Answering these questions contributes to understanding the intricate relationship between social processes and urban spatial configuration as these pertain to the Latin American context. Particularly, they elucidate the social processes underlying urban forms, identifying key aspects such as class struggles, processes for decision making at different scales, and their impact on people's lives.

\subsection{Significance of this Dissertation}

Transportation is a social and physical determinant of health which is associated with heart disease, mental health problems, respiratory disease, and traffic injuries (McCarthy 2005). In addition, the relationship between transportation systems, physical activity and obesity has been well established by scholars from different areas (Davis, Cavill, Rutter, and Crombie 2005). This research is a fundamental part of author's interest in exploring the relationship between the built environment (i.e., physical characteristics and social processes), public health (i.e., physical activity and obesity), and environmental equity in Latin America's urban areas.

Particularly, the interest is in better understanding the complexities of promoting biking as a means of transportation, as a practical way to meet the WHO's recommendations related to daily physical activity to obtain health benefits in large Latin 
American cities. In doing so, the research topic is oriented towards Cali's urbanization process, to understand whether motorized-oriented development adversely affects cycling as a particular mode of transportation and if it does, how it, re-creates social inequalities in the provision and use of public streets.

In summary, the significance of this study is threefold. First, this study is timely and relevant because, the prominence of non-motorized means of transportation, as part of sustainable transportation, is recognized worldwide. Motorized transportation has negative effects on the environment, generating air pollution and global warming, that in turn has short and long-term effects on people's health conditions (Friedman, Powell, and Hutwagner 2001; Khasnis and Nettleman 2005; Künzli, Kaiser, Medina, and Studnicka 2000). In fact, the emission of greenhouse gases by the motorized transportation sector, using non-renewable fossil fuels, is around 26\% (Chapman 2007). All told, presenting evidence regarding the impact of friendly environmental means of transportation in the transportation agenda of any urban may be considered a worthy social contribution.

Such a contribution for Latin American cities may be particularly valuable since studies about bicycling as mode of travel in that region are scarce or non-existent. This investigation contributes to understanding the difficulties of promoting active travel in urban Latin American settings by analyzing historical urban development and focusing on local, national and international forces and processes that influence urban mobility. In order to achieve more effective public health interventions, public health workers need to 
engage with other sectors such as the transportation sector or urban planning officers because they play a key role in promoting active urban environments.

Second, this research is informed by two interrelated fields of knowledge: sociology and public health. A critical sociological analysis of urban transportation systems contributed to understanding what social, political, institutional, and economic conditions determine people's patterns of mobility in urban areas. Using this approach, the researcher is able to identify how decisions on transportation are made under particular contexts that constrain or allow people's mobility. Ultimately, this research seeks to understand how the selection of $\mathrm{X}$ or $\mathrm{Y}$ means of transportation is not just an individual and rational decision but is influenced by power relationships that shape political decisions related to urban mobility (Vasconcellos 2001; Yago 1983). Moreover, from a public health perspective this research contributes to enlighten the complexities of enhancing physical activity levels through biking in urban areas.

Lastly, findings of this research could be used to make visible the historical and current situation that bicyclists face daily in Cali and in doing so, could contribute to alleviate the problem related to unequal distribution of urban streets in this city. Thus far, as a result of disseminating the main research findings of the project, a group interested in influencing public policies related to biking as a mode of travel in Cali has been established (Appendix A). Additionally, this study opens a new research area related to cycling within urban transportation systems (history and its social impacts) which is 
relevant in Colombia where cycling is very well recognized as a sport and recreational activity but not as a mode of travel. In Colombia competitive cycling has a long history and widespread social support and, as a recreational activity, biking is also a wellsupported and a popular practice. In fact, in urban areas there is a significant number of groups of recreational bikers, most of them consist of men from medium and higher socioeconomic status, that organize day trips very early in the morning and at night and/or during the weekends.

\subsection{Structure of the Dissertation}

This dissertation is organized into six parts. Chapter 1 introduces the construction of the object of study, and presents the research questions. Chapter 2 focuses on the review of literature, incorporating relevant topics regarding utilitarian biking in urban areas. The first part of Chapter 2 presents an overview of how utilitarian cycling in urban contexts has been studied, taking into account three fields: utilitarian cycling and public health, the role of the built environment in stimulating cycling as a mode of travel, and the contributions of historical studies regarding biking in Europe. The second part of Chapter 2 identifies main theoretical approaches used to explain transportation equity. Three theoretical perspectives are discussed: transportation as a social determinant of health, transportation and social exclusion, and environmental justice and transportation. Chapter 2 aims to identify gaps in the academic literature related to utilitarian biking. 
Chapter 3 explains the theoretical approach used in this dissertation. David Harvey's ideas related to the intertwined relationship between capitalism, urbanization and the built environment is a key theoretical piece in this research and used to examine how cities are shaped by class interests and power. This approach is complemented by an environmental justice framework used to shed light on the unequal use of urban streets in Latin America cities. Chapter 4 provides the methodological approach used in this case study in which qualitative and quantitative data were used. Then, Chapter 5 presents the results of the research. It is divided into three parts: a) A chronological overview of the urbanization process of Cali, from 1945 to the present; b) The current institutional forces and relationships at different scales that have influenced local decisions related to urban mobility in general and bike use as a mode of travel in urban areas in particular, and; c) The experience of current cyclists travel by bike in Cali. The final chapter, Chapter 6 presents discussion and conclusion for the research. 


\section{Chapter 2}

\section{Literature Review}

\section{Introduction}

Currently, the larger part of human activities is concentrated in urban areas. By 2050 it is expected that $87 \%$ of the world population will live in cities. Latin America and the Caribbean have already $79 \%$ of people living in urban areas (U.N. 2009). Within urbanization, transportation becomes more complex, involving both people and freight mobility and combining different modes and means of travel, and it is also a key factor related to production, consumption and distribution of goods and services (Rodrigue, Comtois, and Slack 2009). Urban transportation, in general and, utilitarian cycling, in particular, are areas of inquiry in several disciplines and both have been studied with different objectives and approaches.

Utilitarian cycling is defined as cycling for different transportation purposes such as commuting to or from work or school, or going shopping and running errands. In this definition, utilitarian cycling is linked with travel or transportation purposes more than for sport or fun. Utilitarian cycling is an area of growing interest from different disciplines including transportation planning, public health, geography, history and urban planning. In spite of this interest, however, the integration of cycling within urban transportation systems and its implications for, and impact on equity is noticeably under researched. In Latin American cities in particular, although cycling is a historical, traditional and prevalent activity that often occurs under conditions of deprivation, in 
terms of both socioeconomic and physical infrastructure, the literature on utilitarian bicycling remains remarkably sparse.

Most studies about utilitarian cycling are from Europe, USA, Canada and Australia. A recent set of literature from 2005 to 2013 (Böcker 2013; Cavill, Kahlmeier, Rutter, Racioppi, and Oja 2008; Heinen, van Wee, and Maat 2010) suggests at least four areas of inquiry pertinent to utilitarian cycling: a. Identification of factors associated with bicycling as a mode of travel; b. Identification of benefits of bicycling on different health outcomes such as physical activity and obesity; c. Identification of economic benefits of active travel, and; d. Identification of initiatives encouraging or promoting utilitarian cycling. The majority of this research is from the public health area, which in recent years, has been interested in cycling for transportation as a mechanism to increase levels of physical activity in a population. Other research conducted by the transportation sector and urban planning have tended to focus on travel behavior for planning physical infrastructure (Broach, Dill, and Gliebe 2012).

The goal of this literature review is twofold. First, it illustrates how utilitarian cycling in urban areas has been studied across various disciplines. Second, critical for this research, it identifies the central theoretical approaches from a sociological perspective that have been used to explain transportation equity in urban environments. 


\subsection{Utilitarian Bicycling in Urban Areas}

Taking into consideration the purpose of this dissertation, two main aspects are addressed in the literature review: the role of utilitarian cycling on people's health and the relationship between utilitarian cycling in urban areas and the built environment. Given the magnitude of research about cycling in urban areas, this part of the literature review focuses on a summary of recently published reviews, since they provide a good synthesis of most relevant studies on cycling as a mode of transportation. In addition, based on a set of historical studies on utilitarian biking, key aspects of the social role of biking will be discussed.

\section{Utilitarian Biking and Public Health}

Studies on transportation, in general, and active travel, in particular, focus on different health outcomes such as injuries, respiratory diseases, mental health, quality of life, obesity, and diabetes (de Nazelle, Nieuwenhuijsen, and Antó 2011; Morrison, Petticrew, and Thomson 2003). Beginning in 1995, studies on utilitarian cycling from a public health perspective have been published (de Carvalho M.L 2012). Particularly, due to the decline in physical activity levels and increase obesity among people worldwide, researchers have been looking for associations and correlations between individual, environmental and social factors and active travel, defined as meeting physical activity recommendations to obtain health benefits, in particular urban settings. 
Saunders et al. (2013) carried out a systematic review, including only trials and cohort studies, to evaluate the impact of active travel on obesity and other health outcomes. Scholars report no association between active travel and obesity among children but "small positive health effects were found in groups who actively travelled longer distances". Health effects include reductions in risk of all-cause mortality, hypertension, and type 2 diabetes. A main discussion in this review is the diverse definitions of active travel and different ways to measure it across studies, which could contribute to narrow the positive health impacts of active travel.

In addition, the systematic review by Lubans et al. (2011), evaluating the relationship between active travel to school and four health outcomes (weight status/body composition, cardiorespiratory fitness, muscular fitness and flexibility) indicate that "active travel to school is associated with a healthier body composition and level of cardiorespiratory fitness among youth" (p. 10); however, association between active travel to school with other health outcomes was ambivalent because several studies were excluded from this systematic review due to methodological limitations of these works. Davison et al. (2008) provide evidence of a positive impact of active travel on cardiovascular fitness among students that commute to school actively.

A recent extensive systematic review by Oja et al. (2011) concludes that there is a reliable positive association between cycling for any purpose and different health 
outcomes among young, middle-aged and ageing people. Health benefits include cardiorespiratory fitness and reduction of risks for all cancer, obesity and morbidity.

Hitherto studies evaluating economic benefits of active travel (walking and cycling) on different health outcomes such as medical costs, cancer, and mortality are limited. The pioneering review carried out by Cavill et al. (2008), based on cost-benefits analyses, demonstrate that infrastructure for biking and walking produce positive benefits-cost ratios for health outcomes. However, Cavill et al. (2008) claim that more transparency of methods within published studies is necessary in order to be clear on the assumptions about the relationship between physical activity and health outcomes made in each study. Explaining assumptions could better elucidate the impacts of different modes of cycling and walking (recreational versus for transportation) on specific health outcomes. Another review of economic analyses by Powell et al. (2010) shows that "the net benefit of infrastructure for walking and cycling outweighed the cost”. For example, investment in a cycling infrastructure network produces improvements in health because it increases levels of physical activity for new cyclists.

For the most part, the public health and transportation literature focuses on interventions and impacts on health. Different initiatives from individualized approaches to urban physical interventions have been implemented to encourage or promote utilitarian cycling, specifically. The extensive literature review carried out by Krizek et al. (2009), examining non-motorized transportation interventions, reports on the importance 
of physical interventions (i.e. separate bike lanes) and policies such as traffic regulations, loans and educational programs to promote safe utilitarian cycling. Moreover, it also indicates that individual preferences could play an important role in decisions related to travel mode. However, the report clear points out that non-motorized transportation is a complex area for both research and intervention, but physical infrastructure with combined interventions are keys to promoting cycling as a travel mode.

Scholars have also investigated the impact of positive and negative financial incentives in encouraging active travel (Moodie M 2013). In this respect, Martin et al. (2012) provide a review of financial incentives for promoting biking. At the microenvironmental level they report just a positive effect of interventions providing free bikes. However, they show that there is limited empirical "evidence on financial incentives for active travel', particularly, at the macro-environmental level or in large communities.

Faulkner et al. (2011) also report that initiatives that introduce economic mechanisms to encourage physical activity by targeting energy expenditure through active travel are scarce. In fact, they conclude that "there was insufficient evidence to clearly recommend specific tax credits or subsidies to promote physical activity. ” (p. 11). A similar conclusion is reached by Shemilt et al. (2013) who, based on a systematic scoping review of interventions to impact diet change and physical activity behavior, did not identify studies implementing economic instruments to promote active travel. In sum, even though the literature suggests that active travel contributes to increase levels of 
physical activity and it is a practice that people could incorporate easily in their everyday life, there is still scarce evidence on economic incentives to encourage active transportation.

In another literature review, Pucher, Dill, and Handy (2010) examine initiatives worldwide to promote cycling, in general. The authors found that several programs, policies and infrastructure projects have been implemented as stimuli for biking. Their main conclusion indicates that integrated interventions have higher impact on levels of bicycling than individual interventions. For example, combined strategies like education programs, physical infrastructure, legal measures, and car restriction increase biking more than fewer of these alone or in combination. Finally, Krizek's report (2009) identifies two groups of strategies to enhance biking. The first consists of two soft mechanisms: a. programs (education and marketing) and b. pricing like increasing cost of driving and automobile parking. The second consists of two hard mechanisms: a. urban design as increasing accessibility destination and urban density, and b. infrastructure design like building separate biking facilities.

Biking as transportation, from a public health perspective, underpins the importance of implementing initiatives to encourage biking in urban areas but it implies articulation between transportation interests and goals in both public health and social equity. However, it is necessary to understand that promoting active transportation in urban areas, such as biking, is not an apolitical public health recommendation, but a complex strategy 
that takes shape at the intersection of economic, political, and social conditions, and among different interests and forces. This research aims to elucidate that utilitarian transportation in Latin American cities occurs in a contested arena.

\section{The Built Environment and Biking}

Within the literature reviewed, the main reported factor associated with biking is the built environment; unfortunately, most studies do not define what they call "built environment", making a comparison of findings problematic (Handy 2005). The review by Handy (2005) reports that the built environment consists of three parts: land use patterns, transportation system, and urban design (i.e. aesthetic characteristics of the built environment). Based on that definition, the author reports that while population, density and several design measures were associated with travel by bike, variables related to transportation system, such as street networks or presence of bike paths, were not found consistently associated with non-motorized travel. However, the author also argues that even though the literature reports that there is an association between the built environment and physical activity (walking and biking), it is necessary to clarify that this relationship depends on what measures of the built environment have been evaluated.

Heinen, Van Wee, and Maat (2010) define the built environment as consisting of urban form, infrastructure and facilities. The authors said that overall, studies show that "Factors contributing to shorter travel distances, such as having a denser network layout, 
higher density and mixed land-use, affect cycling positively." (p. 62). In addition, characteristics of biking infrastructure also matter because they are linked with objective and perceived physical safety. Cities with better infrastructure for biking have higher biking commuting rates. However, preferences regarding infrastructure can differ according to socioeconomic conditions, sex and biking experience. For example, while experienced cyclists do not consider preferences between bicycle lanes or wide curb lanes, women and less experienced cyclists prefer separated bike lanes from motorized traffic. Bicycle paths are observed as the most important factor in encouraging cycling. At work sites, the availability of safe bike parking conditions is the main factor that encourages biking among people more so than showers or lockers.

The systematic review carried out by Fraser and Lock (2011) found that "dedicated cycle routes (on and off road), 'Safe Routes to School' initiatives, short distance of trip, separation from traffic, short distance to a cycle path and presence of green space or recreational land” (p. 739) were associated with active travel. Lastly, Ding and Gebel (2012) led a review of review papers about built environment, physical activity, and obesity. They report weak associations between the built environment and physical activity. However, scholars said that it could be explained in part by methodological problems, conceptual mismatch between environmental features and fields of physical activity, and; difficulties in mode of measures of environmental attributes and physical activity domains. 
In brief, this set of reviews identifies the role of the built environment in biking behavior. The built environment, objective measure and subjective perceptions, have been found associated with biking. However, the number of studies on utilitarian bicycling is limited. Most studies are about biking in general. Biking seems to be heavily influenced by the economic, social, and physical conditions under which it is practiced; and it is difficult to make comparisons between studies from different settings.

Data in most reviewed investigations is from transportation studies and consequently gives little if any attention to a historical perspective to better understand the context of current biking conditions. Indeed, there is little evidence or discussion on the development or absence of physical infrastructure for utilitarian biking as the outcome of a particular constellation of social, economic and political historical forces within specific contexts, nor does there seem to be awareness that the choices on modes of travel are not just the sum of individual decisions but, on the contrary, determined by several social and economic factors beyond individual preferences or characteristics. Of particular relevance for this research is the dearth of reviews focusing on Latin American cities. A circumstance which can be explained by publication biases (i.e. language) and the general lack of studies carried out in Latin American countries.

\section{$\underline{\text { Historical Studies }}$}

The historical perspective that does exist tends to explore the role of bikes over time; particularly, studies focus on the importance of the bicycle in European history, the 
relationship with class and gender and its political angle. Those investigations address the knowledge gap regarding economic, social and political conditions that could explain why in some places biking is more prevalent, accepted and "normalized" than others. However, from a historical perspective there is still a knowledge gap to be breeched: the overlapping relationship between urban spatial configuration and social processes that determines conditions for biking.

Over the last five years there has been increasing interest in studying the social role of biking. Historical studies about cycling in Europe illustrate six interrelated aspects very well. First, biking as a mode of travel became a contested issue among road users particularly when their use increased substantively and motor vehicles were introduced. In fact, history shows that cycling and cyclists have been the subject of debate many times fuelled by the incursion of private motoring into the urban space (Caracciolo 2009). Second, cycling as a mode of travel has been managed differently according to who bike users have been, particularly in terms of class. In Europe cycling passed from bourgeoisie travel to a working class use, and laws and regulations on biking across that transition was a product of class interests (Oldenziel and Adri 2011).

Third, discourses and practices for allowing cyclists' use of road networks became a class issue when the "the bicycle became associated with the working class and with unsafe situations", while private motoring gained a privileged position or status in terms of a discourse of speed, modernity, and safety. Thus, this illustrates that decisions about 
urban traffic is an arena of power and ideologies (Oldenziel and Adri 2011). Fourth, "asymmetry of power" between cyclists and motorists facilitated implementing regulatory practices against groups with lower power levels, in this case bicyclists were workers and motorists were rich men with privileged resources to influence policies (Cox 2011). Fifth, bikers' associations and cycling clubs have played an important role in lobbying for cycling in Europe (Ebert 2012). Interestingly, sometimes those associations were working-class associations (i.e. union associations); however, they also represented bourgeoisie class interests (i.e. bicycle tourism). In brief, those studies illustrate that decisions regarding urban traffic has been an arena where power and ideologies have been contested (Oldenziel and Adri 2011).

Biking history researchers have also noted that biking studies have focused on the bicycle as a machine or technological artifact more than on its social contributions or the political process behind mobility (Cox 2011; Stoffers 2012). Indeed, Stoffers (2012) reports that even though biking for transportation is very popular in the Netherlands, the history of cycling is this country is limited, illustrating a lack of interest in this practice. Moreover, he argues that the history of cycling exhibited in museums worldwide, in general, shows evolution of the bike as a machine more than its social contribution. In addition, bikes are presented as separate from other means of transportation, ignoring their role in mass mobility, particularly in the early 20th century when bikes were used en masse as means of transportation in Europe. 
China, the most populated country in the world, has a long tradition in bike use. However, the country faces a rapid motorization process along with a substantial increase of electric bikes and public policies restraining bike usage (Rongfang Liu 2005; Wei, Xin, An, and Ye 2013). Also using a historical approach, Zhang et al. (2014) study the evolution of bike use and ownership in China. The authors identify four periods, from 1900 to the present, in which government policies have been dissimilar, sometimes stimulating bicycling and other times discouraging bike use as a mode of travel. Those policies have contributed to decreasing bike use and increasing motor vehicle usage in this country.

To summarize, the first part of the literature review highlights what has been published with regards to utilitarian biking. Overall, studies on this topic are mainly from the USA, Canada, Australia and some European cities, where the conditions are very different from Latin American cities. Other studies, from public health and transportation, focus on determinants of bike commuting, interventions at different levels to promote bicycling and identification of health benefits associated with non-motorized transportation. There continues to be a need for historical studies to understand why some cities currently have a stronger bicycling culture (as a mode of travel) than others. Beyond that need, however, several gaps still remain. There is very little literature about the social role of bicycling, and studies that include biking as a form of transportation and, consequently, as part of the transportation sector. This research adopts such a critical approach to improve understanding of the impact of differential incorporation of biking 
as means of transportation and the corresponding impact on urban equity at the street level.

\subsection{Theoretical Approaches in Transportation Equity}

Understanding that bicycling is a mode of transportation, this part of the literature review identifies what theoretical approaches have been used to explain transportation equity in general. It tries to pinpoint the link between transportation and social inequalities. Three main approaches will be presented. The first focuses on exclusion and transportation, a perspective that has been more well-known in the UK. The second centers on the social determinants of health framework which seeks to clarify the intersection between transportation, health and well-being. Lastly, the environmental justice approach which focuses on unequal access to environmental resources and has been more widely used in the USA will be presented.

As Lucas (2012) argues, since the mid-90s, scholars from the UK have shown interest in the link between transportation and social exclusion. Under this perspective, inadequate infrastructure for transportation is identified as limiting access to social resources and opportunities which aggravates poverty and inequities (Office of the Deputy Prime Minister of Great Britain 2003). Moreover, social isolation can be exacerbated by inadequate transportation infrastructure that restricts people's 
opportunities to access labor markets, educational, health and cultural services, and social networks (Delmelle and Casas 2012; Hine and Mitchell 2001; Kawabata and Shen 2006).

This approach goes beyond the simple transportation provision perspective. It argues that decisions related to urban mobility can alleviate or exacerbate social exclusion. The objective is "towards a more people-focused and needs-based social policy perspective, which asks question about equality of opportunity to access key services and equity of outcome rather than outputs, and also begins to raise the issue of redistributive justice." (Lucas 2012; p. 4). It concludes, therefore, that transportation can be a barrier to social inclusion because it can restrict people's access to socially valued resources and services or limit people's participation in social, political and economic activities (Cass, Shove, and Urry 2005).

Studies based on this approach, referred to as transportation disadvantage, discuss problems related to transportation exclusion along several dimensions: accessibility, costs, timeliness, and psychology. In these studies transportation systems are understood to have differential social impacts because they are not designed to serve all people. Disabled people, poor people, and women face more exclusion caused by transportation system conditions (Delmelle and Casas 2012; Hine and Mitchell 2001; Kawabata and Shen 2006). Although, scholars also claim that transportation-related social exclusion is difficult to assess, there is substantial evidence of the negative social impacts of transportation on people who are already vulnerable (Lucas and Jones 2012). 
Within studies on transportation and social inclusion, scholars are interested in developing analytical frameworks to explain what justice means and ways to operationalize this concept. Based on the principle of distribution of benefits, two approaches for studying transportation and inequalities have been suggested. Both focus on redistributive justice. The first is guided by Walzer's "spheres of justice" (Walzer 1983) and the second is based on the capabilities approach proposed by Amartya Sen (Martens, Golub, and Robinson 2012).

Martens (2012), studying benefits of access transportation, uses Walzer's “spheres of justice". He argues that transportation is a social good, with a social and historical constructed meaning, that should be outside the market where regular goods are distributed. In this orientation, transportation entails its own distributive sphere based on the criterion of need, and independent from other distributive spheres where other social goods like money or power are allocated through the market (Martens 2012).

In Martens' analysis transportation as a social good is associated with access to life opportunities such as jobs, education, and recreational infrastructure. Consequently, Martens argues that "access in space" where, regardless of location, all population groups have a similar level of access to transportation and "access by mode availability" is based on the need by all population groups to have access to means of transportation, are the two main issues which need to be achieved for fair distribution of transportation-related benefits. Martens (2012) points out that transportation agencies, when evaluating equity 
issues in transportation, should focus on identifying whether the gaps in access are being addressed.

Briefly, Sen's capability approach states that freedom is essential to achieve wellbeing or justice, and achieving those is related to what one can do or be by virtue of access to opportunities (Sen 1989). In this conceptualization, evaluating well-being or inequalities should be based on people's capabilities more than their income or the goods they consume or possess (Robeyns 2003 a). The capability approach therefore considers that "Well-being and development should be discussed in terms of people's capabilities to function, that is, on their effective opportunities to undertake the actions and activities that they want to engage in, and be whom they want to be."'(p. 6).

Beyazit (2011) recommends using this approach to analyze equity in access to transportation. In her methodological proposal she uses the capability approach as a complement to traditional methods like cost-benefit analysis to evaluate transportation impacts. She argues that Sen's framework helps answer questions such as: “how people value transport systems, what their expectations are, how transport systems can meet these expectations and enhance their capabilities and whether it is possible to distribute the gains and losses occurring from transport systems fairly." (p. 123). To date, Sen's capability approach has been applied in few studies related to transportation (Eitoku and Misokami 2010; Nordbakke 2013). 
Ureta (2008), using a transportation exclusion approach for his work in Santiago, capital of Chile, identifies the relationship between social exclusion and mobility. Interestingly, this research concludes that the limitations which poor people face upon travelling in the city are manifestations of social exclusion. For example, low income families have to travel long distances to get their jobs and, in addition, because of economic constraints, people have to restrict their daily mobility. As Ureta argues: "families studied, given the characteristics of their current daily mobility (costs, time, etc.) limit their everyday travels beyond the walking sphere as much as possible." (p. 286). So, people who are already vulnerable experience greater limitations to transportation which turn contribute to deepen social exclusion. In line with this approach, Martens' research (2013) demonstrates that people at risk of transportation poverty, with and without car, get access to relevant destinations by biking. Bicycling, however, plays a limited role in avoiding transport-related social exclusion. People only travel by bike to places close-by, where jobs are unlikely to be. Older people have limitations to biking long distances, and people perceive limitations to bicycling long distances in order to find a job or to keep networks active.

The social determinants of health framework examines the complex, integrated, and overlapping social structures and economic systems that are responsible for most health inequities. In this approach, transportation is associated with several health outcomes, negative environmental effects, and access to healthy or unhealthy resources, with each operating at different scales. The relationship between transportation systems, heart 
disease, mental health problems, respiratory diseases, traffic injuries (McCarthy 2005) and physical activity as a protecting factor against chronic diseases and stress, and obesity has been well established by scholars from different areas (Davis, Cavill, Rutter, and Crombie 2005).

From a public health perspective, transportation systems could include nonmotorized means of transportation, like walking or biking, to increase levels of physical activity related to transportation in urban areas. Evidence also shows that car dependence is a risk factor for obesity, because people spend too much time driving. This produces an imbalance between energy consumption and energy expenditure (Pendola and Gen 2007). From this conceptual perspective, adequate infrastructure for transportation can propel or stimulate non-motorized means of transportation. However, studies show that the private car continues to be hegemonic worldwide (Roberts, Wentz, and Edwards 2006). As a consequence, initiatives or policies privileging private car use promote an unfair use of cities, because other modes of transportation such as biking or walking, that are easier to access by those at a socioeconomic disadvantage, are neglected.

In urban areas where significant numbers of people have limited access to private transportation, the ability to access healthy food is substantially correlated with the quality of public transportation infrastructure. Research has documented the impact of inadequate access to good transportation on people's nutritional patterns, particularly for disadvantaged groups (Everett, Mejia, and Quiroz 2009). Minority groups and people of 
low income experience more geographical barriers to access healthy food (Burns and Inglis 2007; Zenk, Schulz, Israel, James, Bao, and Wilson 2005). Additionally, motorized transportation has negative effects on the environment, generating air pollution and global warming, that in turn has short and long-term effects on people's health conditions (Friedman, Powell, and Hutwagner 2001; Khasnis and Nettleman 2005; Künzli, Kaiser, Medina, and Studnicka 2000).

At a global scale, disparities in transportation illustrate the processes of internationalization of health risks and benefits. Motorized transportation contributes significantly to the greenhouse effect. In addition to the local urban and regional challenges generated by inequitable transportation systems, the adverse impact of the substantial growth in fossil fuel use on air quality and climate change has been uneven. Chichilnisky and Heal (1993) argue that environmental risks have two characteristics: endogenity, in which "The risks that we face are affected by our actions." (p. 67) and collectivity, since climate change affects the world as a whole, for example.

So, there is an unequal distribution of risks and benefits associated with urban transportation at the global level. Some countries produce more pollution than others according to their transportation activities: higher or lower car tenancy per household, oil dependence on transportation, or participation in international flows of goods ( $\mathrm{O}^{\prime}$ Rourke and S. 2003). However, the impacts of car dependency or oil consumption are shared by 
the global populace because the environmental risk of climate warming does not have political and spatial boundaries.

Taking into account that globalization is a process linked with intensive transportation development and that the transportation sector is unequally developed around the world in terms of car production, car usage, car ownership and oil consumption, the negative and positive externalities of transportation do not follow an equitable pattern. In fact, the emissions of pollution caused by transportation are neither historically equal nor similar in quantity among countries. Several risks caused by transportation systems, however, are shared by populations the world over. Moreover, it is the most vulnerable people who are at the highest risk of experiencing the adverse consequences caused by climate change, to which transportation contributes considerably. Consequently, cost, risks and benefits related to transportation are not equally distributed at any level, local or global, and it can be understood from the environmental justice perspective.

In brief, the social determinants of health approach has facilitated going beyond traditional risk factors and to advocate for trans-sectoral interventions to address health inequalities. However, as some scholars from Latin American argue (López A, Escudero, and Carmona 2008) this perspective has limitations related to lacking a theoretical discussion of the capitalist system, which imposes limitations on the ethical goals of social equity and health equity, leaves aside the discussion about power at different scales 
and its relationship to the social determinants of health, and equity issues are restricted to the distributive sphere.

Environmental justice in transportation can encompass multiple dimensions. Environmental justice is understood as a paradigm, theoretical framework and social movement (Taylor 2000). As a framework, it seeks to elucidate what and why unequal distribution of environmental risks and benefits among populations and places persists. This approach has been used to investigate the distribution and impacts of waste facilities, landfills, and nuclear power plants, among other undesirable facilities or sources of environmental contamination, on people's lives (Chakraborty 2006).

Using the environmental justice approach, scholars explore diverse dimensions in the relationship between transportation and inequalities based on class, race, gender, and geographic location. Most of these studies have been quantitative, modeling exposures and using Geographic Information Systems to capture spatial data. Three main issues have been studied: a. Access to transportation options according to geographic and economic conditions; b. Public participation in transportation planning and processes and; c. Transportation impacts and externalities like air pollution, injuries, noise and real estate value (Sze and London 2008). Moreover, scholars argue that most claims on transportation are related to distributive justice: "who gets what, when, and, to some degree, how". However, studies have mainly focused on costs and benefits. Process- 
based claims of injustice remains an understudied field (Schweitzer and Valenzuela 2004).

Later studies focus on levels and mechanisms of community participation in decision making processes on the provision of transportation. Those studies illustrate that poor people or minorities have fewer opportunities to influence the transportation decisionmaking process. Studies on costs show an unequal distribution of transportation facilities and externalities among populations and how several transportation regulations adversely affect low income people and minorities more than wealthy people (Schweitzer and Valenzuela 2004). Benefits-based studies on transportation illustrate that some minority groups and poor people have restrictions to access economic opportunities due to a lack in transportation opportunities. Moreover, benefit-based claims show that low income people and minority groups get "less mitigation and less protection from the enforcement of environmental regulations than other groups (...) and low-income and minority residents should benefit equally in employment and the award of construction contracts in their communities" (p. 385).

Environmental justice studies have generally used different theories of justice and equity "which provide principles and guidelines for deciding what makes acts equitable or inequitable" (Liu 2001; p. 19). Even though some public agencies have adopted the environmental justice perspective in transportation planning and policies, it has also been reported that having clear indicators to measure environmental impacts of transportation 
developments which could contribute to implement the principles of environmental justice consigned in norms and regulations is necessary (Chakraborty 2006; Sen 2008).

Even though there is extensive literature on environmental justice in general, and research on transportation and environmental justice is increasing, based on this review, three gaps could be identified. First, scholars continue to examine exposure and distribution of unwelcome facilities. From that perspective, the investigation of the distribution of desirable facilities or amenities such as bike paths helps to elucidate power relationships in particular locations. Second, to date the environmental justice framework has not been used to study issues related to biking as a means of transportation. Thus, motorized means of transportation are hegemonic also in studies linking transportation and environmental justice. Third, the environmental justice lens has not been used in Latin American cities to study transportation issues. 


\section{Chapter 3}

\section{Theoretical Approach}

\section{Introduction}

This research explores how the process of urbanization in Cali, as part of the development of the capitalist system, has turned the city toward motorized-oriented development and the implications of this shift for people who need to use non-motorized means of transportation. In addition, given that transportation entails a multi-scale dynamic, this research tries to elucidate the processes and forces of different scales that have influenced the most recent local decisions regarding urban transportation. Cali as a large Latin American city is presented as a case to explore how the way cities are created and re-created in contemporary time is shaped by class interests and power.

The urbanization process in Latin America in general, and in Cali, in particular, imposes particular spatial forms or structures that contribute to capitalist accumulation. As part of the built environment, transportation systems within the context of urban development have been oriented to facilitate economic profits as a priority to the detriment of alternative modes of transportation with less probability to increase returns. In alignment with this orientation, Harvey (1976) maintains that the built environment is also a reflection of the social and cultural aspects through which bourgeois values are inculcated (1976). Within a built environment which favors private motorized 
transportation "the automobile has become an icon of freedom, progress and modernity throughout the world" (Freund and Martin 2000).

As cities became the center of human activity, transportation in urban areas has substantial impact on economic growth, livability, environmental sustainability, social integration, and public health. Urban transportation systems and planning are now more complex and include different actors on different scales influencing national and local related-decisions. Indeed, the growing role of international financial agencies in the transportation sector in medium and large cities is more pronounced with economic globalization, premised on neoliberal approaches, these international agencies significantly influence the role of local and national transportation authorities.

In his analytical framework for examining urban process under capitalism, Harvey (1978) argues that urbanization processes contribute to the development of capitalism as a system. Indeed, he concludes, how a city is configured is a product of class conflicts because interests and powers are involved. According to him, the production and use of the built environment entail a sort of class conflict that occurs outside of the work place. His theoretical framework particularly is useful in examining the role that road networks play, as part of the built environment, in capitalist societies like Cali. It is important to note that the contemporary dynamic of capitalist development requires that urban issues be analyzed within the context of the different local, national and international scales of decision-making that influence them. Harvey's approach is 
well-suited to untangle the process and relationships that have resulted in the dominance of private cars in Cali.

A theoretical framework, informed by an environmental justice perspective, which considers issues of social equity in the distribution of environmental benefits and harms, is better suited for capturing the struggle for urban space at the street level. Indeed, cyclists face adverse urban conditions such as traffic injuries and uneven conditions in road use. This research relies on such an approach to explore how disregarding social and physical conditions to bicycling as a mode of travel affects people in different ways, such as restricting their opportunities to enhance mental and physical health, increasing risks of traffic injuries, limiting opportunities to travel, and, ultimately, recreating inequalities.

In Latin American cities and in Cali in particular, bicycle users are people from lower socioeconomic strata who solve mobility problems by using bikes. Most cyclists are also Afro-Colombian. In conjunction with Harvey's conceptual framework which focuses on class, an environmental justice approach based on class and race allows this research to add greater explanatory specificity as it examines the role of socio-spatial processes in the marginalization of the use of bicycles as transportation in Cali and its consequences on people who ride a bike as a principal mode of travel. 


\subsection{Capitalism, Urbanization, and the Built Environment}

Studying the relationship between capitalism, urbanization and the built environment, Harvey (1976) explains that in capitalist societies production and use of a built environment generates a facet of the class conflict which is outside the workplace. This conflict is related to who defines how urban space is configured and for whom. In this perspective, the built environment consists of all physical structures such as "houses, roads, factories, offices, sewage systems, parks, cultural institutions, educational facilities, and so on.” (p. 255).

Harvey (1976) identifies four "groups" that participate in production and use of the built environment: a) Capitalists who seek appropriation of profits, directly or indirectly. For example, landowners who are directly seeking profits through housing and property leases, companies that are indirectly looking for earnings through land speculation; b) Capitalists looking for profits and interests through building of new infrastructure (i.e. urban developers); c) Capitalist who use the built environment as a channel for investing surplus capital or as a way to improve production and capital accumulation and; d) Workers who use the built environment as means of consumption and reproduction. In essence, production and use of the built environment is an embedded process of power and interests where diverse forces at different levels shape the urban environment. The built environment is a social production. 
Moreover, according to Harvey (1976) the built environment is divided into fixed capital and consumption funds. As fixed capital, the built environment can be used for production such as factories and highways, and it can be used for consumption, for example houses and sidewalks. Harvey conceptualizes these as built environment for production or physical infrastructure for production and built environment for consumption or physical infrastructure for consumption, respectively. However, some built environment items such as transportation networks can be used both as fixed capital and as consumption funds. In this configuration transportation networks are both built environment for production and built environment for consumption. For example, transportation infrastructure requires certain characteristics to facilitate the circulation of merchandise and, at the same time, road infrastructure is necessary for workers' mobility.

One form of the class conflict appears because "Labor, in seeking to protect and enhance its standard of living, engages in a series of battles in the living place over a variety of issues that relate to the creation, management and use of the built environment" (Harvey 1976; p. 268). Thus, class struggles in the built environment occur around living conditions, which is a different struggle than fights in the work place, and it is one consequence of the division between "place of work and place of reproduction and consumption". This division is an imposed condition within capitalism as a system. Consequently, according to Harvey, the way space is configured is both a result of capitalist interests and how conflicts between labor and capital over spaces are solved. 
Even though, as Harvey (1976) argues, "Capital in general, and that faction of it that produces built environment, seek to define the quality of life for labor in terms of the commodities that they can profitably produce in certain locations" (p. 271), results of struggles for living conditions depend on the relative economic and political power of labor and capital. The built environment is the result of political, economic and social conflictive processes over "What is good for accumulation and what is good for people." (Harvey 1976; p. 278).

Physical infrastructure for transportation is necessary for production and reproduction of labor force and it is an arena of class conflict. In terms of transportation systems, both infrastructure and services, struggles are associated with prices of services, access to different modes of transportation, and access to facilities and services through transportation. As a result, the way urban space is configured is the outcome of the kind of decisions that are privileged to facilitate mobility in urban areas. Urban mobility reflects competing values and ideologies (Henderson 2002) associated with contextualized social relationships and class conflicts. Additionally, as Harvey (1976) argues the built environment can also be a strategy for "inculcating bourgeois values" ( $\mathrm{p}$. 282). For example, privileging infrastructure for motorized means of transportation illustrates very well that a car is not just a utilitarian piece of technology, but represents a lifestyle, defining consumption patterns and with implications for class consciousness. 
To explain the role of urbanization in capitalist development, Harvey uses the circuit of capital accumulation theory. In this framework, a change from one economic activity to another is a shift in capital, which is circulated to find a profitable investment opportunity" (Jauhiainen 2006; p. 181). This theory maintains that capital moves from the primary circuit (producing manufacturing, mainly) to the secondary circuit looking for more profitable activities in economic sectors related to investment in real estate and transportation infrastructure. The third circuit of capital accumulation is associated with investment in social services, for example, as happened with health and education when they became commodities market during the 90 s, and as happened with investment in science and technology to improve productivity. Changes from one circuit to another is a consequence of capital's pursuit of profitability or better conditions for profits, which require transformation of the built environment, impacting urban life socially and physically.

Harvey (1978) uses the second circuit of capital to explain urban growth under capitalism. Surplus value from the primary circuit of capital is switched to the secondary circuit of capital and invested in the built environment. The built environment is a temporary way to overcome over-accumulation crises, switching capital from the primary into the secondary circuit. Furthermore, Harvey (1978) argues, "the existence of a functioning capital market and, perhaps, a state willing to finance and guarantee longterm, large-scale projects with respect to the creation of the built environment" (p. 107) is necessary in this secondary circuit. Based on this approach, Harvey (1978) states that 
urban growth is a consequence of waves of investment in the built environment. So, transportation infrastructure as part of the built environment plays an important role in explaining urbanization under capitalism. However, it is important to take into account that, as Henderson (2002) reports "As Harvey argues, investment in transportation infrastructure is essential for the accumulation process, and therefore does not necessarily arise out of a crisis of overaccumulation" (Henderson; p. 30).

In addition, in the process of changing from one circuit to another, for capitalists seeking higher profits, the built environment as fixed capital can become obsolete, so physical infrastructure is destroyed and re-built, in order to avoid obstacles for producing profits. As a result, cities are shaped again and again according to accumulation interests. How did Cali, as an example of Latin American city, experience urban development as part of the capitalist process? The research presented here tries to answer this question by analyzing the urbanization process in Cali, focusing on transportation infrastructure, and the social and political forces that shape it.

In Harvey's approach the built environment and transportation systems as part of it, take on a new connotation. Indeed, as Harvey (1976) points out "The second, fought in the place of residence, is against secondary forms of exploitation and appropriation represented by merchant capital, landed property, and the like. This is a fight over the costs and conditions of existence in the living place." (p. 267). How are citizens in Cali struggling for transportation and how is it affecting their living conditions? 
Taking into account that many features of the built environment are managed, controlled and consumed collectively as public goods or public services (i.e. transportation or streets), the state plays a key role within a conflictive relationship outside the work place between capital, labor and the built environment. Lastly, as the built environment is a source of accumulation, the capitalist class tries to capture profits investing in the built environment. Transportation infrastructure is a key area of capitalist investment. Is this happening in Cali as Harvey explains it?

Even though Harvey's analysis (1976) is based on advanced capitalist countries where the automobile became faster a hegemonic means of transportation, his framework is useful to examine what socio-economic processes have determined changes on urban structure in Latin American cities as well. Additionally, more recently, in Latin American countries globalization and the accompanying neoliberalism processes have contributed to the accelerated motorization and significant transformation of urban areas. Indeed, cities are experiencing large physical transformations because of Bus Rapid Transit implementation, which is observed not only as a mechanism to improve urban mobility but also a strategy to enhance the role of the private sector in urban transportation system. In this context, Harvey's approach with regards to the relationship between capitalism and urbanization is constructive in understanding the marginalization of bicycling as a means of transportation in Cali. 
In relying on Harvey works, however, it is important to take into consideration that peripheral capitalist Latin American countries have several social, political and economic particularities which explain why in Latin America the demand for private cars responds to the middle class view of "capitalist modernization" (Vasconcellos 1997b), while non-motorized means have been neglected and public transportation continues being the principal means of transportation. How does the role of international agencies contribute to explain the particularities of motorization in Latin American cities?

\subsection{Environmental Justice Approach}

This theoretical approach not only explains that some social groups experience more environmental disadvantages than others, but also delineates the processes and mechanisms that create and reproduce environmental inequalities (Walker 2009). In terms of transportation, the environmental justice perspective focuses on "understanding why low-income and minority communities face the brunt of negative impacts from transportation investment" (Litman and Brenman 2012). This framework is used in the present empirical research because it offers a comprehensive approach for understanding historical and multi-scale patterns that reinforce an unequal use of urban streets in a large city such as Cali. An environmental justice approach provides a mechanism for this research to unpack the social, economic and political processes that create and re-create inequalities at the street level in Cali. 
Using the environmental approach in this research is an opportunity to expand its application in the context of Latin American cities where cycling is used for economic need, which is different in the context of advanced capitalist countries where environmental justice's perspective have been used to investigate impacts on equity regarding access to public transportation and private vehicles and the burdens and benefits of transportation transit decisions. This underlies what additional social impacts people who use a bike as their principal means of transportation could face. Moreover, as was pointed out above, this approach has not been used to investigate issues related to biking as a means of transportation nor has it been used in transportation analyses in Latin American cities. 


\section{Chapter 4}

\section{Methodology}

According to Morgan (2007), this research has a pragmatic approach in that the process of defining research questions, the selected methodology (designing and conducting the research) and definition of methods (techniques for data collection and analysis) follow three considerations: abduction, intersubjectivity and transferability. In terms of abductive process, theory and data were used iteratively to explore, understand and answer research questions and re-elaborate new questions. In other words, following Morgan (2007), this research moves from theory (deductive way) to data (inductive way) and vice versa. So, this flexibility allows moving back and forth between theoretical framework and empirical data recurrently. The intersubjectivity solves the dichotomy of vision, observed in the relationship between the investigator and the investigation process, which separates objectivity (quantitative research) and subjectivity (qualitative research).

In fact, as Morgan says (2007): “In a pragmatic approach, there is no problem with asserting both that there is a single "real world" and that all individuals have their own unique interpretations of that world. Rather than treating incommensurability as an allor-nothing barrier between mutual understanding, pragmatists treat issues of intersubjectivity as a key element of social life" (p. 72). Additionally, a transferability approach allows for consideration of the context where investigated social phenomena occur, elucidating what findings are possible to transfer to other contexts. So, some 
findings can be related specifically with Cali, but others can be transferred to other cities in Latin America. Consequently, as a pragmatic approach suggests, this research combines qualitative and quantitative research methods.

Moreover, a case study was selected because it allows for detailed inquiry into the context where social phenomena occur, facilitating the application of social theories to comprehend social processes (Burawoy 2009). Such a case study approach seeks to use social theories to understand the interaction between micro-processes and macro forces that can explain why a particular social phenomenon occurs. This method presents the opportunity to compare or contrast different perspectives from a range of actors in the study (i.e. stakeholders from different organizations); in addition, a case study permits the integration of different data collection techniques, such as surveys, interviews, and document analysis which are appropriate in getting a comprehensive understanding of complex social issues. This approach is particularly well suited to this research context in which political decisions related to transportation reflect the several forces, interests, and participants involved.

A mixed-method case study was carried out to identify socio-spatial transformation processes related to urbanization in Cali that have neglected the needs of bicycle users in this city. Then, it focused on the last years when a network of bike-paths was expected to be built articulated to the Bus Rapid Transit system (BRT) and a new set of constructions were implemented. Moreover, this case study illustrates the 
consequences of constraining the implementation of Cali's bike-path network on people who use a bike as their principal means of transportation.

This mixed-method case study approach makes a two-fold contribution. First, analysis contributes to understanding the set of local and external forces that shape a micro-process that might have potential and significant impact on people's social life, particularly on social equity related to using transportation space, public and health conditions. Second, analysis provides conceptual insight about the connections among the social, economic, and political factors influencing transportation policy outcomes in urban areas and how these constrain or enable individual choices of transportation, particularly bicycling as a means of transportation in Cali.

This mixed-method case study combines qualitative and quantitative methods in a complementary approach (Krathwohl 2009): document review, a population survey and, semi-structured interviews with key participants. This mixed-method design used mostly qualitative data to identify main socio-spatial urban transformations that have contributed to motorization and can explain, in part, the process of marginalization of biking as a means of transportation in Cali. Moreover, qualitative data from interviews was useful to understand the challenges of people who need to use a bike as their principal means of travel. Quantitative data was used to identify socio-economic conditions of bike commuters and social and environmental perceptions toward biking in Cali. Combining 
methods allowed for acquiring evidence of the magnitude and conditions of biking in Cali.

\subsection{Data Collection and Analysis}

This section describes each method, illustrating it along with the rationale for information source selection and modes of data analysis.

1. Document review: this technique consists of a systematic search, selection and analysis of different types of documents such as media reports, registers, legislative material and newspapers, which help to understand the meaning of social process, validate data from other sources of information or shed light on the research problem under study (Bowen 2009).

This case study centered on a deep document analysis to explore why and how transformations of the built environment in Cali have contributed to the current conditions for cycling as a mode of travel in this city. Indeed, revisiting the history (20st and 21 st centuries) of Cali was crucial to identifying key influential circumstances that have shaped the city; so, based on historical research, a chronology was made which allowed for a better comprehension of singularities in the present. The main sources of historical information were: history books, government documents and journals from the 
City Historical Archive and pictures from the Valle del Cauca Photographic Archive. As part of references, a full list of documents used in this historical research is presented.

In addition, public policies and institutional documents from the Transportation Bureau (local, regional and national), mainly related to policies on urban transportation, were reviewed, selected, and analyzed. This set of documents was analyzed using theme analysis; this means searching and exploring themes that arise. Both electronic and paper documents were included in this document review.

The rationale behind employing document review as a research method was threefold. First, the document review focused on identifying different processes within Cali's urbanization process that have contributed to motorization by tracking decisions, key facts and policy changes in transportation infrastructure and systems on different scales (for example, the implementation of the BRT program could be studied in the local, national and international arena); this facilitated understanding the historical and contemporary context within which Cali's experience took place. Second, it helped identify stakeholders, resources, and discourses used in each process and historical period analyzed. Particularly, an extensive and deep document review facilitated the identification of social forces, organizations and social agents that have shaped the phenomenon being studied. Lastly, information called by the document review informed identification of relevant questions for interview guides with policy makers from different organizations. 


\section{2). Population survey:}

During 2010 and 2013 the research group GESP (Grupo de Epidemiología y Salud Poblacional) from Universidad del Valle in Cali-Colombia, and Fundación FES, with a grant from COLCIENCIAS (Departamento Administrativo de Ciencia, Tecnología e Innovación), carried out a research project "To assess the impact of a network of bikepaths articulated to BRT on bicycle use among adults in Cali” (FES-Univalle 2010). Final findings of this project were presented in September 2013. The team for this project consisted of professionals from Geography, Epidemiology, Public Health, and Urbanism. I am one of the main researchers for this project ${ }^{1}$. The first component of the project was a quantitative, longitudinal, multilevel study about cycling as a mode of transportation in Cali and it included also a descriptive analysis on bike-path infrastructure. Description of the socio-economic conditions of people who use a bicycle as a means of transportation and factors associated with biking use in Cali are the main findings from the multilevel study shown in this dissertation.

In the population survey a three-stage sample was carried out. It was a probability sampling. First, a sample was drawn from the primary sampling unit (urban sections); second, from each urban section a sample of blocks were drawn, and then a sample of

\footnotetext{
${ }^{1}$ Luis Fernando Gómez Gutiérrez (Fundación FES and Universidad Javeriana) and Olga Lucia Gómez Gutiérrez (GESP-Universidad del Valle) are principal researchers of this project as well.
} 
households from each block was drawn. One adult between 18 and 44 years old who had at least 1 year of residence in the neighborhood was selected per household.

Finally, the sample included 71 random primary sampling units (psu), 2 random blocks within each psu, and around 12 random households within each block. In addition, geographic indicators related to weather conditions, attributes of the urban built environment (i.e. terrain slope), personal safety (i.e. robbery) and traffic safety conditions (i.e. traffic injuries) were gathered.

In the multilevel study, outcome variables were measured using a long version of the IPAQ (International Physical Activity Questionnaire). The IPAQ is a validated instrument used in Public Health to estimate physical activity levels in both research and surveillance systems (Hallal, Gomez, Parra, Lobelo, Mosquera, Florindo, Reis, Pratt, and Sarmiento 2010; IPAQ Core Group, Sjostrom, Ainsworth, Bauman, Bull, Craig, and Sallis)(Hallal, Gomez, Parra, Lobelo, Mosquera, Florindo, Reis, Pratt, and Sarmiento 2010; IPAQ Core Group, Sjostrom, Ainsworth, Bauman, Bull, Craig, and Sallis). Consequently, outcome variables were: 1 . using a bicycle as means of transportation in the last 7 days and; 2 . using a bicycle as means of transportation in the last 7 days. Covariates were age, sex, race, income, education, occupation, marital status, and car/bike/motorcycle ownership; built and social environment self-perception; and selfperceived health status. An ecological model oriented the multilevel study which allowed to include interrelated variables at different levels (Sallis, Frank, Saelens, and Kraft 2004). 
In this dissertation baseline data ( $\mathrm{t} 0)$ and first measure data (t1) from the large multilevel project is shown. The baseline survey began on September 27, 2011 and ended on January 17, 2012. The t1 survey began on January 11 and ended on April 13, 2013. As was said before, findings from the multilevel study are very useful to illustrate who is biking as a mode of transportation and under what conditions this practice occurs in the city of Cali, at present.

\section{3). Semi-structured interviews:}

Based on two-purposive sampling, participants in interviews were from two groups. The first group was a range of stakeholders from local and national government; people from social organizations (non-government community organizations), private sector and researchers from the transportation and public health area. They were invited to participate in an individual semi-structured interview. The interview questions focused primarily on four areas of inquiry: 1. Vision of main urban transportation (Problems, solutions, and alternatives); 2. The role of transportation cycling on urban transportation planning and policies; 3 . Opportunities and challenges of intermodal urban transportation planning and, policies in Cali; 4. Relationship between urban transportation, social equity and health. (Appendix B)

The second group consisted of participants from the multilevel study described above. People who already cycle for transportation were selected and invited to 
participate in a semi-structured interview to examine the conditions and experience of commuting by bike in Cali. So, in this study, people who reported biking as a mode of travel both in the baseline survey (t0: 2011-2012) and t1 (2013) were interviewed. The interview questions focused primarily on five areas of inquiry: 1. Experience of sharing the public streets among different modes of urban transportation; 2. Perceptions and experiences of fear and wellbeing; 3. Perceptions and use of facilities for pedestrians, private cars, BRT, and motorcycles compared to bicycling amenities; 4. Reasons and consequences of using a bike as means of transportation and; 5. BRT's impacts on bikecommuting (Appendix C).

There are two main justifications for using interviews as method of data collection in this research. First, interviews contributed to explore personal views, beliefs and experiences of people under study. Moreover, it facilitated a deeper understanding of main findings from the quantitative multilevel study related to socio-economic conditions of people who bike in Cali, which is also relevant because biking as a mode of travel is an issue understudied in Latin American cities, particularly. Second, interviewing stakeholders, for example, facilitated obtaining more comprehensive insight on the visions, actions and opinions that policy and decision-makers have about urban transportation in general and biking in particular. In addition, interviews also helped to shed light on facts observed in the document analysis. 
A signed informed consent giving permission to tape-record each interview was requested of all participants. In order to maintain the anonymity of the interviewees, their names are not shown.

Each set of interviews was analyzed using the thematic network technique (AttrideStirling 2001). This tool suggests several steps for qualitative data analysis. Once the verbatim transcript of all interviews was made and its quality verified, it went through the following processes:

1. Data reduction: this step aimed to define of codes and fragmentation of the text according to these codes. Coding framework was based on both what issues arise in the text itself and what the text reveals regarding the problem under examination. Examples of codes were: equity, risks on the street, sharing the street with other transportation modes (Buses, motorcycles and BRT), and stigma. Each transcription was read at least three times. As a result, each interview was dissected according to the coding framework.

2. Identifying themes: more general themes were identified based on each fragment and some of them were reduced. An example of fragment classification into themes and theme reduction is shown below (Table 1). 
Table 1. Data Reduction Steps

\begin{tabular}{|c|c|c|}
\hline Interview Fragments & Themes & Reduced themes \\
\hline $\begin{array}{l}\text { 1. Participant 1: No, I think it is worse with the } \\
\text { MIO, MIO project. It has reduced the space of } \\
\text { the street. So, within a reduced space, cars } \\
\text { cornered cyclists, especially where there are } \\
\text { not bike paths. }\end{array}$ & \multirow{3}{*}{$\begin{array}{l}\text { The MIO has } \\
\text { reduced street } \\
\text { space. } \\
\text { The cars } \\
\text { cornering } \\
\text { cyclists. } \\
\text { Because of } \\
\text { MIO's } \\
\text { problems have } \\
\text { increased bike } \\
\text { use in the city. }\end{array}$} & \multirow{3}{*}{$\begin{array}{l}\text { The implementation of } \\
\text { the MIO has adversely } \\
\text { affected cyclists and it } \\
\text { has also increased bike } \\
\text { use. }\end{array}$} \\
\hline $\begin{array}{l}\text { 2. Participant 2: Before MIO there were more } \\
\text { buses and vans but there was room for } \\
\text { everyone, not now. }\end{array}$ & & \\
\hline $\begin{array}{l}\text { 3. Participant 3: With the MIO we won only } \\
\text { space reduction, especially us who manage } \\
\text { bike. Many people have purchased bike ... } \\
\text { Researcher: Because of MIO's problems? } \\
\text { Participant 3: Exactly for that. }\end{array}$ & & \\
\hline
\end{tabular}

3. Constructing the networks: this stage aimed to develop, describe and explore thematic networks. First, themes sharing similar conceptual content were organized into groups. This constitutes Organizing Themes. Then, based on the Organizing Themes, Global Themes (summarizing both themes and organizing themes) were deduced. Table 2 displays an example of the process of constructing the thematic network which is discussed in section three of findings chapter. Second, each thematic network was described and explored using theory to orient its analyses and quotations from interviews were used to illustrate analyses. Moreover, based on five global themes five thematic networks were defined. Figure 1 shows the methodological rationale of this study. 
Table 2. Constructing the Network

\begin{tabular}{|c|c|c|}
\hline Themes & Organizing Themes & Global Theme \\
\hline $\begin{array}{l}\text { 1. The bicycle is used for work, to make } \\
\text { home delivery, running errands and go to } \\
\text { buy material work. } \\
\text { 2. The bicycle is used for economy (save the } \\
\text { value of the transit tickets). } \\
\text { 3. The bicycle is used because it requires } \\
\text { going to many places during the day and } \\
\text { the money is not enough to cover those } \\
\text { costs of transportation. } \\
\text { The bike is used to run errands and visit } \\
\text { family. } \\
\text { Although stressful, the bicycle is used to } \\
\text { save money required for food or other } \\
\text { necessities. } \\
\text { The bicycle is used because there is } \\
\text { uncertainty about routes of MIO. } \\
\text { The bicycle is used to decrease } \\
\text { transportation times. } \\
\text { The bicycle is used because public } \\
\text { transportation is more complicated to } \\
\text { certain areas of the city (ex. Areas of SES } \\
\text { 6) where there are building constructions } \\
\text { which are workplaces for construction } \\
\text { workers. } \\
\text { The bicycle is used to prevent the number } \\
\text { of transfers that are made with the MIO. } \\
\text { 10. The bicycle is used because it is more } \\
\text { comfortable than take the MIO that always } \\
\text { carries out a large number of passengers. } \\
\text { 11. With the bike people obtain physical and } \\
\text { mental health benefits. }\end{array}$ & $\begin{array}{l}\text { The bicycle is used } \\
\text { for issues related to } \\
\text { work, family visits } \\
\text { and to run errands. } \\
\text { 2. Using bicycle means } \\
\text { saving money and } \\
\text { time. } \\
\text { 3. Public transportation } \\
\text { problems are solved } \\
\text { using bike. } \\
\text { 4sing bicycle, } \\
\text { physical and mental } \\
\text { health is improved. }\end{array}$ & $\begin{array}{l}\text { 1. Using the } \\
\text { bicycle is } \\
\text { beneficial. }\end{array}$ \\
\hline
\end{tabular}


Figure 1. Methodological Rationale

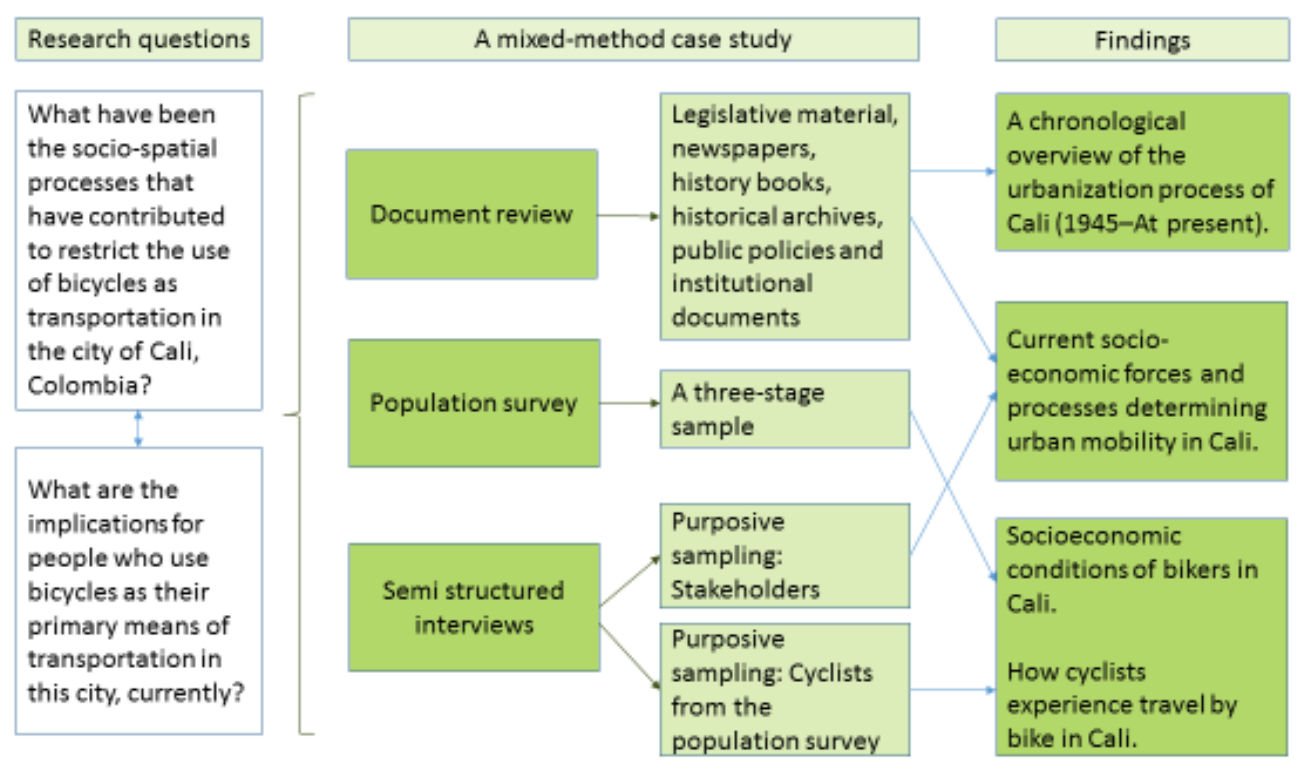

\subsection{Research setting}

Cali, capital of the department of Valle del Cauca and the third most important city in Colombia, has 2.3 million inhabitants. In the last census $26.2 \%$ of people self-reported as black. Data shows that in Cali $21.9 \%$ of people are living in poverty and $4.4 \%$ in extreme poverty. Moreover, the coefficient of Gini in Cali is 0.505. It is located in a flat valley at 995 meters above sea level, and has an average annual temperature of $24 \mathrm{C}^{\circ}$ (Guerrero 2011). It is considered a high-density, compact city with 20.182 inhabitants per $\mathrm{Km}^{2}$. The city is divided administrative and politically in 22 areas called Comunas. Map 1 shows urban areas of Cali. 
Map 1. Cali urban area - Neighborhoods by SES

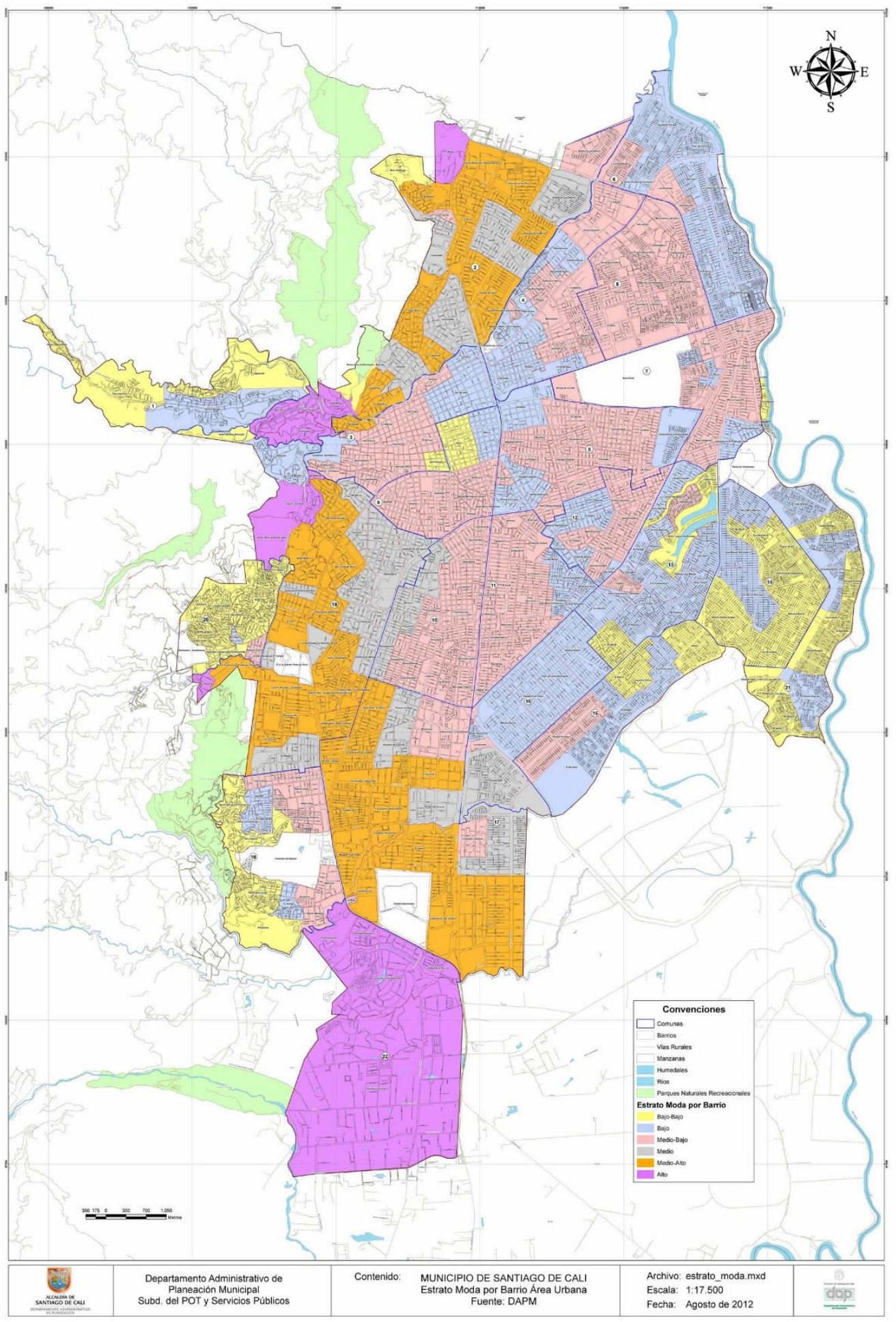

Source: Administrative Department of Planning - Cali 2012 


\section{Chapter 5}

\section{Findings}

\section{Introduction}

This chapter presents the findings and analysis from the data gathered. It is divided into three sections. The first section centers on the main socio-spatial historical processes that have contributed to an ongoing situation of motorization in Cali, and the impact of bike use as a mode of transportation. A chronological overview of the urbanization process of Cali, from 1945 to the present, was made to identify main historical urban transformations. This section is based on a review of historical documents and books.

The second section focuses on the current social and economic forces and processes that determine how cycling as a mode of travel is incorporated into the transportation system in Cali. In particular, it describes the institutional forces and relationships at different scales that have influenced local decisions related to urban mobility in general and more specifically bike use as a mode of travel in urban areas. This section combines data from document analysis and interviews with key local and national actors from different sectors interrelated with transportation.

Section three presents evidence of how cyclists experience travel by bike in Cali.

It exposes the main problems that bikers face daily and why not all road users have equal 
rights and access to road networks in this city. This part of the study is based mainly on interviews with bikers and some data from the population survey.

\subsection{A Chronological Overview of Cali's Urbanization Process}

Using a historical chronological approach, based on main urban developments linked with urban transportation changes during the 20th and 21th centuries in Cali, three periods were identified. Taking into account that transportation as part of urban development is a consequence of economic and social processes and it also produces changes in other processes (Arboleda and Vivas 1991), this historical part of the research centered on tensions between cycling and motorized transportation modes with the advent of Cali's drive toward "modernization".

Historical chronology suggests that Cali has experienced three main periods in the process of becoming a "modern city". First, after the Second World War between 1945 and 1958, during the rise of industrialization, large spatial changes were made, aimed to transform Cali into an industrial city. Then, between the 60 s and 70 s, the city space was developed as part of a revitalization process aligned with the VI Pan-American Games. More recently, between 1990 and 2013, with the advent of the construction of the Bus Rapid Transportation system and a set of new construction so-called "Mega-Obras" (Megaprojects), the built environment has been undergoing an extensive urban renovation. 


\subsubsection{The First Period: Takeoff as an industrial City (1945 - 1958)}

In Cali an incipient industrialization process began in 1920 with local industries producing non-durable consumer goods such as textiles, beverages and food. This prompted local commerce, migration, urban expansion due to the "construction boom" (1925-1929) which built physical infrastructure for public utilities such as water, sewage, phone and electricity, and created an active "working class" including artisans, service providing employees, construction workers and other workers (Vasquez B 2001). Much of the new construction was financed with national and international loans. However, at the end of 1930, Cali also experienced a social and economic recession as a consequence of the worldwide 1929 crisis.

The steam trolley, tranvia a vapor, which was the first mass transportation system in Cali, was implemented during 1910-1926. It was also used to transport coffee for export and other products for local consumption like green bananas and provisions. The tranvia was a private initiative promoted and created by local merchants. The first motorized car, which belonged to Jorge Zawadzky ${ }^{2}$ (Picture 1), appeared in Cali in 1913 and the first locomotive (using coal) was introduced in 1915. This system was named Ferrocarril del Pacífico (Arboleda and Vivas 1991), and it boosted the regional and local economy because it reduced transportation costs of imports. However, the tranvia a vapor faced strong competition with motorized cars which were perceived as a sign of the

\footnotetext{
2 Jorge Zawadzky was the owner of an important journal called "Relator" and he also was a council of Cali.
} 
city's modernization. Motorcars began competing with the locomotive system to transport products and the steam trolley was soon abandoned.

Picture 1. The first car with motor in Cali (1913)

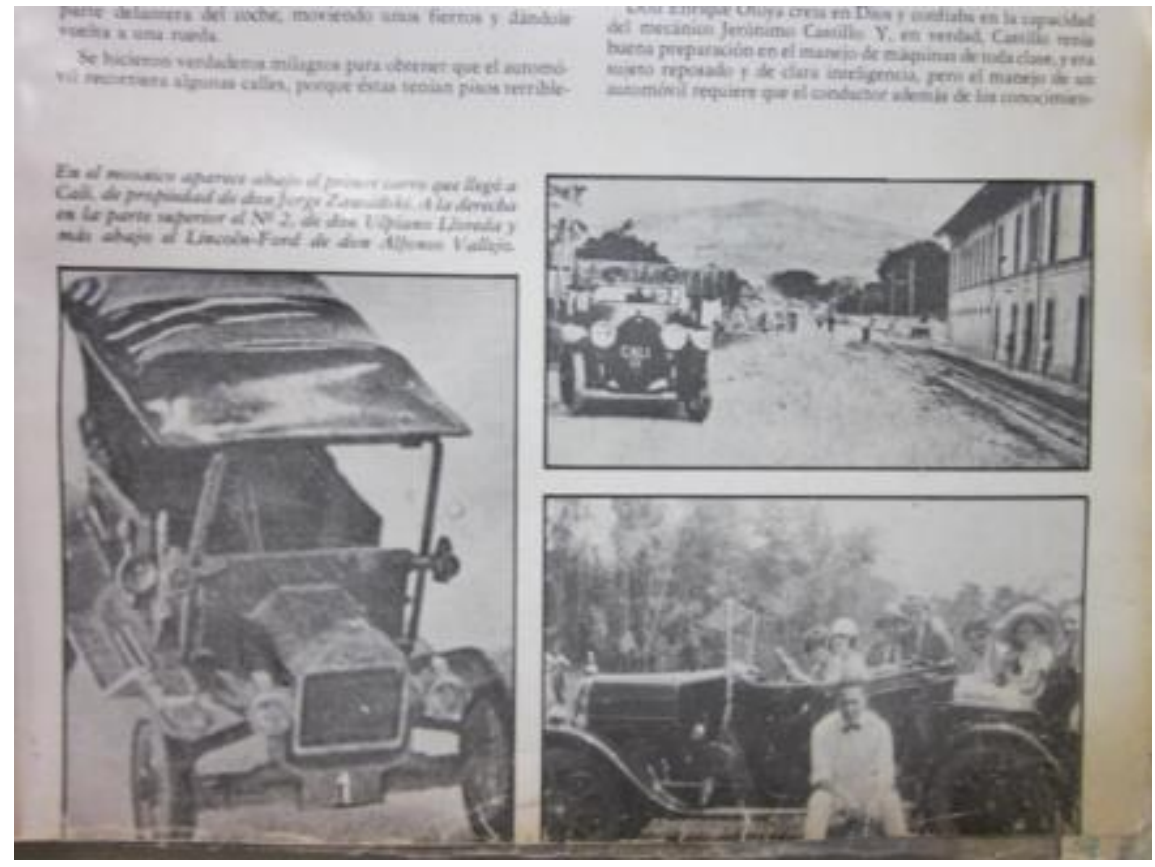

Source: Calero Tejada Álvaro. Cali Eterno. La Ciudad de Ayer y de Hoy. Institucional, Cali, 1983

Arboleda and Vivas (1991) report that in 1923 there were 235 registered private cars and 4 omnibuses in Valle del Cauca but Vásquez (2001) argues that in 1921 Cali had 300 automotive cars. During that period however, Cali did not have any paved streets. It is important to note that private cars provided transportation services for people (Vasquez B 2001). Increasingly travel by cars created demands to widen streets, to pave roads and to issue new traffic regulations. The first Traffic Inspection in Cali was created in 1921 because of increasing traffic accidents.

"The appearance of the car in the narrow, cobbled or dusty streets of Cali caused a real social and urban commotion. Soon more and more vehicles were arriving demanding space and better conditions for circulation." (Arboleda and Vivas 1991; p. 32) 
In 1930 three bus routes started in response to a need for mass transportation. These then expanded to become the main mass transportation system (Arboleda and Vivas 1991). The literature does not report information about bicycling in Cali during the first three decades of the 20th century. However, some pictures illustrate that bikes at the beginning of the century 20th were used by men and women from prestigious families (Picture 2), and bicycling was viewed as a recreational activity. In fact, the photographs of that time capture both cycling competitions and bike riding. (Picture 3, 4 and 5)

Picture 2. Family using a bike (1928)

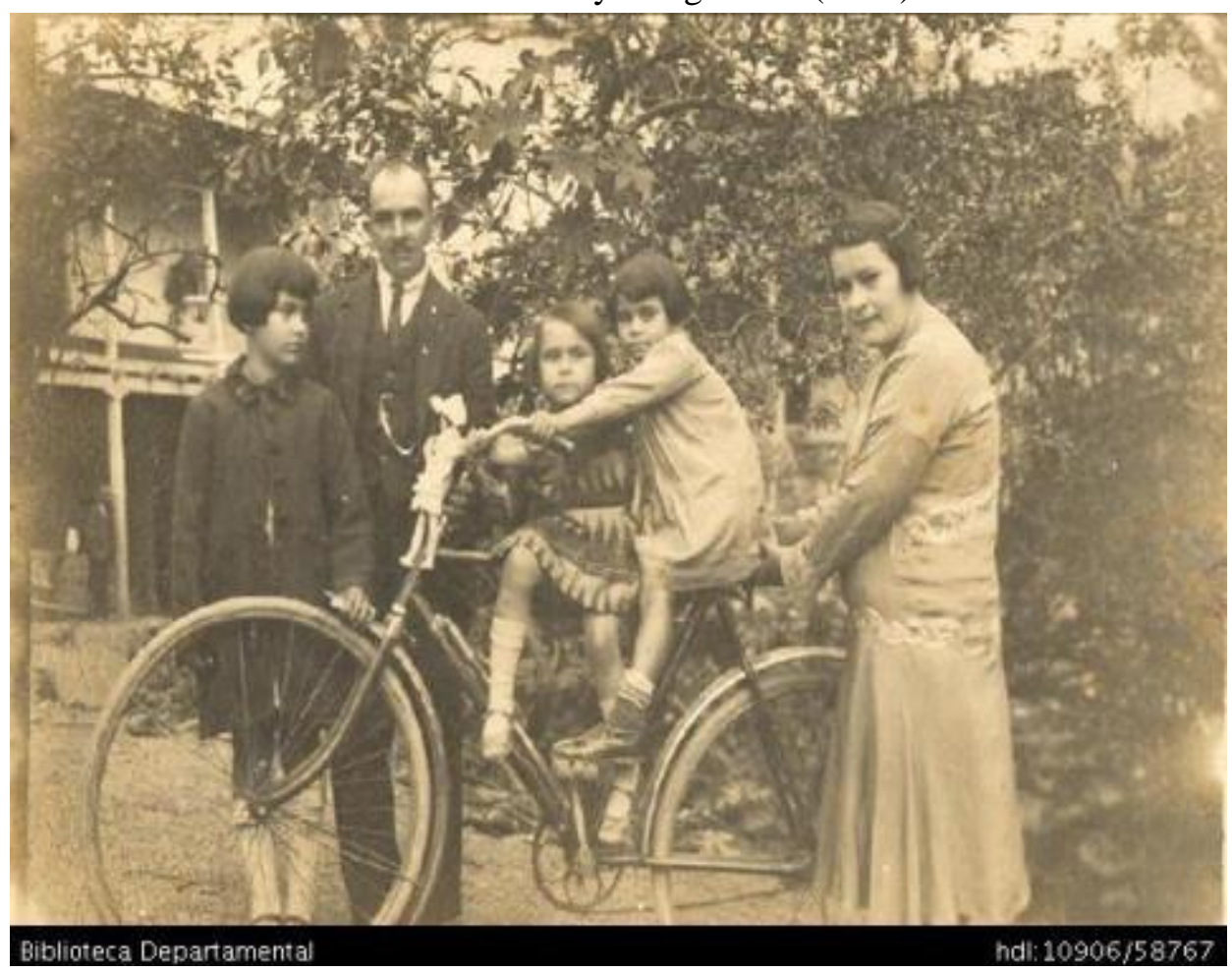

Source: Archivo del patrimonio fotográfico y fílmico del Valle del Cauca de la biblioteca Departamental del Valle Jorge Garcés Borrero - Sección las bicicletas y ca - patrimonial (918) 
Picture 3. Cycling competition (1927)

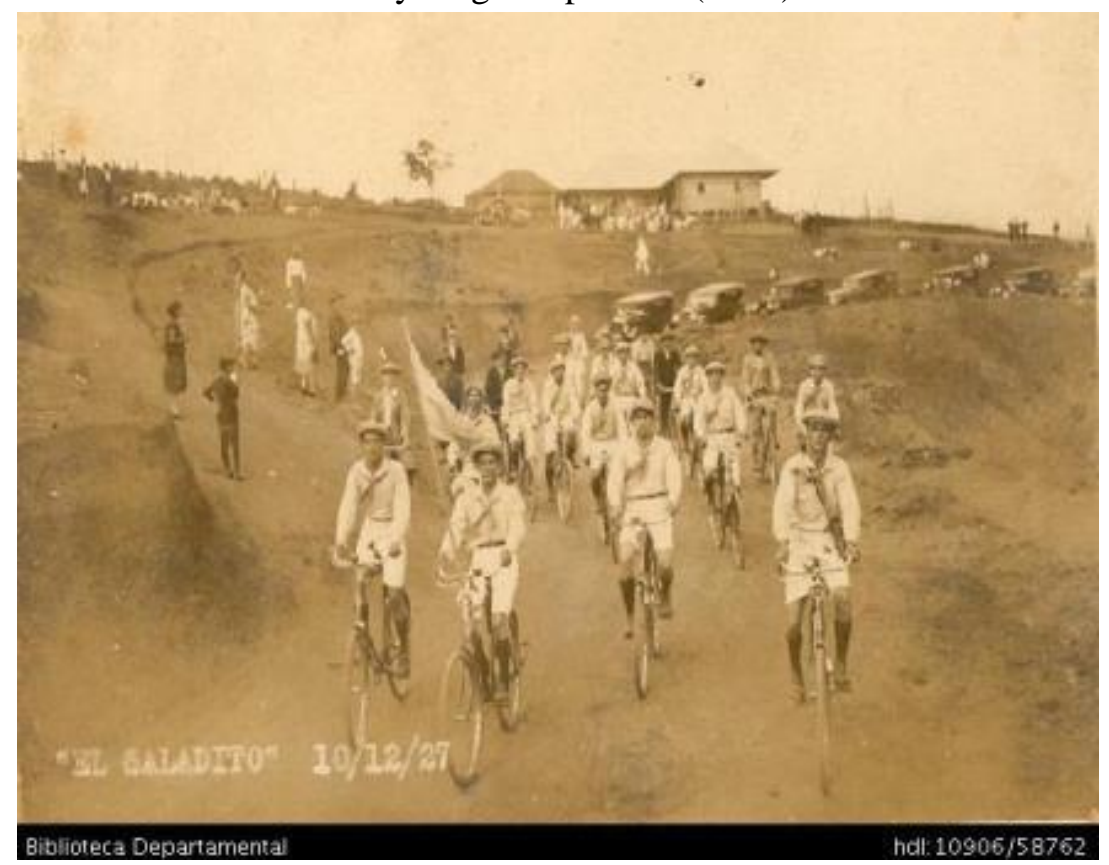

Source: Archivo del patrimonio fotográfico y fílmico del Valle del Cauca de la biblioteca Departamental del Valle Jorge Garcés Borrero - Sección las bicicletas y ca - patrimonial (918)

Picture 4. Cycling in Cali (1920)

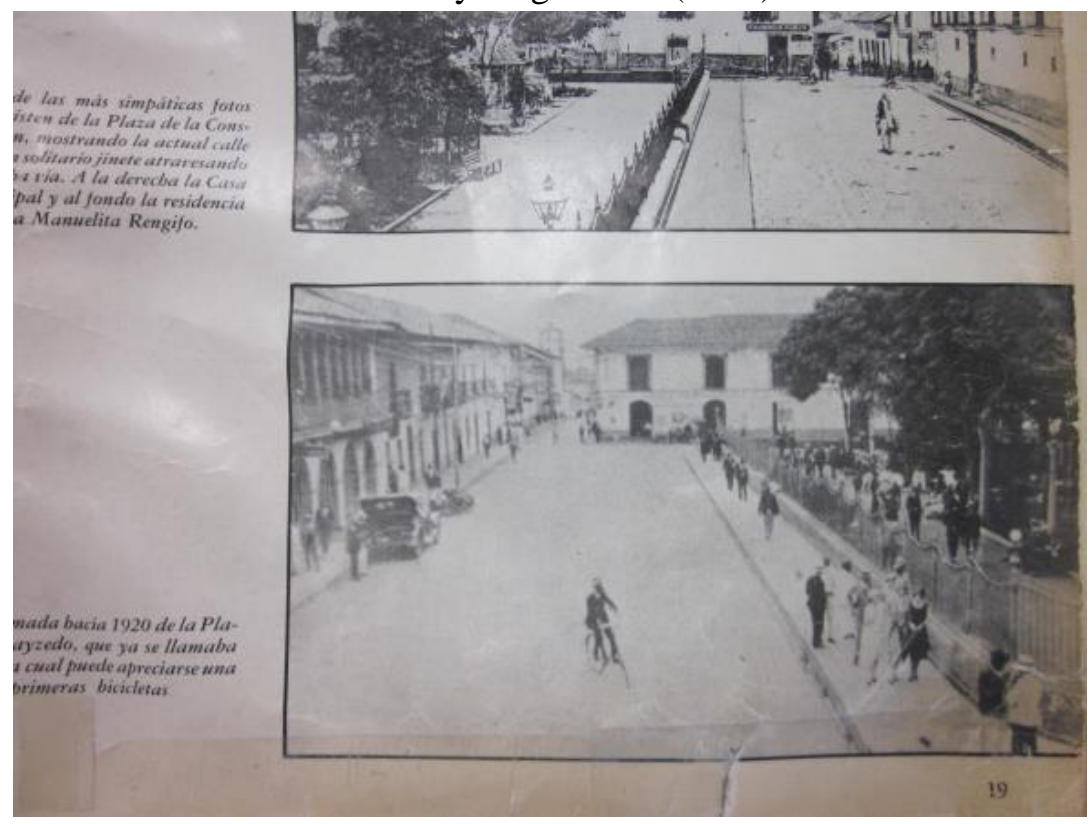

Source: Calero Tejada Álvaro. Cali Eterno. La Ciudad de Ayer y de Hoy. Institucional, Cali, 1983 
Picture 5. Cycling in Cali (1925)

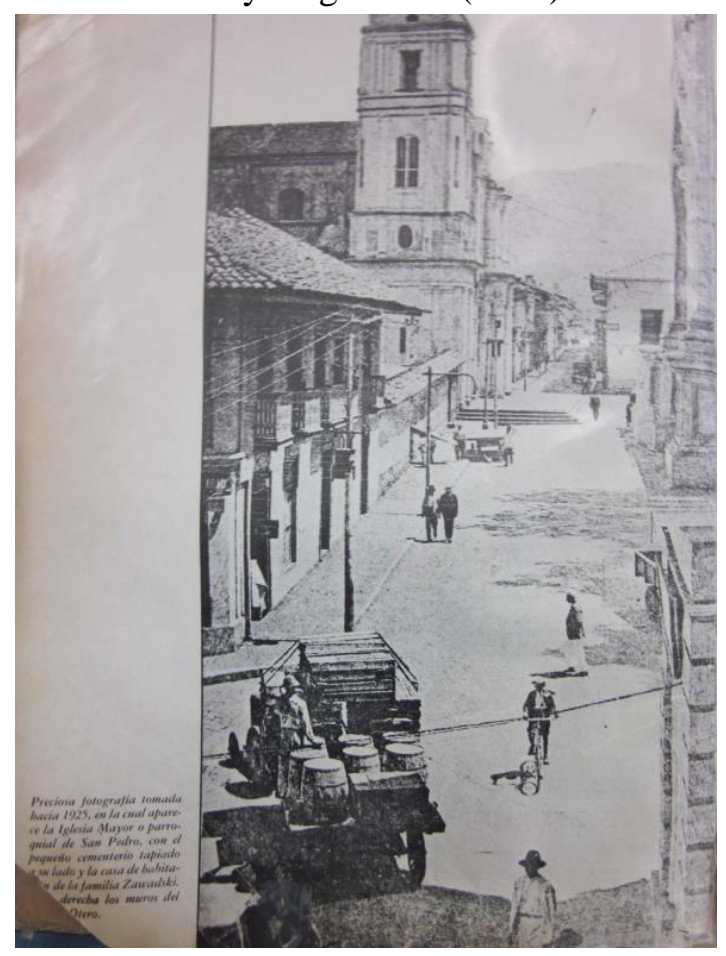

Source: Calero Tejada Álvaro. Cali Eterno. La Ciudad de Ayer y de Hoy. Institucional, Cali, 1983

Even though between 1910 and 1945 pressed by commerce and manufacturers the city of Cali provides the basic infrastructure required for industrialization, it is only after 1945 that an intensive industrialization process takes place and new local and international companies start to produce intermediate and capital goods for local and national consumption, mainly. Between 1945 and 1955, 24 foreign industries and approximately 21 local and national industries were established in Cali (Vasquez B 2001). As a result, the city experienced several economic and social impacts and large changes in the built environment were introduced during this new industrialization phase, with the intent of consolidating Cali as an industrial-urban area. 
People from rural areas looking for jobs and better life conditions were attracted to Cali. During the rise of industrialization, between 1945 and 1958, the population of Cali grew at a rate of $7.22 \%$ annually (Vasquez B 2001). The population grew from 190,015 inhabitants in 1946 to 470,076 in 1958 (Vasquez B 2001) and between 19501960, the city expanded by 2.203 hectares (Arboleda and Vivas 1991). This rapid urbanization process incentivized demand for urban land and the resulting struggles to acquire such space contributed to consolidating the working class. This shift also coincided with the period of "La Violencia" (1948-1953) when Colombia experienced an extreme local war based on partisan conflict. This violence in rural areas propelled migrants to Cali where the new arrivals engaged in the first land "invasions" or squatter settlements in the city (Arboleda and Vivas 1991).

Both industrialization and migration promoted the creation of new industrial zones, the establishment of new residential areas, densification of some areas, and the expansion of other urban sectors.

“(...) Industrial location behaves with a different logic to the tertiary sector. The industry could not locate or remain in the city center. To the extent that it is not linked directly to final customers and immediate users, high land prices in the center represented onerous costs. They must therefore be located or relocated outside the "center" in a periphery where land costs were lower." (Vasquez B 2001; p. 198)

The shift in the productive profile of the city, from manufactured goods to capital and intermediate goods, and in alignment with the accelerated process of urbanization affected the physical and social urban infrastructure. First, the city center was geared towards supporting activities such as the increasing demand for services needed by the 
tertiary sector. New buildings were constructed to meet that need. Second, industries initially located downtown with new industries relocated closer to the rail system, which was divided into five so-called industrial zones. Third, the traditional elite sector of residents moved from downtown to new residential areas in the Southeast of the city. Poor people's demands resulted in the creation of urban expansion to the East and Southeast of the city, where slopes and flood lands were predominant. Fifth, the new economic profile of the city increased the number of vehicles and circulation into the downtown area but the existing road network was not enough to accommodate them. As Bonilla (2012) argues, between 1925 and 1949, motorized transportation caused problems in a colonial city that did not have a hierarchical road system to ensuring traffic flow. .

"Pressure of demand on the central area of the city by the agents of the tertiary sector, with its consequent rise in land prices, necessarily implied demolishing the old houses downtown in order to build upwards. This concentration of commerce, banks, services, and offices for professionals and other public and private institutions radicalized both the monocentric character of the city as well as the slope of land prices that descended into the flood peripheral areas. These conditions concentered vehicular and pedestrian movement in the center of Cali (...)" (Vasquez B 2001; p. 229)

By 1951 Monark de Colombia S.A., a bicycle factory from Sweden, was established in Cali, and it played an important role in increasing bicycle use in Colombia in general and in Cali, more specifically. In fact, Arboleda and Vivas (1991) report that in the period 1950-1960, Cali experienced the most extensive use of bikes as a transportation mode. Bicycling at that time was very popular among workers and students; and consequently, stimulating demand for new local bike shops.

"Besides the Monark plant, dozens of bike-workshops started to produce make-shift bicycles, replacing horses and mules and they dispute, to the private and public vehicles, the expanded road network." (Arboleda and Vivas 1991; p. 44). 
Even though in Cali the local government had mechanisms in place to regulate the expansion of the city, it was only through Municipal Agreement 35 of 1940 that Cali formalized its first planning process (Espinosa $\mathrm{R}$ 2006) with new regulation in the form of the "Plano de Cali Futuro" (Plan for Cali of the Future) which declared the need to identify limits, to regulate the creation of neighborhoods, to define land use, and to delineate the road systems.

Based on this Municipal Agreement (35 of 1940), in 1944 the European architect Karl H. Brunner was hired to design a future plan of the city ("Plan Regulador de la Ciudad Futura"). Brunner proposed a plan in 1947 but nothing came of it because it did not match what were considered new modern ideas (Espinosa R 2006). Later Cali hired an international firm to develop a plan in response to the National Act 88 of 1947, which defined the need for "Planes Reguladores" in cities with a $\$ 200,000$ or more budget and more than 20,000 inhabitants. In Cali the plan was known as the Plan Piloto (Plano Regulador).

The 1950 Plan Piloto (Pilot Plan) was produced by Josep Lluís Sert and Paul Lester Wiener from Town Planning Associates. It recommended dividing the city into four basic functions, based on the Principles of Modern Urbanism: habit, work, recreation and circulation, and suggested one additional area: a civic center with large parking areas, pedestrian sectors and with wide access roads for traffic in which public administration business, cultural buildings and business sectors were to be established. By dividing the 
city in areas with specific functions, the intent was that the road system had as a role to connect all the city not just specific points (Espinosa R 2006). Consequently, it established a hierarchical road system intended to accommodate growth in automotive traffic and suggested a classification of roads according to their function (fast traffic roads, service roads and distribution roads) (Espinosa R 2006).

"(The plan included) the road system as a main tool for structuring the total city and the delimitation of its zoning." (Saenz 2012; p.316).

The Plan Piloto was adopted in 1953 and, although it was not implemented exactly as it was designed, was considered a key instrument in Cali's future urban development (particularly, during 1954-1969). In fact, as reported by Figueroa (2012) the Plan Piloto was a key guide for subsequent developments in Cali. The Plan Piloto supported subsequent plans and mechanisms of urban planning such as Estudio del Plan Vial de Cali (1968), Estudio del Área Metropolitana de Cali (1969), Plan General de Desarrollo de Cali PGD (Concejo de Cali 1970) and Plan Integral de Desarrollo de Cali (PIDECA) (Alcaldía de Cali 1979).

"(The Pilot Plan) virtually defines the city limits and changed the concentric scheme by the linear development to the South (and some new developments to the East and North), foreshadowing the future shape of the city" (Arboleda and Vivas 1991; p. 40).

Moreover, while the adoption of the Plan Piloto was decided in Cali, new roads were built with the intent of urbanizing rural areas ("potreros"). Consequently the new road system contributed to increasing land costs and expanding the city to the South where new neighborhoods for rich people were established. In terms of transportation, 
expanding the city away from industrial areas and away from downtown promoted motorized transportation and with it the process of densification in Cali began to ease.

The Plan Piloto suggested creating pedestrian areas, recreational sectors (corridors), and shopping centers, but it had no instructions relating to the use of bicycles as transportation means; conversely, the Plan Piloto suggested increasing parking space and building wider streets. For example, it was this plan that suggested the construction of the Autopista Valle, an extensive road with six lanes, to connect the cities of Jamundí, Cali and Yumbo. This proposal later supported the construction of Autopista Suroriental (1969-1971) in Cali (Espinosa R 2006). The Plan also included construction of other avenues such as Circunvalación Avenida, Autopista Simón Bolivar, among others, were part of the Plan Piloto (Arboleda and Vivas 1991).

In fact, between 1950-1960, several new avenues were built in the city, among them were: the extension of Avenida Roosevelt (between 1952-1957), the construction of $10^{\text {th }}$ street, extension and expansion of 34th street and extension of 44 street; and it was also during this period that the construction of two of Cali's wider avenues, Autopista Sur and Avenida Pasoancho, started (Arboleda and Vivas 1991). All of these avenues now support major traffic flow; and, the construction of new avenues was a key element for incorporating rural property (haciendas) into the urban area through which the real estate market in Cali was modified. 
"The opening of roads played a role. Several avenues were built (...) did not serve the populated areas but, rather, penetrated unpopulated land, more as a means to develop these "pastures" as instruments to induce urban sprawl (...)" (Vasquez B 2001; p. 238).

As Vasconcellos (1997b) establishes, the economic modernization process experienced in Latin American countries after World War 2 (1939-1945) contributed to reshaped urban infrastructure, by enlarging road systems to accommodate cars, with two main consequences on transportation: disdain for public transportation and support for private cars.

Even though bicycling as a mode of transportation in Cali began in 1920, it was most popular through 1950-1960, as a consequence of industrial development. However, cycling was not part of the modernization process that Cali experienced after the World War 2; on the contrary it was during this period that the city began to be an automobileoriented space through normalizing car use, increasing road construction and regulations with cycling increasingly marginalized as a mode of travel on streets.

To summarize, from 1945-1958 the ideal of Cali as a modern and industrial city was consolidated. This orientation motivated the city to transform in new and different ways. This process was also encouraged and supported by external forces. Establishing foreign industries in Latin American countries was a strategy for firms in industrialized countries to create new markets abroad and to mitigate accumulation problems in core capitalist countries. Indeed, as Harvey describes, restructuring urban spatial forms under capitalism is a way to overcome local and international crises of over-accumulation. 
Urban transformations, as immobile fixed capital, are also barriers to accumulation, thus cities, as can be seen in the case of Cali, can experience physical transformations or continue restructuring in response to the demands set by the production and consumption of capital.

Thus, physical infrastructure, such as roads or buildings, are built and torn down to assure accumulation over time. Urban transformations then can be understood as partly the result of the need to promote capitalist accumulation. Investments in physical infrastructure or initiatives that do not contribute to accumulation, even though they contribute to social well-being, are therefore less likely to be achieved unless they are supported by social movements or organizations who press for their implementation. This might explain the case of biking as a travel mode in Cali. It emerged during industrialization when the city faced a process driven by capitalist class interests and civil organization or existing social movements did not consider transportation by bike as a right to strive for. In fact, within the exception of land invasions and squatter settlements, the ways thriving areas in cities were shaped was not the result of demands by workers during industrialization. Workers were more than likely focused on battling to improve conditions on the work site.

The process of accumulation within capitalism, however, is mediated by social and political struggles that intervene in spatial capital dynamics. As Harvey argues: 
"All those whose labors are engaged in producing and reproducing the city have a collective right not only to that which they produce, but also to decide what kind of urbanism is to be produced where, and how" (Harvey 2012; p. 137).

For example, in the process of industrialization in Cali, struggles for urban land, working class consolidation, and political forces represented by a strong political and economic elite (a ruling class) determined the urban structure of Cali. Thus, as is observed in the case of Cali, political and social organization and physical structures have a dynamic relationship within capitalism. Particularly, in terms of transportation, urban infrastructure was also geared towards increasing land value and accommodating motorized transportation (buses and private cars) without taking into account that workers and students were mostly bicycle users.

As Espinosa (2006) argues, the process of modernization in Colombia was encouraged by architects and engineers as part of the government's bureaucracy of technocrats, influenced by the Modern Urbanism School, which pressured for defining a way to organize the city. As a result, the process of definition of urban plans was directed at building modern cities and away from understandings of "feudal cities" in Colombia. Cali was not the exception. The formal instruments of urban planning also played an important role in driving economic interests through urban landscape. The experience in Cali leads one to conclude that planning and its instruments are neither value-free nor value-neutral. 


\subsubsection{Second Period: Revitalizing the City thought the Pan-American Games}

Sporting events such as the Soccer World Cup or the Olympic Games are considered opportunities to revitalize cities, motivating private and public partnerships to invest in different sectors like transportation infrastructure and services, sports facilities, communications, etc. and are expected to enhance local economies. Those events are also opportunities to inspire the social climate by promoting hopes for the future or in the case of Cali, recovering hopes the city once had. Massive national or international events typically significantly transform the urban landscape (Hiller 2000).

Between 1964 and 1973 Cali experienced one of the greatest periods of physical expansion, to an area expansion of 2860 acres and a population increase from 637.929 inhabitants in 1964 to 991.549 inhabitants in 1973 (4.8\%) (Arboleda and Vivas 1991). This intensive urbanization was a consequence of migration from rural areas, formation of substandard settlements ("invasions") and incorporation of rural land to the urban area. The city expanded towards the south and east, which deepened spatial socio-economic stratification in Cali. The south side concentrated people from higher social and economic strata and southeast had a heavy concentration of poor people. The establishment of settlements was a consequence of violent land struggles.

"The waves of immigrants that in the past decade had occupied the interior of the city, into of home family or friends or had lived in crowded tenements, rushed en masse to conquer land and do battle for housing with the direction of political and social organizations" (Vasquez B 2001; p. 267). 
Cali had experienced an economic slowdown during 1957-1967 (Vasquez B 2001) and coupled with this accelerated and non-planned urbanization, Cali entered into the 1970s burdened with problems such as inadequate public utilities (water supply, energy and sewage), land conflicts, deficient transportation systems and social insecurity. Hosting the VI Pan-American Games was an opportunity not just to transform Cali physically but also socially. Political leadership and citizens saw the games as an opportunity to alleviate the adverse social and economic conditions in Cali.

In 1967 the city was chosen to host the VI Pan-American Games, which it held in 1971. This effort was promoted and organized by local entrepreneurs and politicians. It was considered a strategy for socio-economic reactivation and an initiative to recover Cali's role as a leading Latin American city through the organizing and hosting of international and national sport competitions. In fact, the motto of the city was "Cali: capital deportiva de América" (Cali: Sports Capital of America) (Vasquez B 2001; p. 279-280). Moreover, a discourse of civility was extensively used to recover public confidence in the future of the city. The VI Pan-American Games transformed the city in different ways.

In order to prepare the city for the VI Pan-American Games, the built environment was transformed which included a set of new road investments and sports facilities. Two main design initiatives were implemented to upgrade the city: the design of the Plan General de Desarrollo (General Development Plan) and the implementation of the Plan 
Vial (Road Plan). Zuleta and Bernal (2001) also report that the municipal government made alliances with the Ford Foundation, looking for help to guide the city's urban development (Zuleta L and Bernal B 2001).

Aligned with the interests of the games, the municipal Plan General de Desarrollo -PGD (Concejo de Cali 1970) sets "a new road system, road center transformation and reorganization of routes for the public transportation system" (Bonilla Sandoval 2012; p. 57). In the PGD Cali began to discuss what modes of mass transportation should be implemented. In this plan light rail was considered the city's best alternative but its implementation was considered feasible only years later. In this Plan, accommodations are made for pedestrians but cyclists do not appear as part of the transportation sector. In sum, biking is not conceived as a mode of transportation. The plan suggests, for example, designating some sectors within commercial areas, particularly in the downtown area for pedestrian use exclusively (Concejo de Cali 1970). The plan also contemplates a solution for parking on the public street as a strategy to solve esthetic problems in downtown Cali.

"(...) the city is expected to give incentives to achieve the construction of parking facilities and settle the problem of parking on streets, recovering both the aesthetic balance should be the center of the city" (Concejo de Cali 1970; p. 226).

In the plan most paved areas are located in sector 1 and 2 of the city, favoring motorized transportation to middle and high class zones.

"There is a close and logical relation between no-pavement and low-income, sectors 3, 4 and 5 have almost any paved roads" (Concejo de Cali 1970; p. 221) "... the lack of good roads increases the operation cost due to the deterioration of the auto fleet, in consequence travel times are longer, sometimes forcing provide limited service to those routes that offer a minimum of trafficability" (Concejo de Cali 1970; p. 221). 
Even though the PGD was not approved by the Municipal Council, it guided future urban development in Cali. The subsequent Plan Vial by Otto Valderruten designed in 1969 determined the new transportation landscape in Cali in terms of urban mobility. This Plan maintains that the downtown area of the city is geared toward responding for the need to provide services and commerce but not to support industries. This shift represented a different way of understanding people's needs for mobility or transportation patterns and established a radial road system where the downtown area was considered a fundamental axis of attraction. To accommodate this orientation new roads and streets were built parallel with the radial axis.

During this period, the Inner Ring-Road ("El Anillo Central") was built with an accompanying system of road networks. Most of the new construction was part of the Anillo Central consisting of several elevated bridges and new streets, expansion and extension of old roads, and the paving of several streets. In 1973 the number of paved roads increased by $24.3 \%$ (Vasquez B 2001) potentially increasing the number of vehicles in the city. In Cali the total number of motor vehicles in 1974 was 37,692, very different to that of following years (55,903 in 1979). Thus, between 1974 and 1979 the vehicle fleet increased to $61 \%$ (Alcaldía de Cali 1980).

"Times and urban aesthetic look had changed in a few years. Now modernization had another picture: the high bridges" (Vasquez B 2001; p. 286).

This municipal transformation also included the construction of new public infrastructure buildings such as schools, hospitals and sports centers as well as 
commercial buildings. To accomplish urban renovation the demolition of a number of buildings, old houses, and markets such as the Central Market, and the relocation of traditional markets (satellite markets), the creation of parking spaces, and the installation of the traffic light system was also carried out. The city's transformation also included the expansion of public utilities such as water, electricity, waste management and telephone service.

In order to supply the demand for housing, public and private sectors were motivated to aggressively pursue housing solutions, create a "building boom". However, both the construction of new houses and extension of the road network (mainly towards the southern end of the city with high priced real estate) could be understood as strategies to increase land value that in turn deepened socio-spatial segregation. In addition, most physical infrastructure for sports activities and major road works were built on the south side of the city.

"Large arterial roads towards the South, which were very expensive constructions (paid by all citizens), serve initially only for land speculation in that sector, pushing away further the possibility of the harmonious development of the city." (Arboleda and Vivas 1991; p. 52).

This process of social spatial segregation in the city was consolidated with the emergence of two cities. Poor and working-class residential areas were located far from the downtown area, in the areas of lower land prices with bad public utilities towards the floodplain in the east and northeast side of the city. While the west side of the city that enjoyed good lands closer downtown was reserved for wealthier residents (Vasquez B 
2001). This division concentrated social problems and poverty to one side of the city and maintained a mono-centric city model.

Studying the political elite in Cali from 1958 to1998, Saenz (2012) argues that the policies they supported promoted segregation because, while ill-conditioned lands were underserved and were acquired by poor people, quality lands with better amenities were available to the wealthy. Those decisions were made by an elite who occupied political positions in the city and had economic power as well. In keeping with Vasconcellos' analysis of capitalist modernization in Latin American countries which aimed "to ease the circulation of the social sectors which are relevant to economic accumulation and political legitimation" (Vasconcellos 1997a; p. 293), the evidence suggests that the experience in Cali was in line with that trajectory

"The urban renewal policy was supported by: the fundamental principles of planning, related to the most appropriate places to locate the areas of housing, which recommend that the worker must be near the factories; the middle class must be in the city centers, where they development their activities, thus they can save transportation costs and other services and, finally, the upper class can be located on the periphery, because they have the car and the means to make their functions correctly. ("El País" cited by Zuleta L and Bernal B 2001; p. 107)

Finally, the process to prepare the city for the VI Pan-American Games included imposing new taxes and economic sanctions for citizens that did not follow official requests to "embellish the city of Cali" such as painting the façades of buildings or flying the flag the day of games inauguration (Zuleta L and Bernal B 2001). In terms of urban infrastructure for transportation, the city continued to be in favor of motorized transportation modes as the private car continued to be considered a modern mode of 
travel available for the mobility of people with higher incomes while the private sector provided buses for public transportation.

During the 1960s, the number of bus companies participating in mass transportation increased. This increase in the number of buses began to limit potential options for incorporating cycling as a mode of travel in Cali. In the 1969 Plan Vial there is no reference to bikes as a mode of transportation, even though bikes were observed as a principal mode of travel among workers and students during 1950s.

"From 1963 Cali lives a forced process of "substitution" of the urban transportation system ... the healthy proliferation bicycle use in Cali is stopped by creating transportation buses cooperative (Gris San Fernando, Papagayo, Verde Bretaña, Verde San Fernando) and there was an official harassment against bicycle users (with denial of lanes and frequent raids forfeiture). Urban bike use starts to decline to almost disappear nowadays, except during Ciclovias on Sundays and holidays." (Arboleda and Vivas 1991; p. 48).

Indeed, a report produced in 1969 by the Monark bicycle company and the Industria Colombiana de Bicicleta El Balin indicates that between 1956 and 1968 they produced around 250.000 bikes which were much less than responding to the potential demand -calculated at 5 million based on the number of people in Colombia between 15 and 35 years old- would require. Both companies' (Monark and El Balin) installed capacity reached just $50 \%$. The main objective of this report was to request a tax deduction or elimination from the authorities in order to facilitate the purchase of bicycles by workers and students.

"Industrial companies engaged in the manufacture of a vehicle used by the working classes of the country, aims to interest the State sector on the desirability of the large population with lower income, can acquire the bicycle as a means of transportation, with an accessible price, and without taxes on the sales that prevent its widespread use by the working class of the country." (Monark de Colombia S.A. 1969). 
Monark and El Balin argue that due to the fact that bikes are used by people with lower income, the government should facilitate conditions to buy this means of transportation.

"Because the bicycle is a means of transportation for the working and peasant classes with salaries between $\$ 800$ and $\$ 1000$, it can be said that the price rise on bikes caused in recent years by high sales tax, has influenced the reduced consumption of this economical vehicle for the masses." (Monark de Colombia S.A. 1969).

In 1979 the "Plan Integral de Desarrollo Urbano" (PIDECA) (Alcaldía de Cali 1979) was introduced. Even though this plan keeps the spirit of road construction and wider streets and recognizes the importance of integrating transportation planning and land use, once again bicycling as a travel mode is excluded from local planning.

"To integrate transportation planning and land use, seeking the welfare of human beings and not the comfort of the car, encouraging public transportation and pedestrian transit, and limiting car access to the central area. Bringing the work closer to homes, promoting jobs in populated neighborhoods and housing schemes in areas of employment." (Alcaldía de Cali 1979; p. 51).

In brief, during a short period of time Cali experienced once again an intensive physical transformation. According to some scholars the process divided the city's history in two parts. A historical chronicle of the process concluded that the main objective of this process was that Cali passed "From a village to a city" in one decade (Figueroa P 2012).

The local elite, comprised of entrepreneurs and politicians, promoted a modernization project by transforming the built environment. The redesign and construction of buildings and houses, urban spaces and road infrastructure were considered a force to modernization. The physical transformation of Cali through the 
construction of bridges, highways, street expansion and extension was designed to encourage automobile consumption and the active exclusion of bicycle use. Data from historical documents illustrates that during that time biking as a mode of travel faced constrains not just by limitations on physical space but also explicit police interventions to exclude bikers from roads.

\subsubsection{Third Period: Transforming to be Competitive (1990-2013)}

Since the 1980 s and during following years, the neoliberal process, as a set of economic policies aimed toward privatization, deregulation, and open economy, was implemented in Latin American countries as a strategy to respond to capitalism's structural crisis of the 1970s. The neoliberal project was promoted by the IMF and established through the so-called "Structural Adjustment Program". The project of neoliberalism has had several consequences on different urban areas referred to as the neoliberalization of urban space (Brenner 2005).

In Colombia this economic process started during the presidency of Virgilio Barco, 1986-1990, and focused on setting legal conditions to establish the neoliberal project in Colombia. However, it was during the administration of César Gaviria, 19901994, and successive presidents that neoliberalism was implemented (Ernesto Samper, 1994-1998; Andrés Pastrana, 1998-2002; Álvaro Uribe, 2002-2000). Neoliberalism in Colombia was distinguished by changes in the role of the State, reduction in social 
expenditure, economic and political decentralization, privatization of social services such as education and health, and reforms in labor laws to facilitate labor flexibility (Ahumada 1996). Several impacts can be attributed to the implementation neoliberal policies in Colombia. Focusing on the city of Cali, there were consequences for the role of the cities within globalization, the role of the built environment on this process, and impacts on urban transportation. These will be explored.

To respond to the new dynamics of accumulation within globalization, cities need to be more efficient and competitive in order to be attractive to international capital. As a result, efforts were focused on creating healthy business climates. Latin American cities implemented strategies of urban renovation, tourism marketing, economic restructuring, free trade zones and transportation projects designed to create competitive cities within a global market.

The built environment during this new stage of capitalist accumulation plays a key role in the capitalist dynamic. In particular, restructuring transportation systems to reduce congestion and to increase productivity by moving workers and commodities more efficiently, is a critical factor in improving urban competiveness. Indeed, it is necessary to promote transportation systems that contribute to reduce the turnover time of capital. This means that transportation should not only shorten commodity circulation time (Harvey 1978), but also necessarily facilitate workers' mobility for production and 
consumption. However, by implementing such initiatives that result in neoliberalization of urban space, cities simultaneously aggravated their socio-economic inequalities.

A review of official planning documents as well as interviews with some key officials confirm that Cali, by adopting this neoliberal process of becoming a competitive city implemented two specific strategies related to the transformation of the urban space: the Bus Rapid Transit system and a set of new massive urban construction projects called Megaobras. Both strategies, which are transforming the city socio-spatially, share three main features linked with the implementation of a neoliberal project at the local level. First, the strengthening of the private sector through private-public partnerships that has serious implications for the types of infrastructure that is implemented, the conditions of services offered, as well as population served. Second, implementing blue print initiatives, ignoring the specificity of local conditions, needs and demands. Third, the social goals of redistributive wealth that every transportation system should ideally have are being eroded to make way for the economic benefit of an elite sector. Both of these initiatives increase road infrastructure, favoring better conditions for private car owners and motorcycle drivers.

\section{The Bus Rapid Transit system}

The most recent road plan (Alcaldía de Cali 1993) of Cali continues to approach transportation problems as if motorization was an "inevitable force" in urban areas. The 
plan, keeping a dominant discourse of congestion and road hierarchy, consists of around 19 programs and 487 projects, all of them related to infrastructure for motorized transportation. Consequently, even though the Plan presents a definition of ciclovías (bike routes), it does not suggest any program or project related to this type of physical infrastructure for non-motorized transportation.

Even though as early as 1990 Cali considered implementing a mass transportation system and different feasibility studies were carried out, it was only in 1997 that the national government defined how the participation of the national and local levels should be in a massive transportation project for Cali. In 2002 the national government, led by CONPES (El Consejo Nacional de Política Económica y Social), the most important national planning authority in Colombia and main advisory body of the government in terms of social and economic national development, decided to implement a national program to improve public urban transportation of passengers (CONPES 3167 2002). The initiative advocates for among other issues, promoting sustainable urban transportation solutions to resolve problems in Colombian cities.

Cali implemented the Bus Rapid Transit system (BRT) in 2009, as part of the National Integrated Mass Transit System Program (SITM Spanish acronym). The BRT system consists of a number of high-capacity buses that move along dedicated lanes using fixed stations to pick up and drop off passengers. In Cali the BRT is called: MIO (Masivo Integrado de Occidente). All BRT systems in Colombia are based on Bogotá's 
pioneer experience with TransMilenio which has been evaluated as successful (Ardila and Menckhoff 2002). TransMilenio, the first BRT implemented in Colombia, has been in operation since 2000 and it works similarly to the Curitiba (Brazil) BRT system.

The national government as well as local authorities, the private sector, the World Bank, and the Inter-American Development Bank participated in the SITM program in Colombia. According to the World Bank "The objective of the Support to the National Urban Transport Program Project for Colombia is to enhance the efficiency, affordability, quality, safety, and environmental sustainability, of the provision of public transit services in the participating cities (...)” (World Bank 2011). In support of this orientation, Colombia's national government argued that in big cities (cities with more than 600,000 inhabitants) the SITM may contribute to urban productivity, improve quality of life and stimulate private sector participation in the urban transportation system (CONPES 3260 2003). Strengthening the role of the private sector in the management and delivery of social services is a key strategy of the neoliberal project.

The BRT is expected to meet $100 \%$ of Cali's public transportation demand and cover $97 \%$ of its geographic area. This means that construction of the BRT produces significant changes in the built form, land use and property values. The social environment is also transformed. Designing and building bike-paths and bike parking, as complementary infrastructure, was considered a strategy to improve SITM's accessibility (CONPES 3167 2002; CONPES 3260 2003; CONPES 3305 2004). In actuality in Cali 
resources were allocated for construction of $50 \mathrm{~km}$ of bike-paths articulated to BRT (CONPES 3504 2007; DNP 2008), to encourage bicycle use for transportation. However, as is discussed below, this initiative has had detractors and it has not implemented as originally conceived.

Not unexpectedly, in terms of spatial transformation, the BRT extensively changed the city. The system consists of a set of varied infrastructure such as a 39 kilometer-long network of exclusive BRT corridors and 243 kilometers of secondary bus corridors; 56 principal bus stations and 655 regular bus stops; 17 new pedestrian bridges; 10 new automobile bridges; 11 principal bus terminals; among several intersections and reconstruction of roads (Metrocali). In addition, as part of the BRT, several public spaces were renewed, and improvements related to the air quality, noise and increasing social integration are expected. The relationship between the BRT in Cali and biking as a means of transportation will be discussed in the second and third sections of this Chapter.

One of the main changes expected with implementation of the BRT was that public transportation would move from experiencing competition in the market to competition for the market (Ardila 2008). The government is to regulate who operates routes for the system. Operators compete for the market and win contracts or concessions to operate the system. This set up avoids direct competition in the market ("La Guerra del centavo"). Contracts won in this way can be renewed periodically. 
In Cali the expectation was that MIO would become an exclusively public transportation system. But it simultaneously means involving the private sector in the operation of the whole system through long-term contracts, without any initial financial contribution towards the construction of infrastructure for example. In order to guarantee economic sustainability and profits, private operators need enough citizens to use the system. The logic of this market-based regulatory arrangement has implications on the characteristics of services offered, such as definition of routes. Most significant are the consequences of this arrangement on non-motorized transportation. Not surprisingly, BRT private operators are interested in placing barriers for other means of transportation such as cycling that represents competition for the ridership.

In contrast, the experience of the TransMilenio system in terms of competition in and for the market is different from that of the MIO in Cali. In Bogotá, a city of around 8 million inhabitants, the TransMilenio is not expected to assume all public transportation demand. Rather, the TransMilenio runs alongside a traditional mode of transportation based on conventional buses, which keeps both configurations: competition in the market and competition for the market. In Cali this is not the case since the implementation of the BRT is expected to eliminate competition in the market. In reality the experience in Cali has been that MIO is battling with private buses and other informal transportation systems in order to eradicate competition in the market. 
A new agency was constituted to administer the SITM (Sistema Integrado de Transporte Masivo) in Cali. This agency, called Metrocali S.A., was constituted in 1998 with national and local public funding. Currently, four private transportation agencies (Unimetro, Blanco y Negro Masivo, ETM and GIT) are responsible for operating the MIO. The private-public partnership established to operate the MIO system in Cali is also a strategy for sharing commercial risks between the city and the private sector. In effect, the city and private operators can implement barriers to block other means of transportation from participating in the transportation market. In fact, as will be discussed below, even though in Bogotá a network of bike path articulated to TransMilenio was built, in Cali this initiative has not been implemented. Metrocali S.A. planned only to build bike paths at entrances to the BRT system along with parking areas for bikes. If a main reason to use bikes as a means of travel in Cali is to accommodate the financial limitations of those of lower socioeconomic status, the current MIO bike articulation system is still inadequate.

\section{$\underline{\text { Megaobras/Megraprojects }}$}

As part of the process of turning Cali into a productive and competitive city, in 2008 the city engaged in an extensive physical transformation (Ospina G 2008b). This initiative consists of construction of 11 road expansions, 6 intersections, 7 works of public space and 3 big colleges. In essence, the project focuses on improving road infrastructure to enhance traffic mobility and to solve traffic congestion problems. 
"The mobility in Santiago de Cali is one of the most important challenges to be faced and solved in the most efficient manner possible by the Municipal Administration. In response to the vial backlog of more than 20 years, the local government approved the implementation of "Plan 21 Megaobras" in the city of Cali on 21 July 2008." (Alcaldía de Cali 2010).

Megaobras was an initiative of the local mayor Jorge Iván Ospina (2008-2011) and it found support in the Municipal Council of Cali. The circumstances under which the initiative was developed show how local interests represented in the Chamber of Commerce and the Hotel Association of Colombia-COTELCO (Cámara de Comercio, Asociación Hotelera de Colombia-Cotelco) and political forces were focused on recovering Cali's national leadership and image, the confidence of population in the local administration, and to stimulate economic activity in the city. In this effort the built environment, particularly road construction, was harnessed as a mechanism to revive the city economically, politically, and socially.

"(Megaobras' proposal) It is an investment in mobility strategies for competitiveness, revitalize the local economy through construction and, invigorate local processes of appropriation of the city" (Castillo 2009).

During the early 1980s and 90s Cali experienced complex drug traffic problems with serious adverse social, political, and economic consequences at different scales (local, national and international). Moreover, local administrations from 1995 to 2007 were incapable of governing the city. As a result, Cali accumulated several problems during these years, evident in its negative social and economic indicators (de Roux 2008) Municipal elections in 2008 in Cali occurred amid a crisis and the elected mayor (Jorge Iván Ospina 2008-2011) ran a campaign to "recover" the city. Within this context, 
Megaobras and the BRT projects were public projects designed to take back control of Cali, and achieving goals for productivity and competitiveness by implementing MIO and improving vehicle road pavement, width and repair. Additionally, probably both initiatives responded to citizens' desire to see physical works in the city and in this way to restore confidence in the local administration. Indeed, the Megaobras discourse was centered on the need to address the physical infrastructure lag in the city which limits the development of Cali.

"It reflects the delay of more than 20 years in the modernization of the road network of the city (...) this delay in road infrastructure is perceived through the absence of roads and overpasses." (Ospina G 2008b; p. 50).

The Megaobras project is implementing outside of the Master Mobility Plan and the Land Use Master Plan of Cali (Plan de Ordenamiento Territorial-POT in Spanish). In other words, this set of projects, modifying the built environment, was conceived as an initiative from the local mayor and his alliances and disconnected from other higher-level local plans. Even though Ospina's plan stated that pedestrian and cyclists would be given priority a review of the plan indicates that there are no goals or projects to support this intention in the plan itself. However, some bike-paths were built as part of the Megaobras. Some were conceived for recreational bicycling with bike paths circuits. Some paths were built on very narrow sidewalks, which have led to their underutilization.

Four issues can be highlighted to demonstrate how the politics of mobility in Cali widened inequality at the street level during this period. First, the discourse of 
modernization appears associated with renewal of the built environment. Modernization was understood as building new constructions in order to recover around 20 years that the city had failed to build large road infrastructures such as intersections, bridges and wider roads. The main objective was to attract international capital, energize the tourism sector and local business. In fact, the local government found great support from the business sector. Defining modernity in terms of adopting patterns of mobility based on motorized means of transportation neglects local experiences related to transportation needs and traditional modes, letting investments in the built environment be for economic profits without solving people needs. Support for initiatives that buttressed Cali's recovery of national and international credibility led to the adoption of Megaprojects that were also related to a strategy of urban revitalization. In fact, the current local mayor argues that “(With Megaobras) Cali va a volver a ser la de los juegos panamericanos” (Duzán 2013).

Second, under a particular vision of modernity, by focusing on roads construction and associating it with development, the city reaffirms the importance of motor vehicles. Indeed, a little more than $80 \%$ of the budget from Megaobras goes to road works such as intersections, bridges and wider roads. The politics of mobility in Cali encourage motorized transportation instead of a more sustainable transportation system. Consequently private cars continue to gain urban space and consolidate their hegemony. The substantive unequal outcomes of the mega projects initiative illustrate the power of political groups and economic elites who have envisioned the city without public 
participation. Moreover, the discourse of modernity was accompanied by a discourse of "caleñidad" and "civism", which is a symbolic way of remembering an ideal of how Cali was in the past: a civic city with good citizens (Pinto 2008). The popular appeal of the "caleñidad" discourse contributed in part to the public support achieved by the mayor Jorge Ivan Ospina during his campaign and first part of his administration.

Third, the Megaobras project may be understood as an affront to citizens who do not drive an automobile in Cali. Although the discourse said that Megaobras would benefit the entire population and, therefore, due to the fact that infrastructure would raise the property values (those projects are funded with property tax revenue - impuesto de valorización), in the end all indications are that the Megaobras will benefit investors and people who drive cars in Cali. A recent survey showed that around $20 \%$ of residents in Cali reported having a car at home and just $6.5 \%$ of them reported having driven a car in the last seven days (FES-Univalle 2010). As was exposed by Corrales (2009): 6\% of the Megaobras budget was for parks, $0,75 \%$ for pedestrian areas and $10 \%$ for schools. The cost of improving traffic for automobiles was paid for by the entire population.

Lastly, despite the impacts of Megaobras on people's everyday life modifying urban structure, taxes, and externalities during and after constructions, public participation was absent. While the Ospina Government Plan was part of a public planning process (Ospina G 2008a), the Megaobras initiative was an anti-public planning 
process. In fact, there are several law suits against Megaobras taxes but none of them have yet been resolved (Diario El País 2014)

To summarize, the historical overview of Cali shows that transformation of its built environment, as part of the urbanization process, is interwoven with capitalist development. This chronology specifically illustrates that under capitalism, investments in the built environment, related to transportation, have circulated in areas were profits can be achieved. As Harvey argues (1978), capital shifts from one economic activity to another looking for a profitable investment opportunity and this translates into particular kinds of transformations of the built environment. However, additional research is necessary to identify other cultural and social processes that may have also contributed to change the built environment in the city of Cali.

During the first period (1945 and 1958), Cali was subject to social and economic changes that promoted industrialization (switching from rural development to industrial development). The urban environment was transformed: residential zones are separated from commercial areas, new commercial buildings were built and because of the increase in car use, there was increasing demand for road construction. In tandem with this shift, planning instruments to regulate land use began to be implemented. In the second period (1964-1973) the city of Cali experienced an urban crisis that encouraged support for a massive regional sporting event as a way to recover from that crisis. 
So, private and public investments were channeled to reform the built environment. Sports facilities, road construction, and new buildings were built. However, urban renewal contributed to boost the bus system as the main transportation system and in disdain urban cycling that was popular among workers and students at that time. And more recently (1990-2013) capital switched again from local industrialization to internationalization. In terms of transportation investments the focus has gone to improving efficiency and attracting international capital.

Consequently, within these transformations, Cali has been legitimizing policies, discourse, and practice that widen inequality at the street level, adversely affecting poor people who use the bike as a means of travel and face the hazards of traffic externalities daily, while enhancing conditions for motorized means of transportation. Indeed, motorized means of travel such as private cars, motorcycles and BRT, continue to gain urban physical space and accrue economic resources. Moreover, taking into account that the transformation of the built environment is an economic and social activity, transforming the city to incentivize motorized transportation allows the owners of private cars to gain social recognition, status and legitimacy. 


\subsection{Current Social and Economic Forces and Processes Limiting Bike Travel in Cali}

In Cali recently, the discourse around sustainable transportation is predominant. However, there are different perspectives about its role. In the international arena a number of agencies and organizations from the World Bank to environmental movements participate and shape the discourse about sustainable transportation. There is neither consensus on what sustainable transportation means nor how it should be implemented. Transportation is part of the built environment, and as such, the production of the built environment is a political issue driven by different forces. The built environment is a material representation of how class tensions are (re)solved in a specific context. The following section discusses forces and processes that define urban mobility in Cali.

Particularly, it centers on forces and interests affecting the decision-making process related to the construction of the bike-paths to encourage bike use in Cali. Six forces and processes, at different scales, influencing local decisions regarding urban mobility in Cali were identified: 1 . The World Bank; 2. The automotive industry; 3. The National transportation policy in Colombia; 4. The views on biking in Cali; 5 . The urban transportation planning sector in Cali, and 6. The lack of counter-hegemonic processes in Cali. Those processes and forces are discussed in this section of findings chapter. In doing so, the case of Cali illustrates the political and economic nature of the built environment and, more specifically, how struggles about space for bike travel in the city represent an element of class conflict in urban areas. This section of the findings 
contributes to better understanding why the city, as a local government agency, has experienced restrictions in implementing a local decision that could result in individual and collective advantages.

Findings in this section are based on the analysis of documents mostly from the Transportation Bureau (local, regional and national) and as they relate to policies in urban transportation, as well as information found in documents from international agencies pertaining to transportation policies. These were analyzed identifying key themes. In addition, the analysis is based on information gathered from interviews through a purposive sampling of a range of carefully stakeholders at the local and national level. Table 3 shows some profile information with regards to this group of research participants. A policy maker from the Ministry of Transportation of Colombia, who is expert on BTR implementation, was invited to participate but she postponed the interview four times, and eventually was not participate in the project. It is relevant to inform readers that, for the purpose of this research, it was impossible to identify a public servant responsible for non-motorized transportation in Colombia either through the Ministry of Transportation website or through direct consultation with officials of this agency. 
Table 3. Information on interviewed participants

\begin{tabular}{|c|c|c|c|}
\hline Number & Education & Occupation & Observations \\
\hline 1 & Postgraduate studies & $\begin{array}{l}\text { Ex-public servant from the } \\
\text { Secretariat of Public Health } \\
\text { in the municipality of Cali. }\end{array}$ & $\begin{array}{l}\text { Researcher in public health area } \\
\text { with experience in local political } \\
\text { processes. }\end{array}$ \\
\hline 2 & Graduate studies & $\begin{array}{l}\text { Public servant from the } \\
\text { Colombian Ministry of } \\
\text { Health. }\end{array}$ & Experience in public health. \\
\hline 3 & Postgraduate studies & $\begin{array}{l}\text { A CEO from Metrocali } \\
\text { agency. }\end{array}$ & $\begin{array}{l}\text { Experience in transportation } \\
\text { planning A key player during the } \\
\text { first stage of MIO implementation. }\end{array}$ \\
\hline 4 & Graduate studies & $\begin{array}{l}\text { Public servant from the local } \\
\text { planning office of Cali. }\end{array}$ & $\begin{array}{l}\text { Experience in transportation } \\
\text { planning and urban planning. More } \\
\text { than } 18 \text { years working in the local } \\
\text { public administration of Cali. }\end{array}$ \\
\hline 5 & Graduate studies & $\begin{array}{l}\text { Ex-public servant from the } \\
\text { local planning office of Cali. }\end{array}$ & $\begin{array}{l}\text { Experience in transportation } \\
\text { planning and urban planning. A key } \\
\text { player during the decision making } \\
\text { process of BRT construction. }\end{array}$ \\
\hline 6 & Graduate studies & $\begin{array}{l}\text { Activist from a local bike } \\
\text { organization. }\end{array}$ & $\begin{array}{l}\text { Member of the most recognized } \\
\text { organization pro-bike in Cali. }\end{array}$ \\
\hline 7 & Postgraduate studies & Researcher and professor. & Expert in transportation planning \\
\hline 8 & $\begin{array}{c}\text { Undergraduate } \\
\text { studies }\end{array}$ & $\begin{array}{l}\text { Activist from a local bike } \\
\text { organization. }\end{array}$ & $\begin{array}{l}\text { Member of the most recognized pro- } \\
\text { bike organization in Cali. }\end{array}$ \\
\hline 9 & Postgraduate studies & $\begin{array}{l}\text { Public servant from the } \\
\text { Secretariat of Public Health } \\
\text { in the municipality of Cali. }\end{array}$ & Experience in public health. \\
\hline
\end{tabular}

\subsubsection{The World Bank's Role on Transportation}

The World Bank program for transportation started in 1972. Especially in the last decade (1999-2009) this agency has played a key role in both funding and contributing to, and influencing technical definitions of urban transportation and implementation worldwide (Mitric 2013). In fact, the Latin America and the Caribbean region has been the World Bank's largest customers in credits for transportation projects in the last decade, (Mitric 2013). The World Bank's point of view on transportation is evident in several 
strategic documents. These documents illustrate the criteria that guide the World Bank's lending practices on transportation in so-called "developing countries".

It is relevant to note that data shows that World Bank lending for transportation projects started in the late 1940s and that before formally starting the transportation program of 1972, World Bank lending focused mainly on inter-urban transportation projects at the national level in the form of highway construction, for example (World Bank 1996). A recent evaluation on the World Bank's transportation sector reports that between 1995-2005, 284 transportation projects were implemented, most of them related to the construction, rehabilitation or maintenance of inter-city highways with scarce or null preoccupation on other related sustainable areas or multiple modes of travel (de Buen, Juhel, O’Neill, Plessis-Fraissard, Saghir, Shalizi, Suchorzewski, and Wray 2008).

In 1972 the World Bank produced a document titled "Urbanization Sector" (World Bank 1972) in which it manifested its concern about the "scale and intensity" of urban problems in developing countries and in response, the Bank shifts from financing projects by sector to focusing on problems of urbanization. "Urbanization problems" became a particular area of focus for World Bank lending. This document articulated World Bank transportation policy, arguing that urban growth is inevitable and cities would need huge investments in roads and other infrastructure for transportation, including mass transit. 
Even though infrastructure for bicycling and walking is suggested, the Bank maintains that mass transit is the most important initiative in achieving efficient cities, because it links workers with working places and mass transit also contributes to supporting urban growth. The perspective in the Bank documents also maintains that complementary transportation strategies should control private car use. Lastly, the Bank articulates a new program in which the focus is on promoting mass transit based on buses, urban railways, and road construction (highways and streets) within cities in "developing countries." The objective is to extend road capacity for motorized transportation modes in order to control congestion. There is no evidence in the document for Bank lending projects or initiatives intended to stimulate non-motorized means of transportation, even though at the time of the report there were more prevalent modes of travel in so-called “developing countries".

"Inevitably many new roads and transport facilities, (...) will have to be provided" (World Bank 1972; p. 30).

On the other hand, the relationship between urban transportation, land use, and housing is clearly stated in the World Bank document as it is understood within the document as relevant to control sprawl and, consequently, to prevent increased usage of motorized transportation means. In spite of this however, there are no lending programs for either transportation or housing that focus on this relationship. Rather, each initiative is presented separately and the urban transport-land use-housing relationship is not addressed nor is non-motorized travel. 
"The rapidity of extension of urban areas offers great opportunities for economizing in resource use by more rational development of new areas" (World Bank 1972; p. 64).

An "Urban transport- sector policy paper" from 1975 reveals the vision and role

of the World Bank regarding the transportation sector. In this pioneering paper about the urban transportation sector, the World Bank (1975) recognizes that walking and biking are important means of travel for poor people who cannot afford a car or pay for public transportation; however, the main analysis and recommendations in this document for solving transportation problems are related to restraining private car ownership and use using mechanisms such as congestion pricing, parking charges; improving traffic management; and integrating urban and transportation planning. Overall, World Bank states that those initiatives aim to decrease congestion affecting urban productivity and efficiency.

"The importance of urban transport lies fundamentally in its contribution on the large economies of scale and specialization associated with urban growth." (World Bank 1975; p. 6).

The Bank maintains in its analysis that walking and bicycling should be permitted because poor people cannot afford other modes of travel (World Bank 1975; p. 7), but the analysis does not go as far as to support walking and bicycling as deserving similar treatment as that received by motorized transportation modes because they are modes of travel per se which have positive externalities as well. Moreover, the Bank argues that demand for roads occurs because once people increase their income they will use buses or private cars instead of walking or cycling. In this perspective, non-motorized modes of travel are not considered part of the urban transportation system, but merely necessary for 
poor people who cannot afford motorized transportation. The expectation derived from this perspective is that motorization is inevitably preferred with higher income.

"The worldwide strength of demand for private automobiles reflects the great convenience and the expanded opportunities they provide" (World Bank 1996; p. 8).

Nonetheless, the World Bank does indicate that lending for transportation projects could include facilities for pedestrians and cyclists as part of macro or larger transportation projects. In brief, the main mission of the World Bank in urban transportation is promoting a more rational use of road space that does not mean a more equitable use of road space.

In "Sustainable Transport: priorities for policy reform", a document dated 1996, the World Bank analyses the transportation sector as a whole, using a sustainable framework (World Bank 1996). First, the World Bank argues in favor of competitive markets where the private sector would have an active role providing, operating and financing transportation and the government's role would shift from regulation to focus on "enabling competition". Second, in order to de-regulate the transportation sector the Bank concludes it is necessary to promote institutional arrangements and policy reforms. Third, within this market-based approach, users as clients become important in planning the transportation system.

Even though non-motorized transportation is recognized as part of the transportation system; again the World Bank's point of view on bicycling and walking as 
a means of transportation is limited because it remains a necessity for mobility among poor people but not as a particular and cost-effective means of travel with potential positive externalities for all societies and even a strategy to reverse tendencies of motorization in "under developing countries". It also reports some small pilot projects aimed to support non-motorized means of transportation in African cities, but those projects were lacking in financial support and continuity (Scott 2002). Moreover, the World Bank does not have a clear position on car ownership nor the negative consequences of urban sprawl related to urban sustainability.

"More motorized mobility is neither necessarily good nor inevitably bad" (World Bank 1996; p. 30).

More recently, in 2002, the World Bank published a new document called "Cities on the Move: A World Bank Urban Transport Strategy Review". In this iteration the role of non-motorized transportation in urban areas is discussed more clearly. The Bank suggests incorporating these kind of travel modes "in road fund statutes and procedures" (Gwilliam 2002; p. XIII). However, in the same document an inventory of lending projects related to urban transportation until 2000 is presented.

The evidence indicates that lending had focused on motorized transportation: metros, suburban railways, buses, and facilities for other high capacity passenger vehicles and new roads, as well. Non-motorized modes continued to be considered a mode of transportation for poor people and a source of income for some of them. Consequently, according to this view, walking and bicycling in "developing countries" seem to be 
modes of travel that solve transportation problems for people of low income, and could continue to do so until they can afford a motorized transportation. In fact, it explains that declining bicycling as a mode of transportation is a consequence of rising income. Cycling continues to be understood as outside of the purview of transportation planning.

Finally, another key document on transportation from the World Bank is "Safe, clean and affordable transportation for development - Transport Business Strategy 20082012". The World Bank vision on transportation is associated with transportation as a way to achieve economic development and as an economic business sector. Consequently, in this view, transportation is important because it contributes to economic growth (international integration and efficient movement of goods) and the private sector is exhorted to participate in the transportation business actively to generate competition that is intended to promote efficiency. In this view there is no room for means of transportation that do not produce economic growth or economic return, at least as the World Bank has conceptualized it.

"Non-motorized transport, (...), is not a specific mode” (sic) (de Buen et al. 2008; p. 47).

Overall, several conclusions can be arrived at from the World Bank's guiding documents. Over the time, the main focus for transportation credits has been to systematically support roads and highways (62\% in 2007) (World Bank 2007). Road transportation is a main mode of transportation worldwide. Road transportation means 
different means of travel not just motorized means. However, transportation projects promoted by the World Bank centers their investment on motorized options. In fact, it has been reported that in Sub-Saharan Africa "Since 1985 about 15-20\% of World Bank loans have been for transport investment (roads, railways, ports, etc.), with nearly US\$40 billion in loans credits (...) The bias towards infrastructure and large scale-transport still exist in national government and donor agencies and is reflected in terms of budgets, personnel and professional training" (Starkey 2001; p. 5). This is true despite the fact that several World Bank transportation guidelines consider the need to implement sustainable transportation systems. However, the World Bank perspective on urban transportation remains within the logic of its initial proposals: expansion of the road network leading to maximum capacity of streets, avoiding congestion and improvement of traffic speed. It is clear that this institution has played, direct or indirectly, an important role in shaping cities to accommodate motorized transportation through increasing road construction.

Additionally, when non-motorized transportation is under consideration, the World Bank repeatedly associates it with poor people. Even though it is true that in "under developing" countries non-motorized transportation nowadays is prevalent among poor people, walking and bicycling historically were typical means of travel for everyone, but due to "essentialization of the automobile", they bicycles are losing physical space, visibility and status; so, in keeping them associated with poor people, they seem to lose their own essence as means of travel per se and it seems like they could even be replaced 
by other means, such as public transit or motorized vehicles once poor people can afford these higher end services. In fact, this vision is inconsistent with sustainable transportation proposals that the World Bank wants to promote through its credit program for transportation.

Finally, it is important to note that the World Bank strategy for changing the role of the government in providing urban public transportation could have a negative impact on investments in infrastructure for non-motorized means of transportation, because the economic returns on capital investments in cycling and walking facilities go to the community at large; they are not intended to generate returns for private investors. Implementing non-motorized means of transportation provides socio-economic benefits for a society on the whole. Thus, investing in cycling and walking infrastructure, cities and states obtain benefits related to health costs, environmental conditions (air quality and noise impacts), public transportation cost, jobs (Garrett-Peltier 2011), and quality of life, in general.

Moreover, cycling and walking infrastructure in cities is associated with economic benefits related to tourism, the biking industry, and local business. Additionally, consumers also obtain benefits by avoiding transportation costs, reducing time associated with congestion and improving individual health conditions (Kaplan, Bascom, Ellenbogen, and Gerdel 2012). Consequently, promoting bicycling as a means of transportation could be constrained when urban transportation services are operated by 
the private sector, which seeks to benefit from economic investment and is "subject to the coercive laws of competition" (Harvey 2012; p. 122).

What is more, the World Bank began to participate in urban transportation initiatives in Latin America in the mid-70s. It had more experience in transportation projects in other Latin American countries different from Colombia. In Colombia it played a role first in inter-urban transportation system projects and other urban projects such as running water and sewer infrastructure. In fact, Bogotá was the first World Bank loan for urban transportation. It was made effective in 1996 (Persaud, Alvarado, and Cuellar 1976) and included action to promote non-motorized mobility. It is worth saying that the World Bank loan document indicates that Antanas Mockus, who was Mayor of Bogotá (1995-1996), was involved in promoting alternative modes of travel in the Colombian capital. There was therefore a strong motive to include a small component related to promoting non-motorized transportation in the credit project ("Non-motorized transport study") (Persaud, Alvarado, and Cuellar 1976). In terms of massive public transportation, at that time, the loan focused on the construction of a bus corridor and making the necessary institutional arrangements to improve the administration of public transportation. In the following years, however, studies on alternatives for public transportation systems showed the BRT as the best option for Bogotá, and as part of the BRT initiative, construction of the so-called "ciclorutas" or bike pathways began in 1999, also promoted by a Bogotá Mayor (Enrique Peñalosa), as part of the bike-path program 
and the Master Plan of Ciclorutas. The BRT, called TransMilenio, was inaugurated in the year 2000.

Currently, the World Bank participates in the National Urban Transport Program in Colombia. The initiative focuses on the implementation of transportation systems based on buses, of the TransMilenio type, in different Colombian cities. However, the Bank continues to fail to take into account non-motorized transportation means such as bicycles. Bogotá's experience with non-motorized transportation articulated to the BRT will be discussed below.

The agency's initiatives contain a number of requirements that discourage or encourage certain practices. Two main components of the Bank's loans are: financial contribution by the receiving party or institution and required political and institutional changes. Among the most significant of these institutional changes has been the promotion of private sector participation and / or joint public- private public transportation administration.

The Bank's active participation in national urban transportation policy and mass transportation in Colombia has had two particular implications for transportation policies in Cali. First, the loan has been granted only for BRT (MIO) implementation. Second, it strengthens the private sector's role in the operation of a public service. With these expectations the city is constrained by the World Bank's demand, and gives up the 
initiative of promoting the use of bicycles as transportation, because its resources are for exclusive allocation. These conditions indicate that the efforts of the private sector, in its logic of accumulation, are aimed at discouraging other types of transportation that could compete with MIO.

Additionally, the way the Bank prioritizes the MIO and marginalizes the construction of bike paths, also exposes the municipal government's inability to refocus the World Bank and National Government agendas. In fact, 70 percent of funding for the construction of BRT infrastructure was provided by the national government and 30 percent by the municipality, an unbalanced financial participation which pushed local decision-making to favor a system similar to the Bogotá TransMilenio. In terms of policy transfer, it illustrates that both national government and, more specifically, the World Bank had direct coercive power to point local governments to BRT as the only option for urban transportation, neglecting non-motorized mobility.

\subsubsection{Strengthening of the Car Industry}

In recent years the automotive industry has changed its production patterns worldwide (Vargas da Cruz and Camargo Rolim 2010). Car production moved from industrialized countries (G7: U.S., Japan, Germany, Canada, France, Italy and United Kingdom) to a new group of emerging economies known as the BRICs (Brazil, Russia,

India and China). This new orientation not only shows how the auto industry has 
reorganized to recover and maintain profits, but also the impact of the decline in production and demand for cars in industrialized countries and the industry's strategies to reduce production costs in the form of cheaper labor, fiscal incentives and lower transportation costs. The geographical restructuring of vehicle production is related to not only to conditions of free market economies that allow for establishment of production and/or assembly plants in Latin American cities, but also with opening and consolidating of new market niches for automobile consumption (Bailey D 2010).

In this context, Latin American countries are a potential favored market because car ownership figures are not yet as high as in other countries. Given that an efficient strategy is to consume where production takes place, what is observed is that in industrialized countries that have been producers and consumers of cars, car markets are reaching saturation, making them unattractive continued investment in these countries (Vargas da Cruz and Camargo Rolim 2010).

The reorganization of the automotive industry is closely related to the motorization process of Latin American cities. The case of Curitiba in Brazil is illustrative. The automotive industry expanded rapidly in the Metropolitan Region of Curitiba in the 90 s, as a result of external factors related to the restructuring of the global automotive market and local conditions that favored grouping plants in certain geographic areas such as Brazil. This phenomenon coupled with government incentives to buy cars contributed to increasing private car ownership in this city. In fact, Curitiba 
has the highest rate of car ownership per capita in Brazil (Parra, Hoehner, Hallal, Ribeiro, Reis, Brownson, Pratt, and Simoes 2011). Notwithstanding, Curitiba has one of the most successful BRTs worldwide (Rogat, Hinostroza, and Ernest 2009), although this system has been unable to prevent increasing car ownership in this city.

In the case of Colombia several factors have contributed to increasing motorization in the entire country, not just in main cities such as Bogotá, Medellin or Cali, but in medium sized cities as well. Currently, Colombia is the fourth largest car manufacturer in the Latin American region and the second, after Brazil, in motorcycle production (Tellez, Hernandez, Llanes, and Suarez 2012). This achievement is the result of the productive restructuring process experienced by the automotive sector. The motorization rate in the country has maintained an upward trend over the past 30 years; with the most significant rise seen from 1992 as a response to economic liberalization promoted by the neoliberal project which facilitated the entry of vehicles to the domestic market (Jaramillo, Ríos, and Ortiz 2009)

"Forty one percent of Colombia's automotive industry consists of domestic production while 59,5\% is imported mainly from South Korea, Mexico, India, Japan, Ecuador, China and the United States." (Tellez, Hernandez, Llanes, and Suarez 2012; p. 3)

By 2012 car ownership in Colombia was at 80.2 cars per 1000 inhabitants (Tellez, Hernandez, Llanes, and Suarez 2012), a low rate compared to other countries in the region, and very attractive for the automotive market. In Colombia $64 \%$ of the local market is concentrated in four suppliers who mainly sell private automobiles, and that 
sector is $86 \%$ of the total (Tellez, Hernandez, Llanes, and Suarez 2012). Additionally, in recent trade agreements with Mexico, the U.S.A. and South Korea, the automotive industry is included as a part of a national initiative of world-class business (Tellez, Hernandez, Llanes, and Suarez 2012), with policies to increase the demand for cars. While it is early still to show data about the impact of car importation from Mexico and South Korea on motorization rates, a recent report expects growth in car ownership in Colombia because cars imported from those trade partner countries are cheaper than cars produced in Colombia (Quiroga, Munar, and Peña 2012). Keeping lower and stable car prices in the country could induce even higher consumer demand. In addition, the banking sector in Colombia maintains special credit opportunities and lower interest rates for people who wish to buy cars. Around $60 \%$ of new vehicles are financed by consumerfavorable bank lending in Colombia (Tellez, Hernandez, Llanes, and Suarez 2012). In fact, predictions suggest that Colombia could reach 128 cars per 1000 inhabitants in 2020 (Tellez, Hernandez, Llanes, and Suarez 2012).

As a consequence of a new competitiveness and productivity strategy created in 2006 by the Colombian national government, the auto-parts sector and assembly of vehicles were included as part of the national proposal called the World-Class Initiative which aimed to promote long term strategies to grow these sectors (Meléndez A and Perry R 2009). Even though it is early to evaluate the impact of this strategy on car demand and motorization within the country, developing a strong auto parts sector with 
incentives and tax deductions has potential to expand local auto market and increase demand for cars (Proexport 2012).

Even as Colombia is investing resources in public mass transit, the implementation of these BRT systems still has several problems and seems to be insufficient to reverse the increase in private car use. The case of Bogotá is illustrative. TransMilenio, which started to run in 2000, is the biggest BRT in Colombia moving around 1.926 .985 people daily and covering 30\% of the demand for public transportation (Transmilenio 2013). However, Bogotá has the highest motorization rate of Colombia (Comité automotor colombiano-Fenalco 2013). As Tellez et al (2012) note one potential implication of this situation is that once infrastructure for motorized transportation increases and transportation becomes more organized, conceivably the automotive industry will have more room for its vehicle business.

"The improvement of public transport systems in most Colombian cities, with the introduction of massive systems, can stimulate the purchase of vehicles as long as you achieve significant reductions in urban congestion." (Tellez, Hernandez, Llanes, and Suarez 2012; p. 11)

In Colombia growth in motorcycles use is also affecting non-motorized travel. Data shows that $23.1 \%$ households reported motorcycle ownership in 2013 while $13.3 \%$ had private cars (Perfetti del C., Silva A., and Freire D. 2013). 93\% are produced in Colombia and $71 \%$ of motorcyclists use motors as a means of travel. Increasing motorcycle use in Colombia has been associated with its easy access, lower costs, lower gasoline consumption, exemption of taxes, and non-payment of tolls (Comité de Ensambladoras de Motos Japonesas 2013). 
In Cali around 140.000 motorcycles were reported in 2012 and the city is also implementing an initiative called "Motovías" aimed at separating motorcycles from other means of transportation. "Motovías" are exclusive corridors for motorcycles implemented to reduce traffic injuries while accommodating public transit (Picture 6). Even though this initiative seeks to protect motorcyclists, the population most affected by traffic casualties, it also could be an additional incentive for motorcycle usage. More information is necessary to identify the role played by associations of motorcyclists to generate the initiative of the Motovía in Cali.

Picture 6. Motovía in Cali

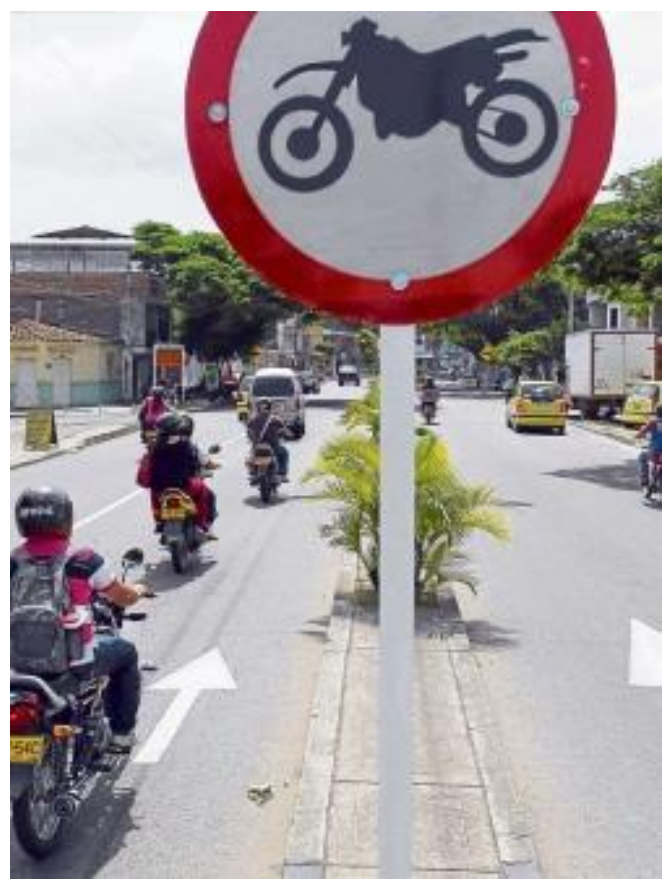

Source: ADN / Santiago Saldarriaga 11/3/2014

To summarize, elimination of trade barriers, national policies to expand the automotive industry by supporting vehicle parts production, the lack of strong measures 
to encourage alternative modes of travel, and the increase in motorcycle ownership are conditions that lean towards predictions that motorization in Colombia will continues to increase dramatically.

\subsubsection{Implementation of the Bus Rapid Transport System in Cali}

While in Bogotá the pioneering initiative to incorporate bike paths as part of the BRT system was promoted by successive mayors and it was incorporated into the World Bank credit program, in Cali, even though bike paths were included in the first MIO project proposal, they were later excluded from the World Bank lending project because financial resources were only allocated for infrastructure for the BRT. The role of the mayor of Bogotá in the outcome of that decision is captured in a World Bank report in the following:

"(Speaking about Bogotá) The current mayor, who came into office in January 1995, is an avid supporter of non-motorized transport alternatives and the proposed project will help finance studies which will examine the feasibility of undertaking investments which would encourage increased use of such transport alternatives." (Persaud, Alvarado, and Cuellar 1976; p. 5).

In the case of MIO, private operators (Unimetro, Blanco y Negro Masivo, Empresa de Transporte Masivo and Grupo Integrado de Transporte Masivo) and Metrocali S.A. are not interested in promoting the use of bicycles as transportation, because it is considered a threat to their economic interests. After 1990 as part of the liberalization and privatization processes, public transportation in Colombia was consolidated as a private 
sector and the role of the government transitioned into regulatory one only. In sum, transportation becomes an area of participation for investors. A government employee who worked at the local planning office in Cali at the time planning for the MIO expressed in an interview for this research that:

"Metrocali disagreed with the bike paths because the cycle routes were conceived parallel to the system; so, they said that the bikes were a mode of transportation, (which) competed with the public transportation system. They saw it because the transportation system was assumed like a business" (underlining added) (No 4)

During the MIO planning process, there were several attempts to incorporate the articulated bike-paths to the BRT system. However, Metrocali S.A. was influential enough to prevent its construction. The main argument was that the bicycle as a means of transportation would be in competition with the BRT; therefore, bicycle paths should not be built parallel to the exclusive MIO corridors.

In fact, it is possible that Metrocali S.A. assumed that people who use bicycles would shift from bicycles to the MIO once this system had been developed throughout the city. However, as has been indicated, using a bike as a mode of travel in Cali is a done by low income people who cannot afford another means of travel. For them, cost is the main reason to choose any mode of travel. However, considerations regarding travel time and comfort need to be taking into account as well when people decide to switch from one mode of travel to another. 
Even though in the local planning office there were officials in favor of building the bike-paths, there were differences in the conception of where they should be built, whether they should be articulated to the BRT or not. Finally, the decision was to build some bike-paths separate from the BRT, along the "environmental or green corridors" where, as an officer from the planning office reported, cyclists could ride more comfortably. This argument, suggested by a government employee from the Municipal Planning Department during discussions on bike paths in Cali, is related to the bucolic vision of biking. In fact, another public servant said that some main public employees from the Municipal Planning Department argued against bike paths parallel to the BRT using environmental and public health arguments. As he explained in an interview for this research:

“(...) the proposal was to build the bike paths parallel with MIO corridors but an important public servant, was among those who said that for him it was a mistake, because one could make cycle routes by areas, along the banks of rivers, through parks or neighborhoods, and that the bike paths reached MIO stations. For him it did not make much sense to put bike riders at the point of smog generated by cars and buses." (No. 1)

Furthermore, the MIO project was not part of the local Traffic and Transportation Office initiatives, but was formed by a new agency (Metrocali S.A.) which worked independently form the transit authority. The Municipal Planning Department played a role in the decisions about the MIO, because the President of the MIO Board was Secretary of the Municipal Planning Office at that time. The latter was not in favor of promoting the construction of bicycle paths articulated to the MIO. 
An important government employee from the Municipal Planning Department argued during the MIO decision-making process that distance travel did not allow for building long bike paths parallel to the BRT because this was unhealthy for people who ride bikes in Cali. This government servant did not expect that people would travel by bike through the city; consequently, bike-paths could be built as circuit and should be connected with the BRT. In the interview he reported that:

"If the cycle paths are designed to move people from south to north or from east to here, then the MIO stations have to be absolutely equipped to store the bike. Because with $15 \mathrm{~km}$ or $16 \mathrm{~km}$ that Cali has, it is hard and you can get to the MIO station and leave your bike and then move, but if we are thinking that these cycle routes leads and brings you every day... Sorry, I think we exaggerate how much we exercise." (No.5)

Contrary to this official's assessment of travel distances the population survey generated for use in this research reports that people who use a bike as a means of transportation in Cali on average travel 3.3 kilometers at day (data reported in section three of fifth chapter, page 138).

In the end, Metrocali S.A. included the construction of $50 \mathrm{Km}$ of bike paths within the MIO project, and the goal was that bikes can be feeders of MIO buses carrying passengers to the BRT line. In addition, bicycle parking will be constructed in main BRT stations and some economic incentives will be implemented if people combine biking and BRT ridership. It would seem however, that planners have overlooked the fact that using bikes as a principal means of travel is a matter of economic necessity among poor people, which is demonstrated by data from the survey generated by this research and 
information from the aforementioned interviews. This vision of bike use is expressed by a Metrocali CEO in this way:

"(...) It would be ideal that the network of cycle tracks were perpendicular, to feed the MIO, so that people bike, then to go to the MIO, leave your bike in a parking lot and then take the mass transit. That would greatly reduce the need for feeder buses in the system and it has all the advantages that people ride a bike every day for one $\mathrm{km}$. (...) Then, to create incentives for people to feed the system using bike and the person who comes and parked his bike in the parking lot of the station could have a reduced transport rate." (No. 3)

Nowadays, the MIO system has a deficit of passengers which does not allow for operators (buses owners) to recover their investment cost and be profitable, putting the whole system at risk. Even though spatial coverage of the system reaches $89.8 \%$, it has also been reported that MIO only has a demand of 51\% (data from December 2012) (CONPES 3767 2013).

"There is a widespread problem in passenger demand, to be well below the expectations created initially in the structuring of projects. (...) In addition, the good performance of the economy in recent years and better income distribution has increased the purchasing power of Colombians, for example, increasing motorization rate (cars and motorcycles). If this situation is compounded with the emergence of parallel transit called moto-taxismo ${ }^{3}$, there is no doubt that the impact on demand of the BRT has been negative." (Marin and Gil 2011)

In this context the MIO, as a transportation system operated by private investors, has no interest in promoting another means of travel like biking, because its main goal is to increase passenger demand.

\footnotetext{
${ }^{3}$ Mototaxismo is an informal transportation means used in many Colombia cities in which private motorcycles are used to carry out passengers.
} 
On the other hand, restructuring streets for MIO buses has also contributed to accommodating private cars and motorcycles because investments have included improving all main road networks (i.e. mixed traffic lanes), reducing the space at the street level for those who need to mobilize by bike. In brief, under a model of competition for the market, the MIO needs to gain in its client base and bikers are the client base. This situation, moreover, is aggravated because public transit without an operational subsidies scheme, based entirely on private operation, has no incentive to promote cycling transportation.

In other respects, the role of activist organizations promoting transportation by bike was limited during BRT planning and construction. Just a small social organization with a membership of about 30 participated, trying to find a place for cyclists in the new urban transportation system. Once BRT implementation started, this organization moved from cooperation to creating a citizen oversight of urban mobility at the national level in 2008 . This small social organization is interested in making cyclists visible and implementing the Master Plan for Cycle Routes in Cali. In this case, activism has taken two forms: civic protests and legal demands. According to participants two main goals have been reached: 1) including biking mobility in the first Cali Master Plan for Land Use 2000-2012 (Plan de Ordenamiento Territorial-POT in Spanish) and 2) including biking in the Cycle Routes Master Plan (2005). 
Even though this small social organization has been working since 1996, participants recognize the need for gathering more members and achieving more local impact. It is likely to be difficult to grow a social organization to promote the right to bike travel because most bikers in Cali are poor people who are "too busy and tired trying to find how to survive every day". An activist from this organization recognized that:

"We have not succeeded in creating a strong social movement of citizen awareness, because there is no sense of belonging. We disseminate to the people from Aguablanca all the propaganda in the world, and they say: yes! But they work incredibly hard to mobilize (...) they are too fatigued (...). No. We have failed; we have failed to link us with them. We believe that they would be the political force... if we could mobilize 5,000 cyclists, I think the bike paths would be already built." (No.6)

Moreover, this organization is not identified as a strong social organization in Cali with capacity to determine the way the city is shaped. On the contrary, as was expressed by an executive from Metrocali S.A., at one point:

"In the case of the bicycle, so, I do not think there's anyone who opposes it as such. Just that no one is promoting it (...) Pressures from people who generate opinion is on doing large projects, major infrastructure projects because they are people with more resources, because they are people who are better able to pressure a Mayor or the local administration, people who use private cars, and they move the half's the agenda that is occurring in the city. " (Underlining added) (No. 3)

Cali's experience reveals that transportation as a business operated by the private sector imposes obstacles for promoting alternative modes of travel. The BRT faces financial problems because the system has not reached the number of passengers projected to obtain economic stability and profits as expected by investors (Molina 2012). As a public servant during the interview said: 
"( ... ) The system (MIO) is not getting the money because there are many people who walk, and if you added that there are a lot of people by riding a bike, even more so. So my argument was that Cali cycle routes had to be designed independently from (MIO)" (No.5)

Additionally, it illustrates the difficulties in involving poor people in decisionmaking on issues related to bike use as a mode of travel, as well as the local government's inability to "re-direct" international and national forces. In fact, national government and the World Bank were interested in mass public transit more than multimodal transportation systems. In Bogotá's case the local mayor was able to override national and international interests, but in Cali the local administration considered the bus system a priority, there were no social forces capable of influencing the decision, and the IDB and World Bank focus on construction of the BRT.

\subsubsection{Views on biking in Cali}

The change in the original project that led to the construction of bike paths also resulted from changing views on bicycle use in the city. Based on data from interviews, three main viewpoints with regards to bicycling in Cali can be identified. First, from the perspective of policy makers, cyclists are not drivers needing to use the road network; on the contrary, cyclists are "lesser people" who barely deserve a marginal space when streets are wide enough to accommodate them. In this perspective, biking is not considered as everyday transportation with a legitimate claim to road space. Therefore, based on this view, the bike has not been part of any transportation initiative in the city. In fact, confusion between public space and space for biking illustrates this mind frame 
which continues marginalizing biking from the road networks and does nothing to legitimate the presence of bikers in the city.

Moreover, as bicycles are no longer considered part of the transportation system, the local government, international agencies and private investors prioritized the construction of the BRT. In addition, the fact that planning occurred in a context of limited financial resources, as a policy maker who participated in the MIO process said:

"Budget constraints meant that we had to give priority to transportation project and, suddenly, cycle routes or other urban themes were postponed until a later opportunity" (No.1)

In addition, bicycle use is valued more as a recreational practice than a transportation related-activity. In this view, current bike paths are conceived as circuits within certain areas in the city and not as a connected network to get to specific destinations. Consequently, as had been considered, bike-paths should be drawn according to the city's environmental corridors and not parallel to the new transportation system. A policy maker expressed with admiration the role of biking in Cali as a recreational practice for executives around a river called Pance in Cali. He said:

"It surprises me, you go by Pance, I think on Wednesdays and Thursdays there are about 200-300 bike riders going at night, because it is enjoyable. Many executives arriving home, they take off their tie, they use full cycling gear and they go biking at night." (No.1)

Additionally, years later, in 2005, the Cycle-routes Master Plan was designed in an attempt to regain the use of bicycles in the city. The Master Plan reveals that the bicycle as transportation is not assigned to any local government agencies in particular. It 
identifies at least six local agencies responsible for bike path construction and maintenance. Indeed, it states that:

"(...) the belief of many people associated with the local government is that the road infrastructure is only for motorized vehicles, whose growth rate in big cities is much higher than other types of vehicles..." (Mayor of Cali 2005)

In the two visions of cycling mentioned above, those who use the bicycle as a regular means of transportation in Cali become "invisible", contributing to maintain or to deepen spatial inequalities in the use of transportation infrastructure in the city. This illustrates a fragmented view in the management of mobility and access in the city. This point will be analyzed later. It should be noted, therefore, that the bike paths are not just places to ensure the physical safety of cyclists but also they are "spaces" to ensure its legitimacy and social inclusion in a city like Cali that tends to neglect interventions in favor of alternative modes of transportation.

\subsubsection{Urban Transportation Planning Sector}

The way issues related to urban transportation are problematized and, specifically, how mobility is defined, demonstrates the competition between different values and ideologies which associated with class conflicts (Henderson 2002). The way mobility is configured in both discourse and practice in a city exposes the relationships of power or, more accurately, class conflicts outside the workplace. Additionally, as Harvey (1976; p. 282) argues, the built environment can also be a strategy to "inculcate bourgeois values". 
In this sense, it is important to consider that, for example, initiatives favoring infrastructure for motorized transportation, reflects that the car is not just a technology, but a lifestyle defining consumption pattern, with implications for class relations and class consciousness.

In Cali, as in other Colombian cities, the transportation system has focused on motorized means of transportation, and traffic congestion has been analyzed as the main urban transportation problem. As was discussed by a participant in this study, an expert in urban transportation planning, in transportation planning there are different ways to measure road congestion. For example, road congestion can be measured in delays between motorized vehicles or through traffic volume, and each measure provides different information. Most estimations of road congestion ignore the role of nonmotorized modes of travel in the transportation system as a whole. However, decisions on transportation are made based on these estimations. The following quotation, from an expert in transportation planning, captures the problem of decisions on transportation based only on motorized vehicle measures:

"I would say that users (cyclists and pedestrians) are second class, I think. Second category not in the sense that worth less than another. But when one quantifies the demand, pedestrian and cyclist demand are too incipient, at least in long distances in comparison with the vehicles. Then, when you do analysis of urban scale, the role is reversed." (No.7)

So, the problem of traffic congestion is understood to be a technical more than a political one. As this transportation expert continued to explain:

"The technician provides information to political to make decisions (...) Of course, when you speak in terms of ownership (car versus bikes), say, they are very close, but when you 
talk about mobilization capacity and the occupied space, then one says congestion ..." (No.7)

In this perspective, if traffic congestion has been the key to problematize the issue of transportation in Cali, changes in urban infrastructure seek to better accommodate the number of cars in circulation, in order to increase the speed of movement and, in turn, reduce travel times.

This conception of the urban transportation problem has oriented public expenditure towards implementation of mass transit in the form of BRT (MIO in Cali), expansion and improvement of the road network and overpasses, incorporation of strategies to control the number of cars and motorcycles in circulation -such as alternating license plate restriction, No Car Day and Motovías- as well as improvements in technology to regulate traffic flow. However, in the end, what is observed is that while the problem has been focused around congestion (speed and travel time and lack of roads) there is no discourse on options to encourage non-motorized transportation modes, because investments on the built environment focus on infrastructure that is economically profitable: road networks that contribute to decrease merchandise circulation time (Harvey 1978).

On the other hand, in Cali there are several public agencies in charge of transportation planning. In fact, Cali does not have only one Transportation Planning Board which is a key element for centralizing decisions related to urban transportation and its articulation with land use, for example, and to make middle and long term 
decisions. There are at least six (6) public entities responsible for urban and rural transportation, in general. All of these agencies have responsibilities related to the use of bikes in urban areas, from educational programs to mass events. This fragmentation of decisions on the use of bikes among different public agencies, has led to fragmentation of perspectives and projects and this is reflected not just in the deficiency of physical infrastructure for biking (i.e. bike lanes, parking, signals, signage, connectivity) but also a in a lack of vision about the importance of biking in terms of health, equity, and environmental benefits as well as to the importance of ensuring safe social and physical infrastructure for those who are already riding for transportation.

Indeed, while it is necessary to enhance conditions for workers who are already riding for transportation and to connect and improve two underutilized $14 \mathrm{Km}$ of bike paths built several years ago, in recent years several new "bike paths" have been built in different parts of the city street network, most of them separated from motorized transportation. This has been done in response to interests or resources of the public agency that built them and most of them do not represent major improvements to bicycling. For example, within the second stage of Megaprojects, a new bike path has been projected in a recreational area of Cali ("Ciclo ruta a La Vorágine”).

Map 2 shows the routes that cyclists are currently using in Cali (Map generated from the population survey in which cyclists were asked about main daily route). It illustrates that most routes are from the east to the south of the city. The south of the city 
is an area of urban expansion. Map 3 shows existing bike paths and Map 4 shows bike paths projected in the new POT of Cali (Master Land Use Plan). Those maps demonstrate that bike-paths are being built without taking into consideration the travel needs of people who already use a bike a mode of travel, such as workers residing in the Eastern side of the city.

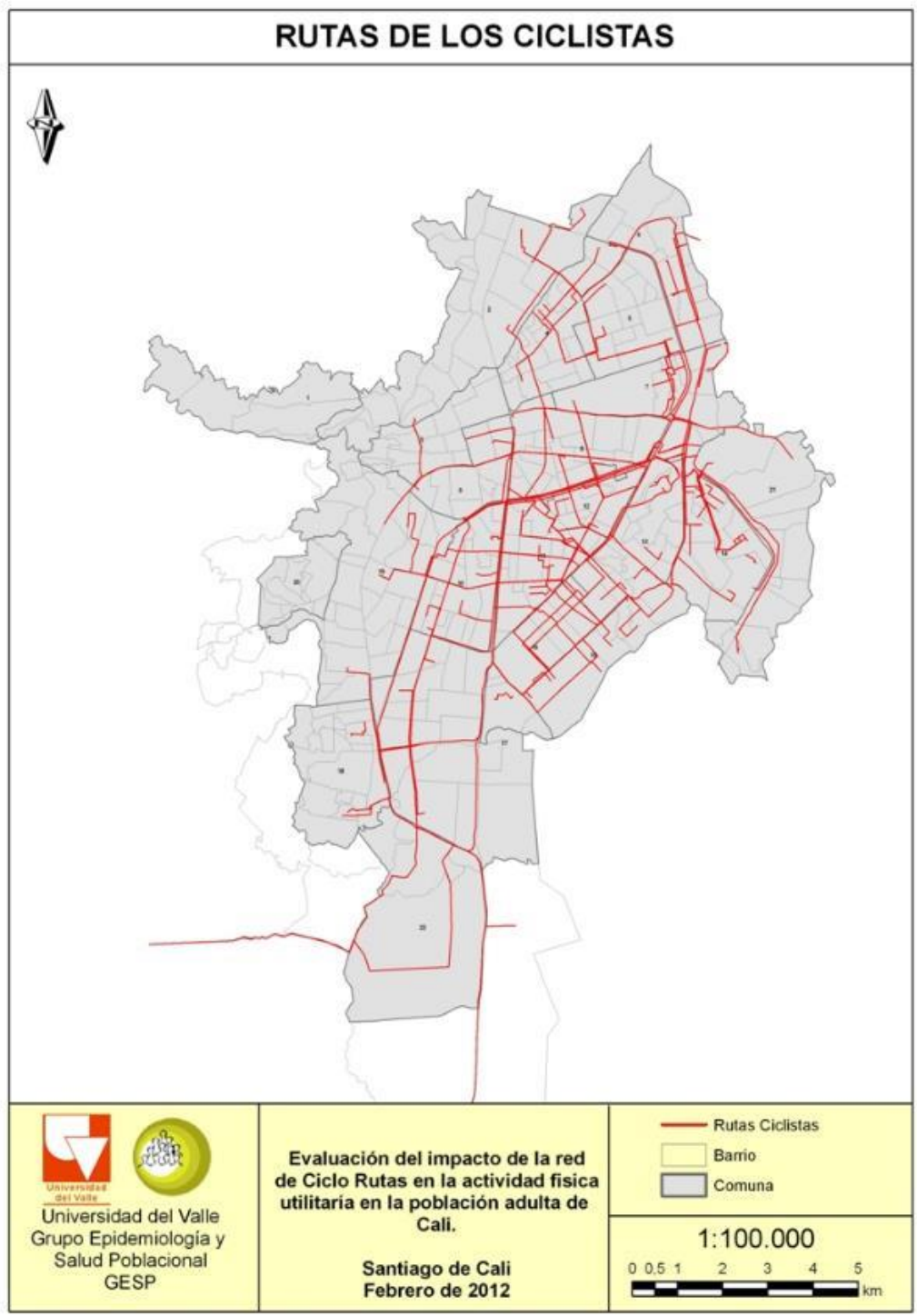

Map 2. Routes used by cyclists in Cali, 2011-2012 
Mapa de las ciclo rutas de Cali, años 2011 y 2013

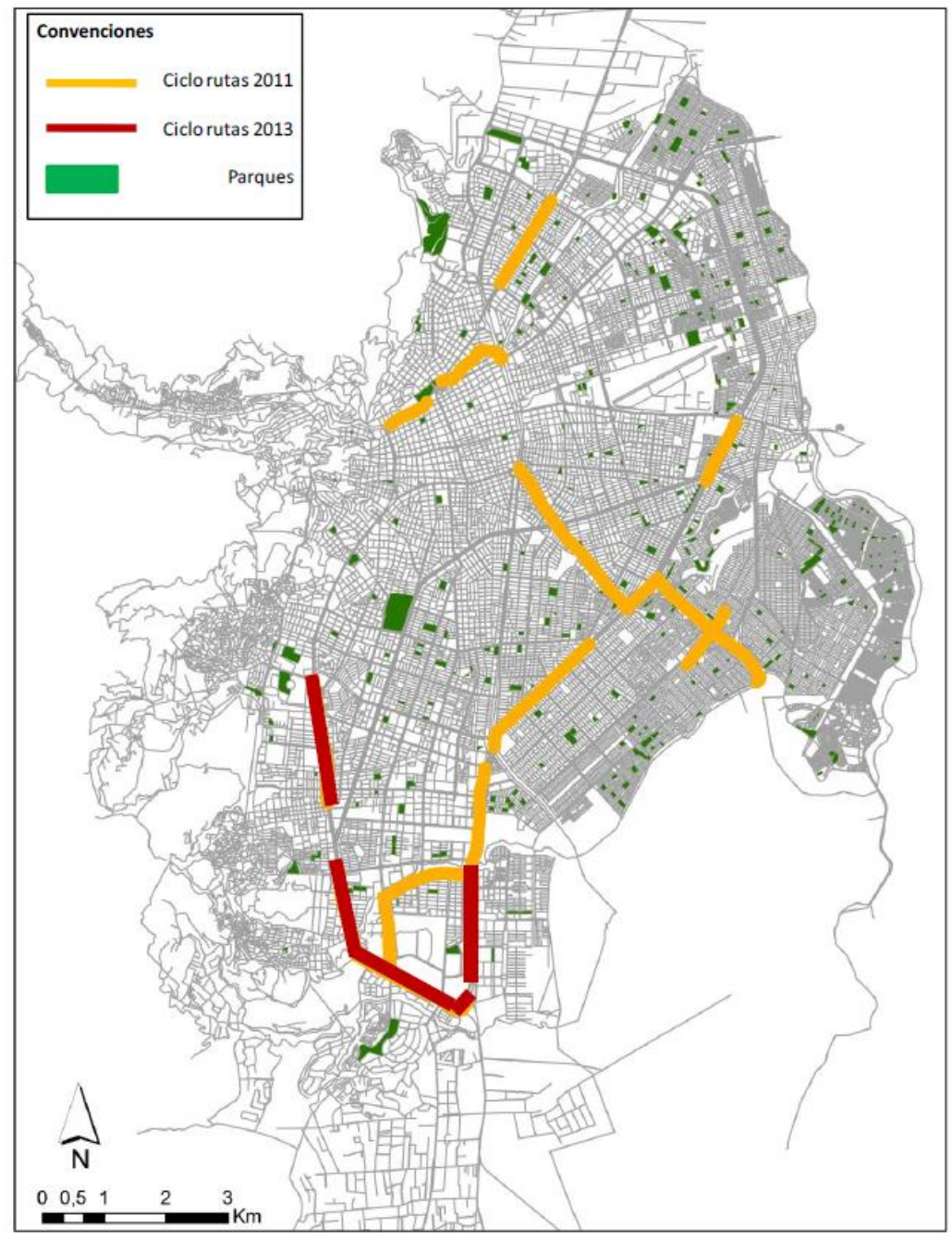

Map 3. Current bike paths in Cali, 2011-2013 


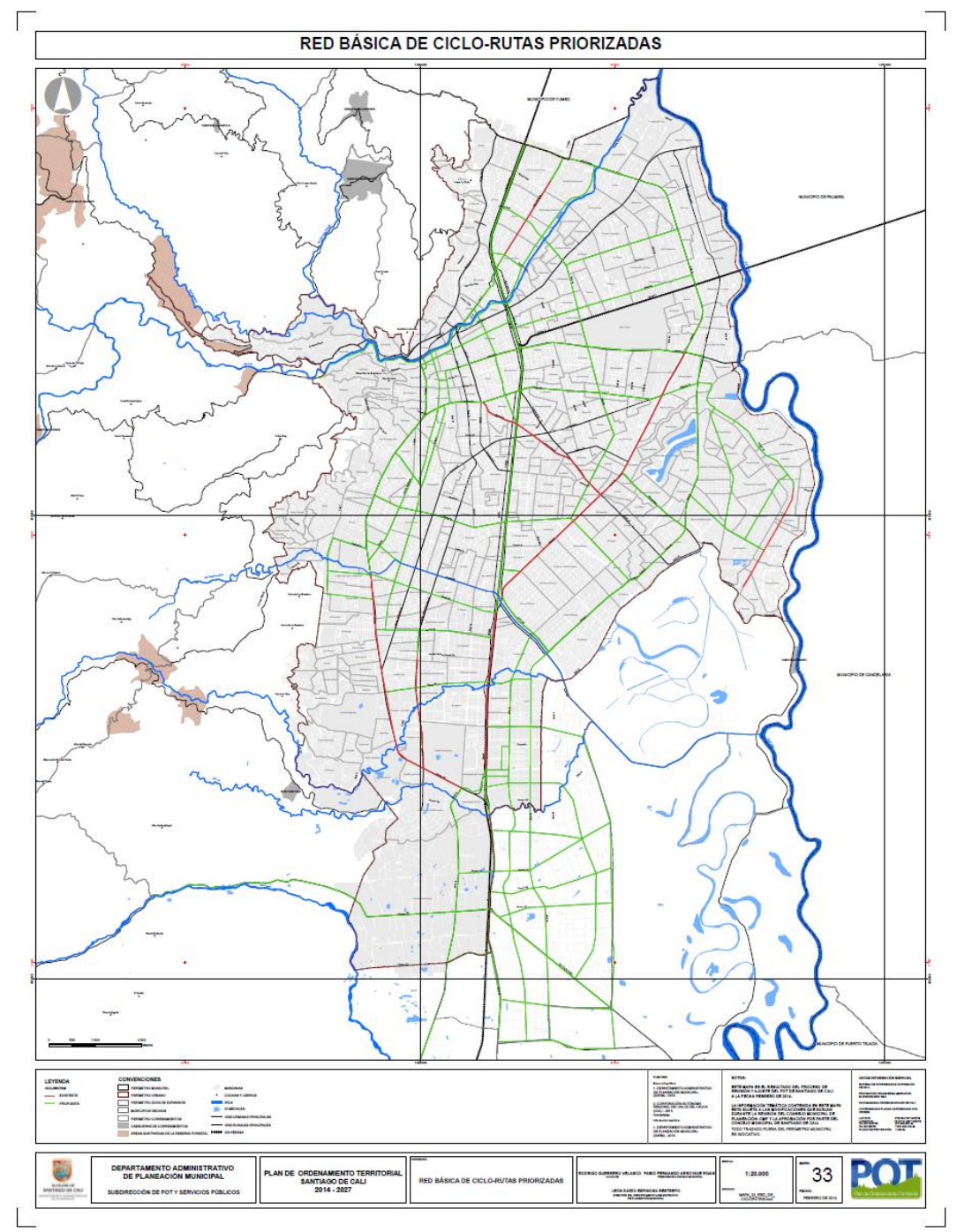

Map 4. Projected bike paths in Cali, POT 2014-2027 


\subsubsection{No Counter-hegemonic Social Processes}

Colombian history demonstrates that social protests related to housing, access and costs of public services, salaries and working conditions, access and costs of social services such as education, health, and transportation have been significant. However, in recent decades, this country has seen a decline in both the number of organizations or social movements as well as their capacity for mobilization and achieving demands (Archila $N$ 2002). In the case of transportation, social protests demanding better conditions to use non-motorized means of transportation in Cali were neither reported by participants in this study nor found in the documents analyzed. However, in Cali nowadays the population has protested against taxes for Megaprojects and local conflicts have emerged associated with problems in BRT implementation such as delays and lack of number of buses, and complaints from small companies or individual transportation entrepreneurs who will be excluded from the transportation business.

The most part of the discussion with research participants regarding why conditions in Cali are so adverse to bike use as a means of transportation focus on the economic interests supporting the building of physical infrastructure such as BRT or Megaprojects and the "lack of political will". Interviewees such as the CEO from Metrocali, the Planning officer and the social activists responded that taking into account that while cycling infrastructure is not an attractive economic sector for investment, large projects attract the attention of private investors who have more resources to influence 
local decisions, as was observed by a public servant interviewed: "For me it is pure political will, because large contracts represent building infrastructure for vehicles." (Underlining added) (No. 4)

The following interview segment illustrates two interconnected facts: the local population wants to see investment in large infrastructure projects because it means "progress or development" which supported by the discourse of modernity, and politicians want public support. Hence politicians prefer to build large projects because it garners public support. As stated by a CEO from Metrocali:

Researcher: What limitations are there in Cali to have a multimodal transportation?

Participant: Well, the main ones are political, because usually investments for infrastructure for travel on foot and by bicycle do not generate as a great political and social support. That people understand to give support to bicycle travel, no. Usually, what people see as progress are major infrastructure, bridge for automobiles, and highway for cars. People normally see these projects as evolution in the development of a city. So, the city needs someone with a different city vision and the mobility in order to be against of this and to orient the city towards a different model of development. (Underlining added) (No. 3)

Based on the interviewee's opinion, "lack of political will" could be interpreted as the way the transportation issue is defined by politicians (and, what initiatives are chosen to solve the problem, obviously) and with whom politicians are working. If urban transportation policies just focus on congestion (i.e. increasing travel speed), neglecting problems such as equity in mobility and accessibility, and public health and environmental problems associated with transportation, the city of Cali will continue driving in the wrong direction: favoring motorized traffic. This outcome is entirely 
possible within a local context of political violence, lacking in strong social movements, where other social problems such as housing, jobs and health have been prioritized by the population.

On the other hand, there is a kind of naïve view around bike path construction among people from the small activist organization mentioned earlier. For example, when a biker activist was asked about why it has been so difficult to enhance conditions for bikers in Cali, he responded:

"Simply, we have proposed to build a cycle lane, that is a space be demarcated on the road with markers, with tacked. It is necessary simply that the government has the will to draw bike lanes through which bikes can to transit." (Emphasis added) (No. 6)

This quote illustrates how, among activists, building bike paths seems to be an apolitical issue because it is not yet understood not only that bicycling can contribute to deter motorization and control congestion but it is a political issue connected to distribution of urban resources. Moreover, it illustrates also that there is an unequal correlation of forces between those who need travel using bikes and those who have more political and economic power to influence local decisions but disregard cycling as a legitimate mode of transportation.

Even though only this small activist group perceives that there are some forces against enhancing conditions for biking, such as "the gasoline cartel" and the automobile industry, they have not connected those forces with the "lack of political will". They do 
not recognize building bike lanes to improve conditions for biking as political and economic issues.

In brief, as stated by Harvey (1976), although the processes of urbanization and, in that sense, the way cities are designed respond to the needs of capital accumulation, there are social and political processes involved in the spatial configuration of capital. Social struggles mediate the processes of urbanization. Although the city of Cali has a long history of social struggle for urban land (Urrea and Murillo 1999), until now it has not shown evidence of social processes claiming equitable use of urban space. Adapting the city to motorized transportation has had no opposition advocating for inclusion of nonmotorized transportation. Different sectors of users of urban space have not had the same treatment.

Those who use the bicycle as a means of transportation are not only road users considered marginally, but also they have been marginalized from decision-making on urban transportation. Probably other demands such as housing, health and education have been a priority for the poor and claims with regards to space for non-motorized mobility are reduced to sporadic demonstrations. In this case, taking into account that transportation is a manifestation of power relationships, at the moment power is consolidated with motor vehicles. 


\subsection{Biking as a Mode of Travel in Cali}

This part of Chapter Five discusses the main findings of empirical research carried out in Cali during 2011 and 2013. This research consisted of two components. The first component was a quantitative longitudinal multilevel study about cycling as a mode of transportation in Cali and it included as well as a descriptive analysis of bike-path conditions. As indicated earlier, these research findings are part of a larger project carried out by the Grupo de Epidemiología y Salud Poblacional (GESP) at the Universidad del Valle and Fundación FES, with financial support from Colciencias (FES-Univalle 2010). Data form the longitudinal multilevel study shed light on the socio-economic conditions of people who use bicycles as a means of transportation and factors associated with travel by bike in Cali, at present.

The second component, aimed to explore the experience of traveling by bike in Cali by users that in the longitudinal multilevel study reported using a bike as their means of transportation in both measurements in two time periods: during the baseline (20112012) and in the first time measure (2013).

\subsubsection{Socioeconomic Conditions of Bikers}

From the probability multi-stage sampling, a total of 729 individuals were surveyed from 1090 who were eligible. Eligibility was based on time of residence in the 
neighborhood (equal to or more than 1 year). The survey included people between 18 and 44 years of age, from one to five socioeconomic strata (SES) ${ }^{4}$.

$$
\begin{aligned}
& \text { SES } 1 \text { = Low-Low (Bajo-bajo) } \\
& \text { SES } 2 \text { = Low (Bajo) } \\
& \text { SES } 3 \text { = Middle -Low (Medio-bajo) } \\
& \text { SES } 4 \text { = Middle (Medio) } \\
& \text { SES } 5 \text { = Middle-high (Medio-alto) }
\end{aligned}
$$

The overall response rate was $66.9 \%$. Response rates were higher than $60 \%$ in SES 1, 2 and 3. In SES 4 the response rate was 53.5\% and in SES 5 it was $45.8 \%$. In addition, a subsample of 185 respondents' participated in the second measure carried out in 2013 (time 1). The overall rate of response was $57.6 \%$.

Overall socioeconomic conditions of population from this study show that most participants were women, the majority of people had achieved secondary school education, average age was 29.9 years in 2011-2012 and 31.4 years in 2013, and most participants self-identified as mestizo or mixed-race. Moreover, around 20\% of people interviewed reported having a car, $36 \%$ of participants reported having a motorcycle in

\footnotetext{
4 The Colombian Statistics Institute (DANE) created a socioeconomic stratification which has six categories. Strata one is the lower and six is the higher. This stratification is based on a combination of factors related to physical internal and external characteristics of the household (i.e. wall's materials, access to/ownership of durable goods) and characteristics around the home (i.e. area of residence, existence of public services).
} 
2011-2012 and this percentage increased to $41.6 \%$ by 2013 . However, bike ownership was most prevalent in both measurements (2011-2012 and 2013). Table 4 shows socioeconomic conditions of participants in the study.

Table 4. Socio- demographic characteristics of population included in the study

\begin{tabular}{|c|c|c|c|}
\hline & \multicolumn{2}{|c|}{ 2011-2012 } & \multirow{2}{*}{$\begin{array}{r}2013 \\
\mathrm{n}=185\end{array}$} \\
\hline Variables & $n=729$ & $\%$ or mean & \\
\hline \multicolumn{4}{|l|}{ Age group } \\
\hline $18-24$ years old & 227 & $31.1 \%$ & 48 \\
\hline 25-34 years old & 267 & $36.6 \%$ & 68 \\
\hline 34-44 years old & 235 & $32.2 \%$ & 69 \\
\hline Age average (years) & & $29.9(\mathrm{DS}=7.65)$ & \\
\hline \multicolumn{4}{|l|}{ Sex } \\
\hline Female & 461 & $63.2 \%$ & 121 \\
\hline Male & 268 & $36.8 \%$ & 64 \\
\hline \multicolumn{4}{|l|}{ Education } \\
\hline None & 4 & $0.5 \%$ & 0 \\
\hline Primary school & 93 & $12.8 \%$ & 29 \\
\hline Secondary school & 514 & $70.5 \%$ & 133 \\
\hline $\begin{array}{l}\text { Beyond secondary } \\
\text { School }\end{array}$ & 118 & $16.2 \%$ & 23 \\
\hline \multicolumn{4}{|l|}{ Occupation } \\
\hline Work & 360 & $49.5 \%$ & 94 \\
\hline Work/study & 71 & $9.8 \%$ & 13 \\
\hline Study & 65 & $8.9 \%$ & 12 \\
\hline Housekeeping & 176 & $24.2 \%$ & 53 \\
\hline Looking for job & 38 & $5.2 \%$ & 9 \\
\hline Retirement & 1 & $0.1 \%$ & 0 \\
\hline Other & 17 & $2.3 \%$ & 3 \\
\hline \multicolumn{4}{|l|}{ Race } \\
\hline Afro-descendent & 128 & $17.6 \%$ & 30 \\
\hline Mulatto & 104 & $14.3 \%$ & 26 \\
\hline Indigenous & 33 & $4.5 \%$ & 10 \\
\hline Mixed race & 349 & $47.9 \%$ & 84 \\
\hline White & 112 & $15.4 \%$ & 35 \\
\hline Other & 2 & $0.3 \%$ & \\
\hline $\begin{array}{l}\text { Time of residence in the neighborhood } \\
\text { (years) }\end{array}$ & & $14.19(\mathrm{DS}=10.54)$ & \\
\hline \multicolumn{4}{|l|}{ SES } \\
\hline Strata 1 & 202 & $27.7 \%$ & 73 \\
\hline Strata 2 & 283 & $38.8 \%$ & 68 \\
\hline Strata 3 & 188 & $25.8 \%$ & 40 \\
\hline Strata 4 & 45 & $6.2 \%$ & 2 \\
\hline Strata 5 & 11 & $1.5 \%$ & 2 \\
\hline Car ownership & & & \\
\hline
\end{tabular}




\begin{tabular}{|c|c|c|c|}
\hline Yes & 141 & $19.3 \%$ & 37 \\
\hline No & 588 & $80.7 \%$ & 148 \\
\hline Motorcycle ownership & & & 77 \\
\hline Yes & 267 & $36.6 \%$ & 108 \\
\hline No & 462 & $63.4 \%$ & 134 \\
\hline Bike ownership & & & 51 \\
\hline Yes & 495 & $67.9 \%$ & $32.1 \%$ \\
\hline No & 234 & . & \\
\hline
\end{tabular}

Source: Final report to COLCIENCIAS "Evaluación del impacto de la red de ciclo-rutas en la actividad física utilitaria en la población adulta de Cali” GESP- Fundación FES, 2013

In the population survey, utilitarian cycling was evaluated by three questions:

1. Have you used a bicycle during the past 7 days?

2. How many days and how long (hours and minutes) have you used the bicycle during the last 7 days?

3. Have you used the bicycle during the last three months?

Descriptive data on demographic characteristics indicates that $12.61 \%$ of people reported using a bike as a means of transportation in the last 7 days in the baseline (20112012), and this percentage increased to $20.11 \%$ in Time 1 (2013). Moreover, walking as a means of transportation also increased while using motorcycles and private car decreased. Table 5 presents frequency of modes of transportation among people from the study. 
Table 5. Modes of transportation among population included in the study

\begin{tabular}{|l|c|c|}
\hline & $\mathbf{2 0 1 1 - 2 0 1 2}$ & $\mathbf{2 0 1 3}$ \\
\hline & $\mathrm{n}=729$ & $\mathrm{n}=185$ \\
\hline & $\%$ & $\%$ \\
\hline Drove car in the last 7 days (Total people who has car) & $47.5^{*}$ & $32.4^{9}$ \\
\hline Drove car in the last 7 days (All population) & 9.2 & 6.5 \\
\hline $\begin{array}{l}\text { Drove a motorcycle in the last 7 days (Total people having } \\
\text { motorcycles) }\end{array}$ & $46.4^{\psi}$ & $28.6^{¥}$ \\
\hline Drove a motorcycle in the last 7 days (All population) & 17.0 & 11.9 \\
\hline $\begin{array}{l}\text { Use a motor vehicle (MIO, taxi, private car, motorcycle) in } \\
\text { last 7 days }\end{array}$ & 85.3 & 82.7 \\
\hline Walking as a means of transportation in the last 7 days & 69.96 & 82.7 \\
\hline Ride a bike in the past 3 months & $44.6^{\varpi}$ & $42.8^{\circ}$ \\
\hline Use a bike as a means transportation in the last 7 days & $12.6^{\varpi}$ & $20.11^{\circ}$ \\
\hline To take somebody for a bike ride in the past 3 months & $17.9^{\varpi}$ & $11.3^{\circ}$ \\
\hline Somebody take you for a bike ride in the past 3 months & 13.3 & $9.7^{\circ}$ \\
\hline
\end{tabular}

*Percentage of 141 people who own a car, ${ }^{9}$ Percentage of 37 people who own a car, ${ }^{\psi}$ Percentage of 267 people who own a motorcycle, ${ }^{¥}$ Percentage of 77 who own a motorcycle, ${ }^{\circ}$ Percentage of 659 who learned how to ride a bike, ${ }^{\circ}$ Percentage of 159 who learned how ride a bike

Source: Final Report to COLCIENCIAS "Evaluación del impacto de la red de ciclo-rutas en la actividad física utilitaria en la población adulta de Cali” Universidad del Valle -GESP- Fundación FES, 2013

$66.27 \%$ of commuter bicyclists respondents in 2011 were male and $33.73 \%$ were female, similar proportions appear in data from 2013 (67.57\% and 32.43\%, respectively). By age, $34.94 \%$ of those 18 to $24,42.17 \%$ of those 25 to 34 , and $22.89 \%$ of those 35 to 44 and people with secondary school reported biking more than people with another education level. In Time 1, a little more than 50\% reported being between 35 and 45 years old and $86.48 \%$ achieved secondary school. In the baseline around of $80 \%$ of people from lower socio-economic strata (1 and 2) reported bike use as a mode of travel, people who self-identified as afro-descendent $(25.30 \%)$ and mixed race $(42.17 \%)$ had higher bike use in Cali than other racial-ethnic groups. (Table 6) 
Table 6. Participants from the study who reported biking in the last 7 days (2011-2012 $n=86 ; 2013 n=37$ )

\begin{tabular}{|c|c|c|}
\hline & $\begin{array}{c}\text { Participants 2011-2012 } \\
\text { n (\%) } \\
\end{array}$ & $\begin{array}{c}\text { Participants } 2013 \\
\text { n }(\%) \\
\end{array}$ \\
\hline & Baseline & Time 1 \\
\hline \multicolumn{3}{|l|}{ Age group } \\
\hline $18-24$ years & $29(34.94)$ & $5(13.51)$ \\
\hline $25-34$ year & $35(42.17)$ & $13(35.14)$ \\
\hline 35 - 45 years & $19(22.89)$ & $19(51.35)$ \\
\hline Total & $83(12.61)^{*}$ & $37(20.11)^{*}$ \\
\hline \multicolumn{3}{|l|}{ Sex } \\
\hline Female & $28(33.73)$ & $12(32.43)$ \\
\hline Male & $55(66.27)$ & $25(67.57)$ \\
\hline \multicolumn{3}{|l|}{ Education } \\
\hline None & 0 & 0 \\
\hline Primary school & $9(10.84)$ & $5(13.51)$ \\
\hline Secondary school & $64(77.11)$ & $32(86.49)$ \\
\hline $\begin{array}{l}\text { Beyond secondary } \\
\text { School }\end{array}$ & $10(12.05)$ & 0 \\
\hline \multicolumn{3}{|l|}{ SES } \\
\hline Strata 1 & $26(31.33)$ & ND \\
\hline Strata 2 & $41(49.40)$ & ND \\
\hline Strata 3 & $10(12.05)$ & ND \\
\hline Strata 4 & $4(4.82)$ & ND \\
\hline Strata 5 & $2(2.41)$ & ND \\
\hline \multicolumn{3}{|l|}{ Race } \\
\hline Afro-descendent & $21(25.30)$ & ND \\
\hline Mulatto & $13(15.66)$ & ND \\
\hline Indigenous & $3(3.61)$ & ND \\
\hline Mixed race & $35(42.17)$ & ND \\
\hline White & $10(12.05)$ & ND \\
\hline Other & $1(1.20)$ & ND \\
\hline \multicolumn{3}{|l|}{ Occupation } \\
\hline Work & $50(60.24)$ & $26(70.27)$ \\
\hline Work/study & $12(14.46)$ & $1(2.7)$ \\
\hline Study & $5(6.02)$ & $1(2.7)$ \\
\hline Housekeeping & $8(9.64)$ & $8(21.62)$ \\
\hline Looking for job & $7(8.43)$ & $1(2.7)$ \\
\hline Retirement & 0 & 0 \\
\hline Other & $1(1.20)$ & 0 \\
\hline
\end{tabular}

Note: $\mathrm{ND}=$ no data; $* \mathrm{n}=658 / \mathrm{n}=185$

On the other hand, median time riding a bike was 15 minutes in both surveys (baseline and Time 1) and the mean increased from 19.9 minutes in the baseline to 23.1 minutes in Time 1. (Table 7) 
Table 7. Time in minutes riding a bike as means of transportation in the last 7 days (2011-2012 $n=86 ; 2013 n=37)$

\begin{tabular}{|l|c|c|c|c|c|c|}
\hline \multicolumn{1}{|c|}{ Year } & Mean & $\begin{array}{c}\text { Standard } \\
\text { deviation }\end{array}$ & Minimum & Maximum & Median & $\begin{array}{c}\text { Percentile } \\
\mathbf{2 5}\end{array}$ \\
\hline $\mathbf{2 0 1 1 - 2 0 1 2}$ & 19.9 & 19.3 & 3 & 120 & 15 & 10 \\
\hline $\mathbf{2 0 1 3}$ & 23.1 & 17.4 & 5 & 60 & 15 & 10 \\
\hline
\end{tabular}

Source: Final Report to COLCIENCIAS "Evaluación del impacto de la red de ciclo-rutas en la actividad física utilitaria en la población adulta de Cali” Universidad del Valle -GESP- Fundación FES, 2013

In the survey all respondents were asked about their perception of the environment related to riding a bike. Overall, people who do not ride a bike perceive more unsafe conditions in the neighborhood than bikers; but perceptions about difficulties in ride a bike due to cars and motorcycles are similar among bikers and nonbikers. (Table 8)

Table 8. Socio-environmental perceptions among bikers versus Non-bikers $(2011 / \mathrm{n}=83 ; 2012-2013 / \mathrm{n}=37)$

\begin{tabular}{|l|c|c|c|c|c|}
\hline & & & $\begin{array}{c}\text { Very } \\
\text { unsafe/ } \\
\text { Unsafe }\end{array}$ & $\begin{array}{c}\text { Not } \\
\text { much, } \\
\text { not too } \\
\text { little }\end{array}$ & $\begin{array}{c}\text { Very } \\
\text { safe/ } \\
\text { Safe }\end{array}$ \\
\hline \multirow{2}{*}{$\begin{array}{l}\text { How safe is your } \\
\text { neighborhood to ride a } \\
\text { bike during the day? }\end{array}$} & $\mathbf{2 0 1 1 - 2 0 1 2}$ & Bikers & 27.71 & 24.10 & 48.19 \\
\cline { 2 - 6 } & $\mathbf{n = 6 5 5}$ & $\begin{array}{c}\text { Non- } \\
\text { bikers }\end{array}$ & 45.28 & 27.80 & 26.92 \\
\cline { 2 - 6 } & $\mathbf{2 0 1 3}$ & Bikers & 36.11 & 27.78 & 36.11 \\
\cline { 3 - 6 } & $\mathbf{n = 1 8 1}$ & $\begin{array}{c}\text { Non- } \\
\text { bikers }\end{array}$ & 51.03 & 22.76 & 26.21 \\
\hline \multirow{2}{*}{$\begin{array}{l}\text { How safe is your } \\
\text { neighborhood to ride a } \\
\text { bike at night? }\end{array}$} & $\mathbf{2 0 1 1 - 2 0 1 2}$ & $\begin{array}{c}\text { Non- } \\
\text { bikers }\end{array}$ & 67.02 & 20.53 & 12.46 \\
\hline
\end{tabular}




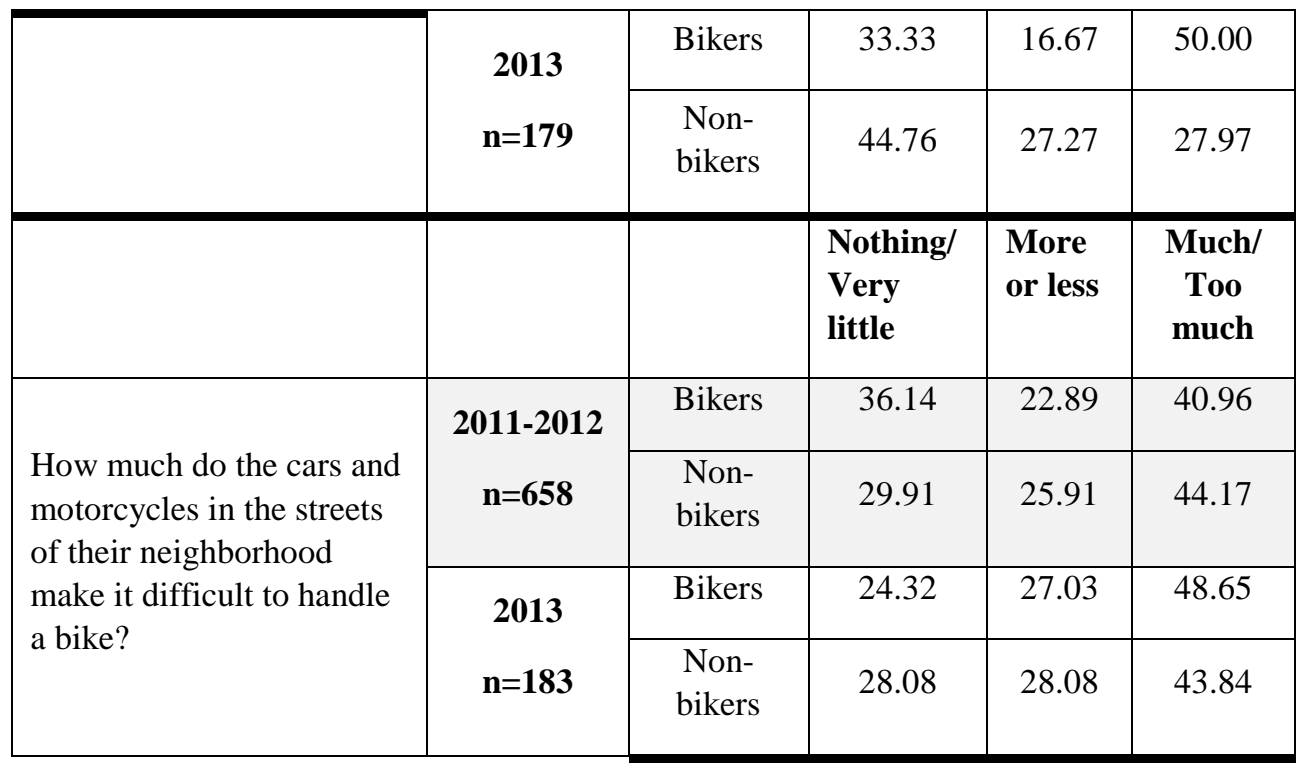

The survey also asked about how bikers perceive social and environmental conditions of riding a bike. In particular, it inquired about perceptions on the characteristics of the path when using a bike in the baseline and in Time 1. Overall, bicyclists recognize unsafe conditions bicycling at night and the perception of unsafe conditions related to traffic injuries increased from 2011-2012 to 2013. Cyclists perceive that cars and motorcycles hinder cycling and they also perceive that the number of people who ride a bike in the city has increased sharply. (Table 9)

Table 9. Socio-environmental perceptions among bikers ( $\mathrm{n}=83$ 201; $\mathrm{n}=37$ 2012/2013)

\begin{tabular}{|l|c|c|c|c|c|c|}
\hline & Very safe & Safe & $\begin{array}{c}\text { Not much, } \\
\text { not too } \\
\text { little }\end{array}$ & Unsafe & $\begin{array}{c}\text { Very } \\
\text { unsafe }\end{array}$ \\
\hline $\begin{array}{l}\text { How safe is } \\
\text { the path that is } \\
\text { outside the } \\
\text { neighborhood } \\
\begin{array}{l}\text { to ride a bike } \\
\text { during the } \\
\text { day? }\end{array}\end{array}$ & $\begin{array}{c}\mathbf{2 0 1 1 -} \\
\mathbf{2 0 1 2}\end{array}$ & 1.20 & 37.35 & 30.12 & 26.51 & 4.82 \\
\hline
\end{tabular}




\begin{tabular}{|c|c|c|c|c|c|c|}
\hline \multirow{2}{*}{$\begin{array}{l}\text { How safe is } \\
\text { the path that is } \\
\text { outside the } \\
\text { neighborhood } \\
\text { to ride a bike } \\
\text { at night? }\end{array}$} & $\begin{array}{l}2011- \\
2012 \\
\end{array}$ & 3.66 & 17.07 & 23.17 & 43.90 & 12.20 \\
\hline & 2013 & 2.94 & 20.59 & 26.47 & 35.29 & 14.71 \\
\hline \multirow{2}{*}{$\begin{array}{l}\text { How safe in } \\
\text { terms of theft } \\
\text { or robbery, is } \\
\text { the path which } \\
\text { is outside the } \\
\text { neighborhood } \\
\text { when driving a } \\
\text { bike? }\end{array}$} & $\begin{array}{l}2011- \\
2012\end{array}$ & 1.20 & 19.28 & 28.92 & 34.94 & 15.66 \\
\hline & 2013 & 0.0 & 14.71 & 50 & 20.59 & 14.71 \\
\hline \multirow{2}{*}{$\begin{array}{l}\text { How safe in } \\
\text { terms of } \\
\text { accidents on } \\
\text { the way which } \\
\text { is outside the } \\
\text { neighborhood } \\
\text { when driving a } \\
\text { bike? }\end{array}$} & $\begin{array}{l}\text { 2011- } \\
2012 \\
\end{array}$ & 2.44 & 25.61 & 29.27 & 31.71 & 10.98 \\
\hline & 2013 & 0.0 & 17.65 & 44.12 & 35.29 & 2.94 \\
\hline \multirow{3}{*}{$\begin{array}{l}\text { How safe is it } \\
\text { to cross } \\
\text { intersections } \\
\text { on the route } \\
\text { which is } \\
\text { outside the } \\
\text { neighborhood } \\
\text { when driving a } \\
\text { bike? }\end{array}$} & $\begin{array}{l}\text { 2011- } \\
2012 \\
\end{array}$ & 1.23 & 27.16 & 23.46 & 35.80 & 12.35 \\
\hline & 2013 & 0 & 23.53 & 35.29 & 38.24 & 2.94 \\
\hline & & Very Light & Light & $\begin{array}{c}\text { More or } \\
\text { less }\end{array}$ & Dark & Too Dark \\
\hline \multirow{3}{*}{$\begin{array}{l}\text { How good is } \\
\text { the lighting in } \\
\text { the path which } \\
\text { is outside the } \\
\text { neighborhood } \\
\text { to ride a bike } \\
\text { during the } \\
\text { day? }\end{array}$} & $\begin{array}{l}2011- \\
2012\end{array}$ & 8.54 & 39.02 & 34.15 & 14.63 & 3.66 \\
\hline & 2013 & 5.88 & 44.12 & 41.18 & 8.82 & 0.0 \\
\hline & & Too Much & Much & $\begin{array}{c}\text { More or } \\
\text { less }\end{array}$ & A little & Very little \\
\hline \multirow{2}{*}{$\begin{array}{l}\text { How much do } \\
\text { the cars and } \\
\text { motorcycles in } \\
\text { the path which } \\
\text { is outside the } \\
\text { area makes it } \\
\text { difficult when } \\
\text { handling bike? }\end{array}$} & $\begin{array}{l}2011- \\
2012\end{array}$ & 16.87 & 34.94 & 21.69 & 14.46 & 12.05 \\
\hline & 2013 & 34.29 & 31.43 & 20 & 11.43 & 2.86 \\
\hline
\end{tabular}




\begin{tabular}{|c|c|c|c|c|c|c|}
\hline & & Nothing & Very little & $\begin{array}{l}\text { More or } \\
\text { less }\end{array}$ & Much & Too much \\
\hline \multirow{3}{*}{$\begin{array}{l}\text { How do } \\
\text { drivers on the } \\
\text { route, outside } \\
\text { of the } \\
\text { neighborhood, } \\
\text { respect people } \\
\text { who drive a } \\
\text { bike? }\end{array}$} & $\begin{array}{l}2011- \\
2012 \\
\end{array}$ & 24.10 & 33.73 & 32.53 & 7.23 & 2.41 \\
\hline & 2013 & 20.59 & 29.41 & 35.29 & 14.71 & 0.0 \\
\hline & & None & Few & $\begin{array}{c}\text { More or } \\
\text { less }\end{array}$ & Many & Too many \\
\hline \multirow{3}{*}{$\begin{array}{l}\text { How many } \\
\text { people do you } \\
\text { see riding } \\
\text { bicycle on the } \\
\text { way out of } \\
\text { your } \\
\text { neighborhood? }\end{array}$} & $\begin{array}{l}2011- \\
2012 \\
\end{array}$ & 3.61 & 15.66 & 15.66 & 51.81 & 13.25 \\
\hline & 2013 & 0.0 & 5.88 & 20.59 & 71.76 & 11.76 \\
\hline & & Very willing & Willing & $\begin{array}{c}\text { Neither } \\
\text { great nor } \\
\text { small }\end{array}$ & $\begin{array}{l}\text { Somewhat } \\
\text { willing }\end{array}$ & $\begin{array}{c}\text { Not } \\
\text { willing }\end{array}$ \\
\hline \multirow{2}{*}{$\begin{array}{l}\text { How willing } \\
\text { would you be } \\
\text { to continue } \\
\text { using the } \\
\text { bicycle as } \\
\text { transportation } \\
\text { if given the } \\
\text { opportunity to } \\
\text { purchase a } \\
\text { motorcycle or } \\
\text { car? }\end{array}$} & $\begin{array}{l}2011- \\
2012\end{array}$ & 24.10 & 44.58 & 12.05 & 12.05 & 7.23 \\
\hline & 2013 & 14.29 & 54.29 & 8.57 & 17.14 & 5.71 \\
\hline
\end{tabular}

Finally, a multilevel logistic regression analysis was carried out to explore factors associated with biking as a means of transportation in Cali. Data from the adjusted model shows that biking as a mode of transportation was associated with being a male (POR= $3.44,95 \% \mathrm{CI}=1.91-6.20, \mathrm{p}=0.000)$, the perception of safe or too safe to ride a bike within the neighborhood $(\mathrm{POR}=2.90,95 \% \mathrm{CI}=1.47-5.72, \mathrm{p}=0.002)$, and to the perception of difficulties to ride a bike due to car and motorcycle traffic $(\mathrm{POR}=3.47,95 \% \mathrm{CI}=1.60$ - 
7.55, $\mathrm{p}=0.002)$. A marginal association was found with being Afro-Colombian $(\mathrm{POR}=1.72,95 \% \mathrm{CI}=0.89-3.31, \mathrm{p}=0.106)$. Additionally, a negative association was found with being from socio economic strata $3(\mathrm{POR}=0.26,95 \% \mathrm{CI}=0.11-0.64, \mathrm{p}=0.003)$. In relation with climate variables, it only reported a negative association with a $3^{\circ}$ tertile of humidity. (Table10)

In other words, the adjusted model shows, after controlling for covariates, three main socio-economic conditions associated with biking: being a male, perceiving safe conditions to ride a bike within the home neighborhood and perceiving difficulty handling the bike due to car and motorcycle traffic. In addition, the adjusted model shows a marginal positive association with having reported as Afro-Colombian.

Table 10. Biking use as a means of transportation in Cali (Multilevel Regression Model)

\begin{tabular}{|c|c|c|c|c|c|c|}
\hline Variables & & $\begin{array}{c}\text { Unadjusted } \\
\text { model }\end{array}$ & & $\begin{array}{c}\text { Adjusted } \\
\text { model }\end{array}$ & & \\
\hline & $\begin{array}{c}\mathbf{P O R} \\
*\end{array}$ & (CI 95\%) & $p$ & POR* & (CI 95\%) & $P$ \\
\hline \multicolumn{7}{|l|}{$\begin{array}{l}\text { Environmental attributes } \\
\text { (GIS) }{ }^{\psi}\end{array}$} \\
\hline \multicolumn{7}{|l|}{ Presence of bike-paths } \\
\hline No (reference) & 1 & & & 1 & & 0.908 \\
\hline Yes & 1.64 & $(0.67-4.04)$ & 0.278 & 1.94 & $(0.67-4.04)$ & \\
\hline \multicolumn{7}{|c|}{$\begin{array}{l}\begin{array}{l}\text { Fatal injuries from traffic } \\
\text { (cyclists) }\end{array} \\
\end{array}$} \\
\hline No (reference) & 1 & & 0.691 & 1 & & \\
\hline Yes & 1.18 & $(0.53-2.62)$ & & 0.79 & $(0.34-1.84)$ & 0.585 \\
\hline \multicolumn{7}{|c|}{$\begin{array}{ll}\begin{array}{l}\text { Socio } \\
\text { conditions }\end{array} & \text { demography } \\
\end{array}$} \\
\hline \multicolumn{7}{|l|}{ Sex } \\
\hline Female (reference) & 1 & & & 1 & & \\
\hline Male & 3.70 & $(2.20-6.21)$ & 0.000 & 3.44 & $(1.91-6.20)$ & 0.000 \\
\hline \multicolumn{7}{|l|}{ Age group } \\
\hline $18-29$ years (reference) & 1 & & & 1 & & \\
\hline $30-44$ years & 1.51 & $(0.90-2.51)$ & 0.116 & 1.48 & $(0.83-2.62)$ & 0.185 \\
\hline Education level & & & & & & \\
\hline
\end{tabular}




\begin{tabular}{|c|c|c|c|c|c|c|}
\hline $\begin{array}{l}\text { More than secondary } \\
\text { school } \\
\text { (reference) }\end{array}$ & 1 & & & 1 & & \\
\hline Secondary school or less & 0.65 & $(0.30-1.37)$ & 0.254 & 0.75 & $(0.31-1.83)$ & 0.530 \\
\hline \multicolumn{7}{|l|}{ SES $^{\sigma}$ (neighborhood) } \\
\hline SES 1 y 2 (reference) & 1 & & & 1 & & \\
\hline SES 3 & 0.30 & $(0.13-0.68)$ & 0.004 & 0.26 & $(0.11-0.64)$ & 0.003 \\
\hline SES 4 y 5 & 0.66 & $(0.22-1.96)$ & 0.451 & 0.60 & $(0.16-2.20)$ & 0.440 \\
\hline \multicolumn{7}{|l|}{ Working/studying } \\
\hline No (reference) & 1 & & & 1 & & \\
\hline Yes & 1.82 & $(1.00-3.31)$ & 0.051 & 1.34 & $(0.67-2.65)$ & 0.409 \\
\hline \multicolumn{7}{|l|}{ Being Afro-Colombian } \\
\hline No (reference) & 1 & & & 1 & & \\
\hline Yes & 1.64 & $(0.90-2.97)$ & 0.103 & 1.72 & $(0.89-3.31)$ & 0.106 \\
\hline \multicolumn{7}{|l|}{ Car ownership } \\
\hline No (reference) & 1 & & & 1 & & \\
\hline Yes & 0.66 & $(0.33-1.30)$ & 0.229 & 0.93 & $(0.42-2.06)$ & 0.864 \\
\hline \multicolumn{7}{|l|}{ Climate variables } \\
\hline \multicolumn{7}{|l|}{ Precipitation } \\
\hline $1^{\circ}$ tertile & 1 & & & 1 & & \\
\hline $2^{\circ}$ tertile & 0.96 & $(0.50-1.86)$ & 0.909 & 2.28 & $(0.81-6.36)$ & 0.117 \\
\hline $3^{\circ}$ tertile & 0.60 & $(0.29-1.26)$ & 0.179 & 0.97 & $(0.36-2.61)$ & 0.954 \\
\hline \multicolumn{7}{|l|}{ Humidity } \\
\hline $1^{\circ}$ tertile & 1 & & & 1 & & \\
\hline $2^{\circ}$ tertile & 0.75 & $(0.40-1.41)$ & 0.371 & 0.67 & $(0.25-1.78)$ & 0.421 \\
\hline $3^{\circ}$ tertile & 0.60 & $(0.29-1.21)$ & 0.157 & 0.26 & $(0.08-0.88)$ & 0.030 \\
\hline \multicolumn{7}{|l|}{ Temperature } \\
\hline $1^{\circ}$ tertile & 1 & & & 1 & & \\
\hline $2^{\circ}$ tertile & 0.81 & $(0.40-1.62)$ & 0.546 & 0.36 & $(0.14-0.93)$ & 0.035 \\
\hline $3^{\circ}$ tertile & 0.98 & $(0.48-1.97)$ & 0.948 & 0.44 & $(0.16-1.21)$ & 0.111 \\
\hline \multicolumn{7}{|l|}{ Environmental perception } \\
\hline \multicolumn{7}{|l|}{ Safety bicycle handle } \\
\hline Unsafe and very unsafe & 1 & & & 1 & & \\
\hline Not much, not too little & 1.62 & $(0.82-3.20)$ & 0.163 & 1.66 & $(0.80-3.45)$ & 0.176 \\
\hline Safe and very safe & 3.47 & $(1.89-6.38)$ & 0.000 & 2.90 & $(1.47-5.72)$ & 0.002 \\
\hline \multicolumn{7}{|l|}{ Proximity cycling destinations } \\
\hline Close and so close & 1 & & & 1 & & \\
\hline Far & 0.99 & $(0.60-1.63)$ & 0.956 & 0.93 & $(0.53-1.64)$ & 0.806 \\
\hline \multicolumn{7}{|l|}{$\begin{array}{l}\text { Difficulty handling bike by } \\
\text { traffic }\end{array}$} \\
\hline $\begin{array}{l}\text { Nothing, very little, } \\
\text { More or less }\end{array}$ & 1 & & & 1 & & \\
\hline Much & 0.65 & $(0.35-1.20)$ & 0.171 & 0.71 & $(0.36-1.42)$ & 0.335 \\
\hline Too much & 2.21 & $(1.10-4.43)$ & 0.026 & 3.47 & $(1.60-7.55)$ & 0.002 \\
\hline
\end{tabular}

Note: $*$ POR $=$ prevalence odds ratio; ${ }^{\circ} \mathrm{SES}=$ Socioeconomic strata at the neighborhood level; ${ }^{\psi}$ GIS = Geographic Information Systems. Source: Final Report to COLCIENCIAS "Evaluación del impacto de la red de ciclo-rutas en la actividad física utilitaria en la población adulta de Cali" Universidad del Valle GESP- Fundación FES, 2013 


\subsubsection{Cyclists Experiencing Travel by Bike in Cali}

For this part of the research eight people were interviewed at length. Those people were selected because they reported using bike as a means of travel in the quantitative multilevel study both times: in the baseline survey (2011-2012) and in the first time survey (2013), and it was expected that they would share their experiences of travel by bike in Cali. Initially 10 participants were selected but two of them were missing: a man moved on to another city and a woman changed her address and it was difficult to find her again. The interviews were conducted between June 2013 and December 2013.

Information from participants show that all of them can be considered "urban cyclists" because bicycling is considered their principal means of transportation, they have been using bike for at least 3 years or more and the distance reported (from origin to destination) is an average of $3.3 \mathrm{Km}$. daily. Moreover, biking as a main means of transportation has been incorporated to run errands, go to work and carry other people.

(Table 11)

Table 11. Contextual information from interviewed participants

\begin{tabular}{|c|c|c|c|l|}
\hline$\#$ & Gender & Age & $\begin{array}{c}\text { Log total } \\
(\mathbf{K m}) \mathbf{¥}\end{array}$ & \multicolumn{1}{c|}{ Travel context } \\
\hline 1 & Female & 40 & 0,2403554 & $\begin{array}{l}\text { She cycles four or five times per week to do her work as home } \\
\text { stylist. She also cycles every day to run errands. }\end{array}$ \\
\hline 2 & Female & 31 & 1,584785 & $\begin{array}{l}\text { At the time of survey she had cycled every day to work during } \\
8 \text { years. Her workplace (establishment typographer) was } \\
\text { located around 15 minutes from home. } \\
\text { At the time of interview, because she got a new job, she used } \\
\text { public transit (MIO) and sometimes her husband carried her in } \\
\text { his motorcycle. }\end{array}$ \\
\hline 3 & Male & 32 & 2,147754 & $\begin{array}{l}\text { At the time of survey he cycled every day to work. He was a } \\
\text { construction worker. He quit his job because of mental health } \\
\text { problems. At the time of interview he was an assistant joinery. }\end{array}$ \\
\hline
\end{tabular}




\begin{tabular}{|c|c|c|c|l|}
\hline & & & & $\begin{array}{l}\text { He cycles every day to run errands related to his job and } \\
\text { walks from the workplace. }\end{array}$ \\
\hline 4 & Male & 27 & 0,7035517 & $\begin{array}{l}\text { At time of survey he worked as construction worker and } \\
\text { cycled every day to work. At time of interview he was } \\
\text { unemployed. }\end{array}$ \\
\hline 5 & Male & 41 & 0,7727016 & $\begin{array}{l}\text { He came from rural area to Cali four years ago. He works in } \\
\text { the informal sector (shoe manufacture and reparation). He } \\
\text { cycles every day many times a day to run errands related to } \\
\text { his job. }\end{array}$ \\
\hline 7 & Male & 38 & 0,8647285 & $\begin{array}{l}\text { He cycles at least twice a week to run errands and to visit his } \\
\text { mother. }\end{array}$ \\
\hline 8 & Male & 43 & 10,12623 & $\begin{array}{l}\text { He works in construction and cycled every day to work. He } \\
\text { was a professional cyclist but quit because he was injured in } \\
\text { an assault to steal his bicycle. }\end{array}$ \\
\hline
\end{tabular}

Note: $¥$ Refers to the total distance from the origin to the destination using bike. This information is

provided by the survey

Table 12 presents the main socio-economic characteristics of this "urban cyclists" group. Most of them are from lower SES and have achieved secondary school education.

The interviewees self-reported as black or mestizo.

Table 12. Information on interviewed participants

\begin{tabular}{|c|c|c|c|c|}
\hline Number & Education & Occupation & Race & SES \\
\hline 1 & $\begin{array}{c}\text { Secondary school and } \\
\text { courses in hairdressing }\end{array}$ & Professional stylist & $\begin{array}{c}\text { Mestizo or } \\
\text { Mixed race }\end{array}$ & 2 \\
\hline 2 & Secondary school & Call center & $\begin{array}{c}\text { Afro- } \\
\text { Colombian }\end{array}$ & 1 \\
\hline 3 & Secondary school & Joinery auxiliary & $\begin{array}{c}\text { Afro- } \\
\text { Colombian }\end{array}$ & 2 \\
\hline 4 & Secondary school & Unemployed & $\begin{array}{c}\text { Mestizo or } \\
\text { Mixed race }\end{array}$ & 2 \\
\hline 5 & Primary school & $\begin{array}{c}\text { Worker from the } \\
\text { informal sector }\end{array}$ & $\begin{array}{c}\text { Mestizo or } \\
\text { Mixed race }\end{array}$ & 2 \\
\hline 6 & Electromechanical & Electromechanical \\
technologist & Mestizo or & Mixed race & 2 \\
\hline 7 & Technical school & Assistant topography & $\begin{array}{c}\text { Mestizo or } \\
\text { Mixed race }\end{array}$ & 5 \\
\hline 8 & Technical school & Caregiver & $\begin{array}{c}\text { Mestizo or } \\
\text { Mixed race }\end{array}$ & 2 \\
\hline
\end{tabular}


Qualitative data analysis yielded, based on thematic network analyses, five global themes, discussed here. This constitutes five thematic networks each one with different number of Organizing Themes and Basic Themes. For each global a thematic network was elaborated (Attride-Stirling 2001).

\subsubsection{Class Conflict at the Street Level}

The first global theme is "Class conflict at the street level". It is one thematic network comprising two organizing themes and six basic themes. This network represents how participants experience the use of the road space in the city. (Figure 2)

In Cali, biking as a means of transportation is grounded in class. This practice is not exercised equally among the population. It was clear among cyclists that biking represents "the mobility option" for workers' who cannot afford other modes of travel. In other words, biking is a mode of travel associated with the working class such as construction workers and informal economy workers, who need to save on transportation money every day in order provide for other necessities. Moreover, as a necessity for mobility sometimes biking turns into a very stressful situation. This issue is illustrated with the following interview segment:

Researcher: Let's say, from one to ten, what do you think is your stress level handling bike in Cali?

Participant: Oh ... like nine

Researcher: Nine ... if so stressful, why do you continue doing that?

Participant: Because it is necessary

Researcher: Why do you need it? 
Participant: For transportation, one needs it. One tries to avoid spend money in transportation, such as 3,200 pesos. One needs this money for food or other necessities.

Another example of this view is from a 27 year old man with secondary school education, for who using the bike was the option to save money but he must ride for about one hour and forty minutes twice per day which was hard for him:

Participant: Suddenly (...) to save money

Researcher: Yeah, and what time did you go?

Participant: I left at 20 before 6 am and I arrived there at 8 am. No one enjoys this... I arrived tired...

Cyclists are not necessarily stigmatized as poor or workers but using the bike to get around is the main option for workers in Cali. Biking is objectively associated with people from lower socioeconomic strata and, consequently, this practice has low social status. Moreover, cyclists associated car use with rich people. When one takes into account their incomes, cars would be an almost unattainable option for poor people.

Not surprisingly, for current cyclists, motorcycles would be the most desirable and next attainable transportation option to achieve. Five out of the eight cyclists say that once their economic condition improves then will likely buy a motorcycle which, according to cyclists, has more social status and some practical advantages when compared with bikes. One of the workers interviewed perceives the differences between driving a motorcycle and riding a bike, in this way: "(...) Say, sometimes people do not use it (the bike) ... because of the status" ... (No.2), and he added: 
"For example, a person's office is different than a Russian man, a man of construction. We (construction workers) we go on our bicycles. We know we're going to sweat (...) you will always get powder when biking like in motorcycle. But in motorcycle you use jacket because you drive fast. By bike you reduce your speed and you sweat. Mainly the sweat, this is the disadvantage of biking: the sweat. (...) Sure, a lot of dust, and addition sweat, and for one of us to go to an office ... then, maybe, for that reason they do not use bike and also because it has a higher rank (motorcycle)."

Moreover, another man said that people without money really want to switch from a bike, to a motorcycle at least:

“And if you don't have motorcycle, you use bike. People want always a motorcycle, so, I say: people use the bike for economic situation but here everyone wants a motorcycle."

People who use the bicycle as a primary means of transportation in Cali battle for space everyday with all motorized transportation modes. According to participants, this conflict is based on an unequal distribution of the physical space which has created a kind of denial of bikers over roads. However, it represents a class conflict as well because bikers, in this case, are from lower SES than people who drive cars in Cali. It is not only an objective fact but it is an issue that bikers perceive as well. For example, an expert urban biker who works in the construction sector and uses his bike every day during week days, recognized that working class people are unable to afford a car, and people from higher SES not only can afford a car but they need it for personal security as well. In this regards, a worker said:

“(..) for me, people who have a car are because they can buy it. The worker, we, uses bicycles. Who has a motorcycle is a worker as well. There are very few executives who have a motorcycle (...) those who have economic resources use car, they also use car for safety because you are safer in a car than on a bike or in a motorcycle." 
In addition, another biker expressed that the local government is not interested in supporting infrastructure for biking, as a mode of travel, because bikes do not pay taxes. In this respects this biker explained:

"Bikes do not pay taxes, so, the government promotes them (bike paths) but without too much importance. Bicycles do not pay vehicular taxes, they do not pay anything, and so, they do not care about bicycles. They care about motorcycles, cars, because cars and motorcycles give money."

Bikers interviewed unanimously expressed that the main conflict is related to the lack of space for bikers on the road and the dominance of motor vehicles in the city. (Picture 7)

Picture 7. Lacking of physical space

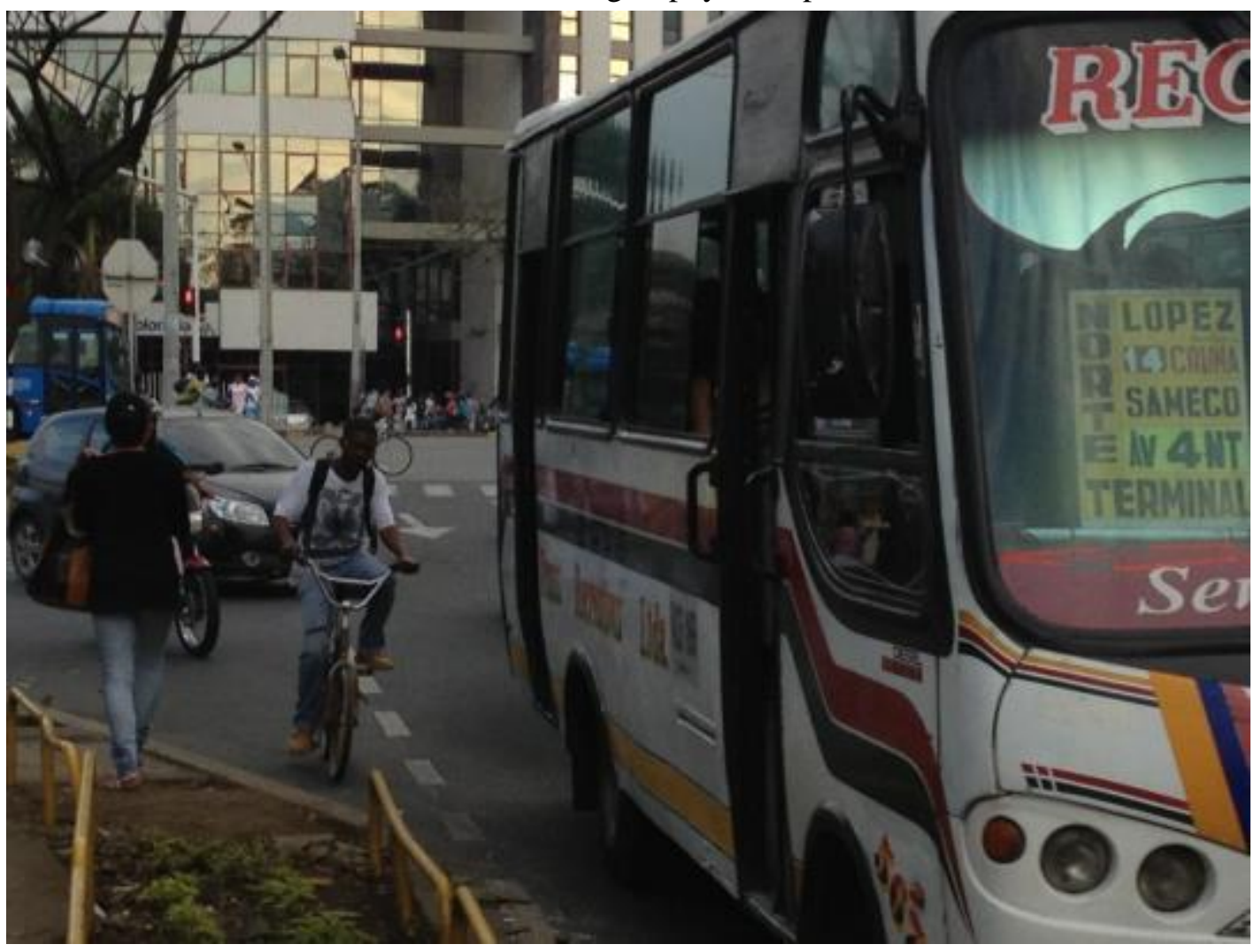

Source: Janeth Mosquera Becerra and Yoseth Ariza, Cali 2013 
Bikers reported that when there is space in the city, it is reserved for motorized vehicles which can move faster than bikes. In other words, the ability to move faster allows drivers to use the streets more effectively. So, wider streets are reserved for faster vehicles, while a portion of smaller streets can be used by bikers. A participant recognized that "Well, here there are few wide streets for bicycle lanes and wide roads are for cars that go fast."

In this case, bikers understand and assume that their road space is around $50-100 \mathrm{~cm}$ from the sidewalk. Moreover, they said that this small space is shared with motorcycles which are also obligated to use the right side of the street. From the point of view of bikers, it seems that they receive similar treatment than motorcyclists when decisions about street use are made in the city. However, they also understand that bikes cannot be treated as other motorized vehicles because they are more vulnerable and run at lower velocity. The topography assistant interviewed realized that he rides his bike using a small edge of the road:

"Yes, cornered $50 \mathrm{~cm}$, and ... and that is for do not going into the sewer system..."

On the other hand, bikers believe that they deserve physical space, but only when there is modified space specifically for bikes and separate from motorized transportation, for example in the form of segregated bike paths. In other words, most bikers agree that it is not right to use the road networks for cyclists. This right is reserved for automobiles needing to move faster. A father of a disabled boy who uses his bike every day considered that: 
"Having a unique route for riding a bike, would be good. But here there is no room for that on the streets. (The streets) are not as broad and those broader are freeways which are for faster vehicles."

At the same time, bikers perceive that those who use motorized vehicles have no interest in sharing the space, but rather they consider cyclists not only a hindrance but a nuisance. Moreover, they believe it is not about invisibility, it is about trying to put or keep bikers outside of the road network. Interviewees reported two strategies intended to harass cyclists: motorcyclists and drivers increase speed when passing very close to the bike rider and they use also the vehicle horn repeatedly asking them to move aside. In fact, some cyclists have experienced or witnessed very negative and dangerous episodes "sharing" the street. For example, the professional stylist reported that:

"(Motorcycles) Yeah, they go very fast. Once I was on the highway and a guy in a motorcycle for doing evil, caught him with his foot and pushed him (a cyclist)..."

In summary, the evidence suggests that within a motorized environment where biking as a mode of travel is practiced predominantly among poor people, conflicts for space represent also a class conflict outside of the workplace, because the road network is not just a space for mobility but also an arena of struggles for living conditions. In this case, cyclists dispute space over the street to get to their job, but it happens within a context that denies their presence (reducing space, lacking signals and signage) and, at the same time, putting their lives at risk daily. From an environmental justice perspective the thematic network illustrates that in the city of Cali transportation decisions do not meet the need of people who need use bikes as a mode of travel. On the contrary, those people are more exposure to adverse traffic conditions. 
Figure 2. Thematic network for "Class conflict at the street level"

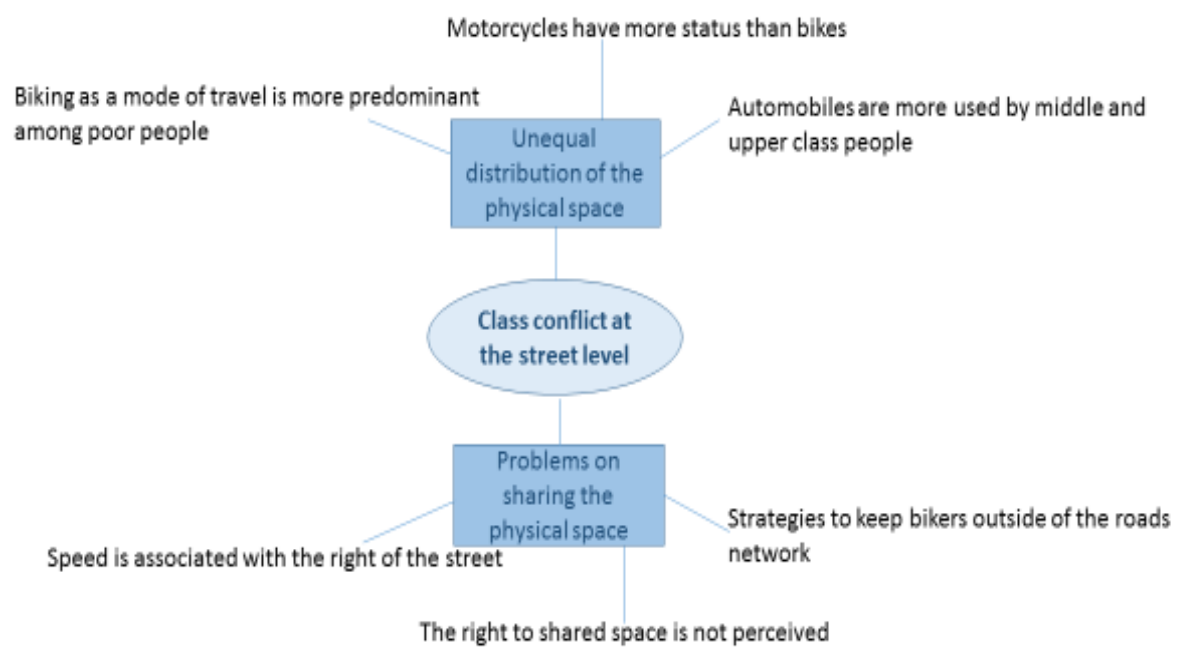

\subsubsection{Bus Rapid Transit and its Impacts on Biking}

The second global theme is "Bus Rapid Transit and its impacts on biking. This constitutes one theme network comprising two organizing themes and five basic themes. This network represents how bikers face the main urban changes associated with the new BRT (called MIO) on their daily ride. (Figure 3)

It is widely recognized that the Bus Rapid Transit (BRT) implemented in 166 cities around the world, is the largest urban change in Cali in recent years. All research participants indicated that both construction and operation of the MIO has had several impacts on cycling as a means of transportation. During the first stages of MIO's construction the city experienced problems with mobility and congestion. It was a common issue. Moreover, construction of the first BRT lines took longer than planned. In 
this context, participants explained that congestion problems related to BRT construction and delays in BRT implementation prompted many individuals to rely on biking. This resulted in rising bike use.

Once the BRT, -characterized for its problems related to capacity, schedules, routes, and delays- was operational, participants explained that those operational problems had led more people to seek to resolve their mobility needs through different means of transportation such as motorcycles and bicycles, in particular. Thus, people switched to other modes of transportation to fulfill their necessity.

On the other hand, with the construction of BRT, a good portion of road networks such as paving and signaling around BRT lines which run on main streets was enhanced. Consequently, according to participants, those improvements allow cars and motorcycles to run faster on the streets. These improvements, simultaneously, however, expose cyclists to more physical risks and traffic injuries. In other words, improving road conditions for motorized transportation increases threats to people who use bicycles in Cali. However, taking into account that cyclists use the same roads, some participants recognized that improvement of the road network and signaling is good for bikers as well. As the 32 year-old joinery auxiliary explained:

"It's better in the sense that they have arranged the streets, in the sense of the streets. With the MIO they have repaired many roads, and they also have built a small space on the sidewalk for bicycles, only for bicycles. That's the advantage." 
Additionally, the discussions also revealed that reducing road space is another BRT impact on biking as a means of travel. Indeed, the system has reduced road space for other means of transportation because BRT buses run along exclusive corridors. Currently, public transit has more road space, so cars and motorcycles looking for space "corner" the cyclists on the road. On the other hand, as was noted for bikes, some bikepaths have been built in recent years as part of different urban projects. In particular, some bikers recognize that some urban improvements associated with public space recovery as part of the BRT implementation and Megaobras have been useful for bikers. In this case bikers indicate that some bike paths located on the sidewalk could be beneficial for bikers.

However, by changing the distribution of road space among users and locating the construction of bike lines on sidewalks, it would seem that bicyclists only have the right to run on bike lines built for them; so they have no right to be on the road on their bike. In this case, the MIO deepens the unequal distribution and use of the city road network. This issue needs to be understood within a context that provides additional road space for motorized transportation through Megaobras projects while biking infrastructure is reduced to short corridors with no connections between them, as characterized unanimously by participants. The problem in Cali is that, to this day, bike-paths are built not to respond to the needs of cyclists but as circuit more for recreation than for travel. A research participant, who travels by bike every day, emphasized that:

"I think the situation has worsened with the MIO. (The space) has been reduced. Now cars try to corner bikers, especially where there are no bike lanes (...). Before there were 
more buses and minibuses, but there was room for everyone, not now. With the MIO we only win space reduction, especially for us who ride bike."

Interestingly, the BRT was also perceived as more dangerous than normal buses for cyclists. Higher velocity, plus size, and difficulty stopping quickly, were the main aspects mentioned related to BRT risks for cyclists. However, this discussion again was suggested within a context of increasing motor vehicles and refusal to consider nonmotorized means of transportation as part of transportation planning and policies. (Picture 8)

"Because they (MIO buses) go fast and it difficult those cars to stop (...). One has to ride with more precautions, especially when those cars go next to one. It is better to stop, in order to wait that they pass and then can one to continue..." 
Picture 8. MIO and Cyclists

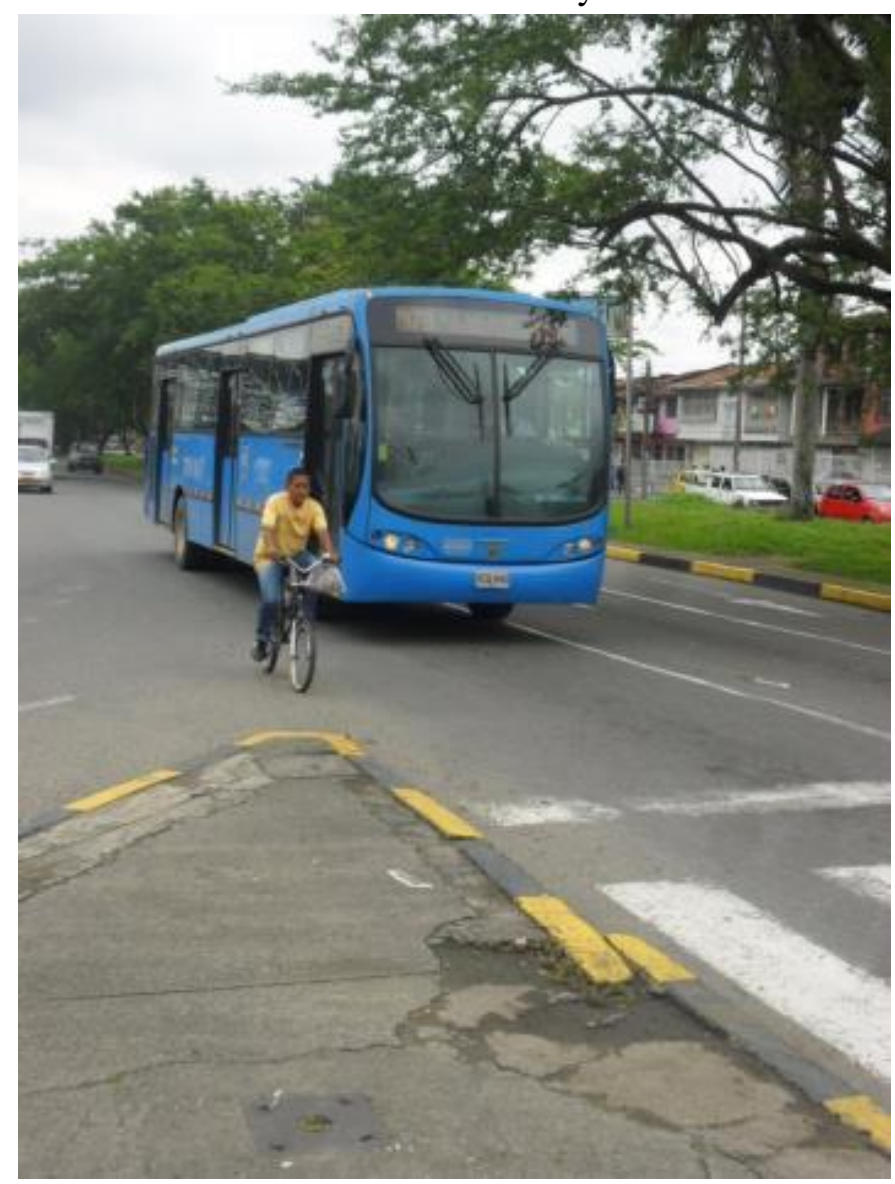

Source: Students from Franja Social I, Universidad del Valle, Cali 2012 
Figure 3. Thematic network for "Bus Rapid Transit and impacts on biking"

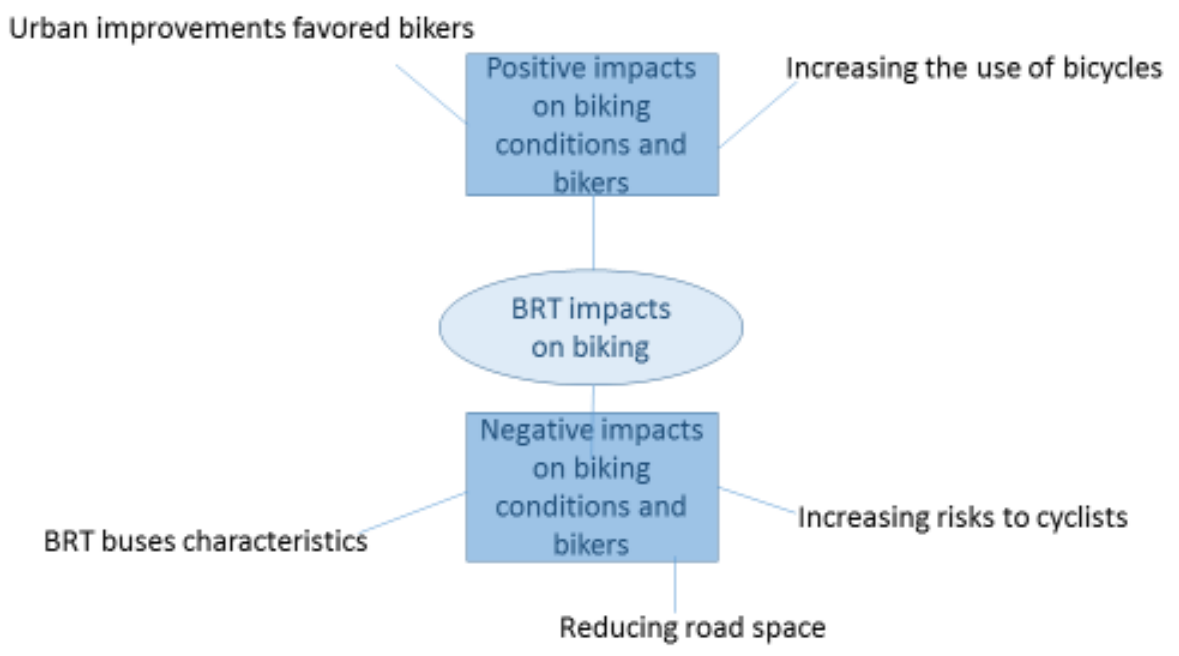

\subsubsection{Negative Social and Physical Urban Conditions for Biking}

The third global theme "Conditions for biking in Cali" constitutes one theme network comprising one organizing theme and seven basic themes. This network represents perception of social and physical conditions that affect travel by bike. Figure 4 shows the network for this global theme.

It pertains to social and physical adverse conditions which cyclists deal with every day in Cali, as indicated by participants. The main idea expressed by bikers was that biking is a necessity (solving mobility) for a great number of people, but it happens under very bad conditions. One of the drawbacks of cycling was the possibility of being robbed of their bikes and placing their lives at risk for that reason. Moreover, most of them have 
experienced personal robberies or they have witnessed robberies. In fact, some of them have lost up to three bikes over the course of their lives.

"(Riding a bike) can also be dangerous. Several bikes have been stolen (...). The danger while riding a bike is being stolen and suddenly, by stolen a bike one could be hurt"

Feeling fear is not a limitation in continuing this practice, because the need for travel is predominant and people do not have money to use any other mode other than biking. They keep travelling by bike because they have no other option, biking is the option. As was said by one interviewee, there are no other options:

"Yes, there is also much insecurity because they steal many bicyclists but they are the risks that you have to deal with."

In addition, one of the women in this study reported that once her husband moved to another city she had reduced the distance of traveling by bike. She said:

"Because, I used to go to the north of the city until last year when my husband was here, I used to go with him (...) Alone I don't go. I am afraid that something bad happens to me or that being robbed."

However, taking into account that bikers perceive more risk of robbery at night, most cyclists, men and women, avoid biking at that time. They dissuade their relatives from travelling by bike, which illustrates another way that riders are constrained in their use of the city.

Moreover, the anti-cycling environment is also related to coping with all kinds of motorized means (MIO, public buses, private cars, taxis, and motorcyclists) on the roads and was characterized in two ways: not having the right to be on the road and facing an 
environment too dangerous and hostile for biking. As was said above, within an environment of increasing motorization and BRT implementation, cyclists observed that they have no space on the road but also drivers try "to erase" them from the road. In fact, data shows that cyclists suffer a high burden of mortality from road traffic injuries, which represents another health inequality because it happens in a context where biking is more prevalent among people from lower socioeconomic status. Moreover, in order to avoid being a victim of traffic injury most cyclists have learned strategies to cope with road insecurity.

"I, practically, bike on the sidewalk, because if one is on the roads those cars try to delete one, to remove one without compassion. That's delete boy! And if you do not have good reflexes and if you do not have good handling, they put you away from the highway..."

Another constraint faced by cyclists is the absence of parking areas. It is not just want of physical infrastructure for parking, which was discussed by participants; it is also that some public spaces are reserved for "more prestigious vehicles and people with money":

"Just they tell: you cannot park the bike (near the bank), or they tell you to look elsewhere (...) so, they do not allow to parking bikes. But they allow parking cars, cars from people they know, partner people, all which, but not one who has arrived cycling and you have to look elsewhere for parking. You say, you go around to the area, and you leave the bike in a private parking and, then go do your errands and then return for your bike and goes (...) I mean... How do I tell? Because the cars often are from known people, partners, people who will give their money, however who is biking, I do not know how they think about them, how they see bikers."

Moreover, when bikers use some of the bike lanes segregated from motorized transportation, they are looking for protection; even if it is poorly connected, badly designed, without signals, signage or badly paved. Indeed, as bikers said, riding a bike 
every day is a stressful experience, but they recognize that they have developed some maneuvers to cope under an anti-biking environment such as exists in Cali in order to travel. But it is important to consider that cyclists face an unsafe environment in terms of traffic injuries. Biking in Colombia is a risky activity in terms of morbidity, mortality and disability. Data from 2011 shows that in Cali 16\% of deaths from traffic injuries involved cyclists and in 2010 this figure was $15 \%$. The case of Cali shows that bikers suffer disproportionately traffic externalities which is an issue that the environmental justice movements seek to address. A woman in this study related her experience facing traffic risks:

"The bus came, clearly it came so fast and it pulled me out the road and I hit a woman who was walking at the time. (I said) Oh sorry! The bus was coming, it almost hit me and I'd rather jump into the sidewalk than to be killed."

Finally, negative social conditions for biking were related by participants as a lack of respect for bikers. Particularly, interviewees had aspirations that with a few investments in infrastructure and strong educational programs, it will be easy to get better conditions for cyclists. It seems to be a significant cultural challenge in a car-friendly city", and this point of view represents a naïve view of the implications of a city shaped mainly by economic interests, as was shown in the historical overview.

"The problem for me is culture. People do not respect. You can add a separate bike path, but people do not respect, there is no respect. That's culture, as simple as if people become aware that a line should be respected and that is enough, because they know they have to respect bike paths because they are only for bikes."

Better infrastructure is not enough to achieve road equity. It is necessary to create a more supportive social environment. This last fact is linked with how riding a bike as a 
mode of travel has very different social and cultural support than riding a bike for recreational purposes, which will be discussed later.

Figure 4. Thematic Network for "Negative social and physical urban conditions for biking"

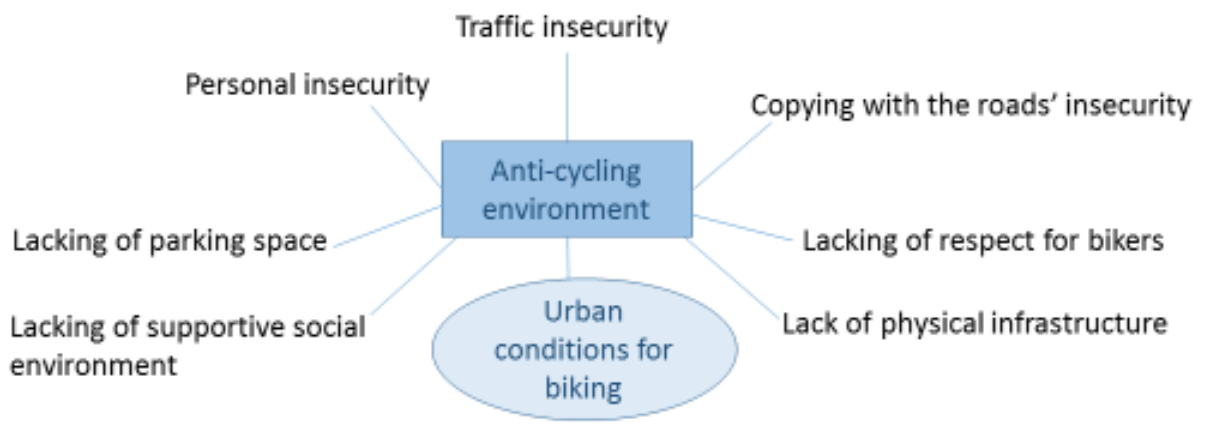

\subsubsection{Benefits of Biking}

The fourth global theme is "Benefits of biking". It is one theme network comprising three organizing themes and eight basic themes. This network shown in Figure 5, represents individual and social advantages that current cyclist perceive in Cali.

Among bikers participating in this research, the discussion of the advantages of bike-riding reveals four aspects. First, travel by bike was observed as a practice that enhances health. Actually, the health benefits of cycling were associated with the physical effort involved daily. Interviewers argued that: 
"Riding a bike you always have health. Gain health" As said a man who works as Assistant topography

"I have a partner who is driving car, he is increasing more and more his belly, while one is always normal, always with the same body" as told by an unemployed man, 27 years old.

For an independent worker who rides a bike throughout the day as part of his job and used to live in the countryside, biking is a way to enhance health but it is a way to have fun in the city as well. He explained that:

"Well, for me it is as a means of health, because in the city one remains locked. So that (biking) is the only thing to go out and enjoy, mostly for health as well. Because when you bike you feel like (deep breath), and riding a bike you do a lot of exercising."

However, it was also reported by participants that sometimes they must travel very long distances due to lack of money and then fatigue is so intense that they no longer perceive health benefits.

Second, it was seen as a significant practice to save money, particularly among informal economy workers who need to go around different parts of the city every day. Some informal workers discussed that this is the most important reason to travel by bike because they usually need to get around different parts daily in order to provide home services such as haircuts, to attend clients by delivering goods, or pick up merchandise. Consequently, for them biking is the most affordable mode of travel. As said by the woman who works as stylist: "Because essentially by the time you pay bus fare nothing keep left (money)"

Additionally, two independent workers said that: 
“(...) the bike has something that it brings one very fast. Also the savings because you wherever you go, you save a lot money for transportation, it is like \$1,600,\$1,600” A man who works as joinery auxiliary

“(...) the economy, right? Using the bike you save a lot of money for transportation, because one goes up to 3 times daily to downtown." From a man who work in the informal sector.

Third, another benefit of biking as a mode of travel discussed by participants was the chance to avoid problems related to quality of service in MIO such infrequency, delays, crowding, confusion on transfers, and inaccessibility. However, most of them have little experience using the MIO but they referenced those problems based on observations and the experience of relatives and friends. Indeed within a context of unreliability in public transportation it is likely that for poor people cycling must be "the option" because they have no another choice. As the man who works as joinery auxiliary, said:

"About half an hour, and sometimes if the bus is busy ... humm, it can take about 45 minutes. Instead of 20 minutes if is cycling."

Finally, a participant who rides a special bike in order to transport his seven-yearold autistic son expressed that he is using this means of transportation for two reasons: transportation costs and comfort for his son. For this father moving around with a child with disability seems to be a complex situation, because as a child with special needs, his son attends a rehabilitation center at least three times per week, and the cost of transportation is very expensive for the family. The option for transportation is travelling by taxi, but that is too expensive for his family. Moreover, this father avoids dealing with public transit because his son has behavioral problems associated with his disability. In 
addition, this cyclist perceives that his son enjoys travel by bike. This case illustrates a situation where riding a bike is "the option" to travel with another person, particularly children or women, which is a popular practice in Cali among lower income families. In fact, in the population survey, among those who reported using a bike as a mode of travel in the last three months, $17.9 \%$ had also carried another person on his/her bike. (Picture 9)

Picture 9. Bike from a father with a boy with disability

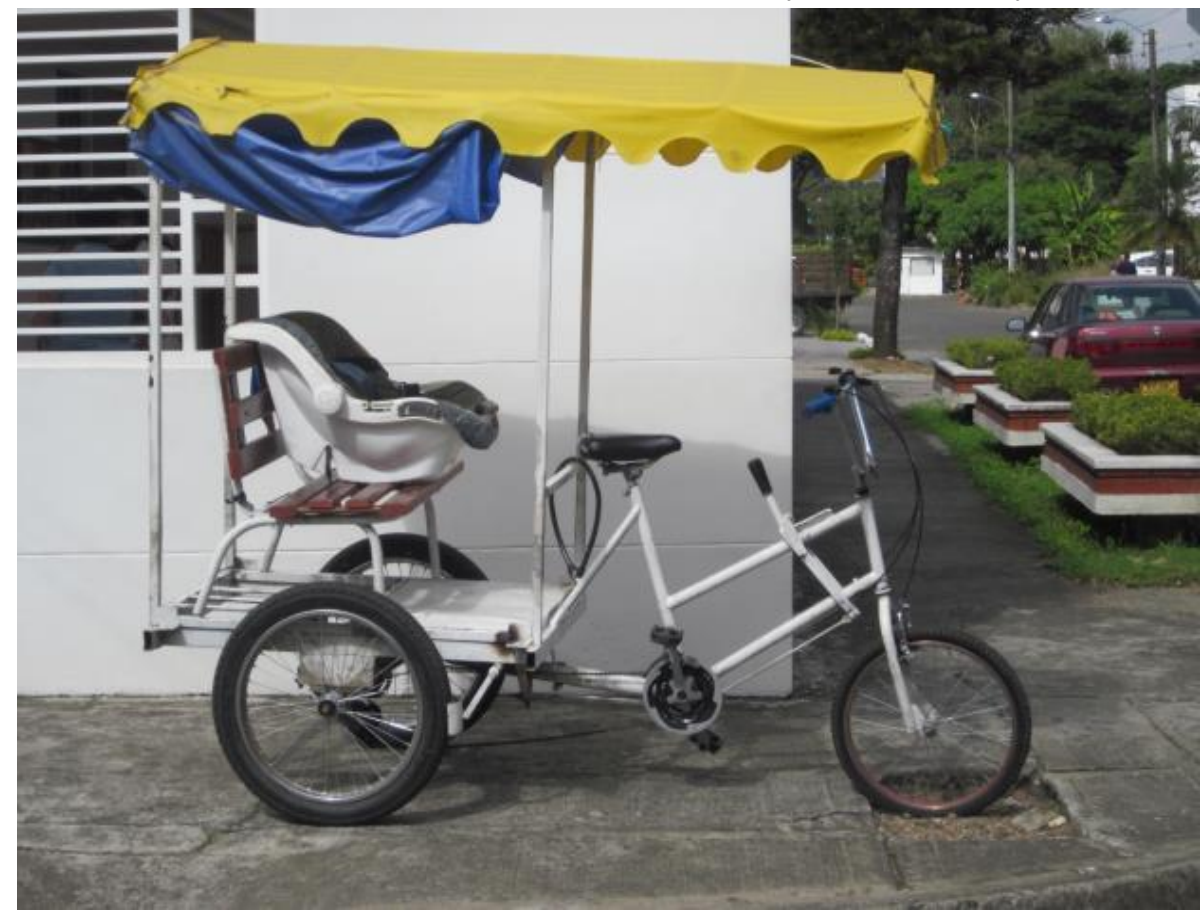

Source: Janeth Mosquera Becerra, Cali 2013 
Figure 5. Thematic Network for "Benefits of Biking"

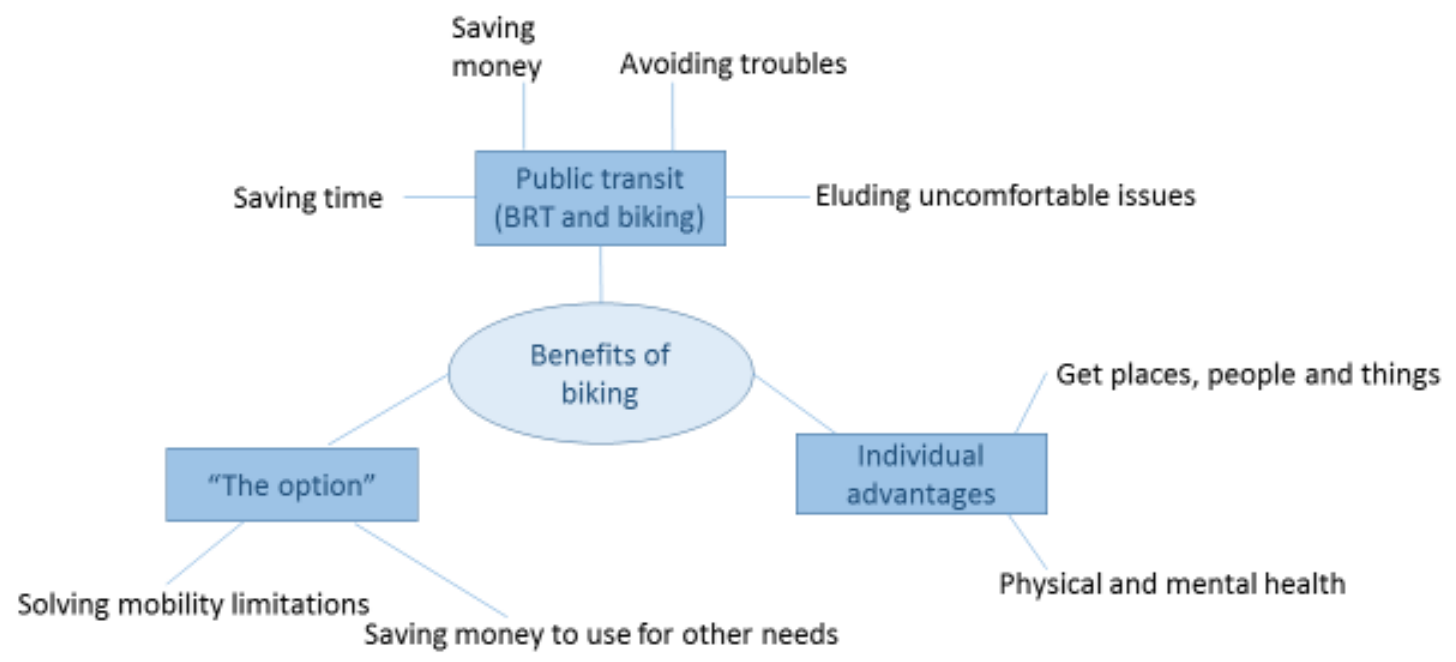

\subsubsection{Switching Social Status}

The fifth global theme is "Switching social status: from recreational biking to utilitarian biking". This constitutes one theme network comprising two organizing themes and five basic themes. This network represents perceptions of current bikers on how people in Cali distinguish differences between riding a bike for fun and riding a bike for daily transportation. Figure 6 shows this thematic network.

Most Colombian cities have an established cycling culture. In other words, in Colombia and Cali, in particular, children and youth learn how to ride a bike early, enjoying cycling for leisure and it is "normal" that they use bike in their daily life. Indeed, 
both the population survey and interviews with cyclists show that in Cali people learn how to ride a bike early and most bikers keep this practice up during their life. In addition Colombia has an important tradition in bike racing at the national and international level.

However, the situation is different when riding a bike is a mode of transportation as is more prevalent among low income people. This is when a turning point occurs: riding a bike as a mode of travel becomes a negative social practice. Within a motorized context and, particularly, under increasing motorcycles ownership and use, using bikes as a mode of travel is a temporary strategy to solve mobility. But, once income increases, people hope to switch from bikes to motorcycles because being a cyclist is associated with poverty.

In fact, at the time of the interview one woman who used to ride a bike every day from home to work twice per day during 8 years, explained that once she got a different job, she switched from bike to public transit or her husband's motorcycle. Today, she has a better job (from assistant typography to call center attendant), and she does not want to continue commuting by bike because "it's not right now" but she continues to ride on Sunday or at night as a recreational activity. As she said:

“(...) I would not go biking to my work because of the condition of my clothes, but we use a lot the bike here for sport on Sundays, to go with the kids."

Moreover, as was said by an interviewed participant, once people get a new job with better wages it is expected they change from the bicycle to a motorized mode of transportation because "it is socially looked down upon to continue using a bicycle as a 
mode of transportation". A new specific cultural context emerges that proclaims motorization as the normal way to get around and riding a bike as a mode of travel becomes a negative practice, linked with poor people. Most research participants recognized that getting a better job represented an opportunity to abandon commuting by bike even though time consumption and transportation costs increase. For example, as an experienced cyclist realized:

Participant: (...) one make changes to improve working conditions, but MIO bothers me, so we must wait. Sometimes, I leave tired and want to go quickly to my house, which was unlike the other work, even though I was wet or despite was sunny, I knew that in 10 minutes I was in my house ... but now there is no other choice, and at night the MIO is difficult.

Researcher: You told me 1 hour and a half to get your new job using MIO ... How much time would you calculate biking, if you were riding a bicycle, you who is a good rider?

Participant: Hummm I would arrive in half an hour

In summary, this thematic network illustrates the tension between biking for fun and utilitarian biking in Cali. Both are popular in the city but one enjoys more social recognition among people who bike and among friends or co-workers as well. 
Figure 6. Thematic Network for "Switching social status"

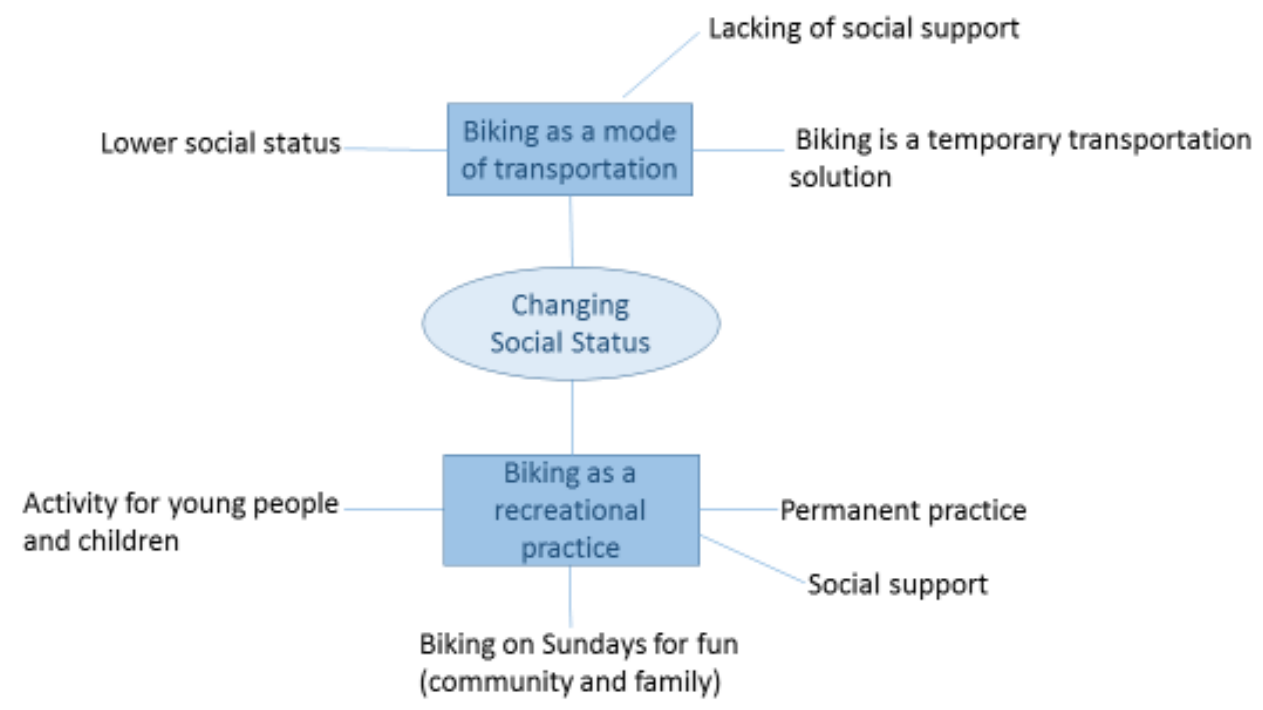

Findings' research from this case study shows that the city of Cali, during the process of urbanization, has experienced key physical transformations intended to facilitate motorized mobility as part of the capitalist development. In the course of industrialization and using the discourse of modernization the city improved and enlarged road networks and changes in land use propelled urban expansion, increasing land prices. In the meanwhile, buses and private cars demanded construction of road networks and biking turned into a popular means of transportation among students and workers. In addition, new urban planning instruments begin to be implemented in order to regulate land use and transportation infrastructure for motorized means of travel. Then, a second larger urban transformation occurred as a consequence of capital investment to prepare the city to hold the VI Pan-American Games. In this period again the built environment is 
transformed. New buildings are built while old ones are demolished, the road network is expanded, the use of motorized vehicles increased, and the city expands sharply. Biking a as mode of travel is explicitly excluded while a transportation system based on buses gain urban space. In the last period, the city faces a new stage to become a competitive city when a neoliberal project is implemented.

In terms of Harvey's framework this historical overview shows the role of urbanization in consolidating the capitalist system. Capital interests incessantly look for profitable activities. As a consequence of changes on economic activities, from manufacture to industrialization and from industrialization to services, the built environment is transformed in Cali to respond to accumulation interests. Particularly, with the shift from one economic activity to another, transportation infrastructure for motorized means is favored. Key players from multiple scales participate in this process: local and national government, international agencies, and local investors. Quite significantly, planning instruments and discourses have been useful to support those urban transformations.

Following, Harvey (2012) who suggests that it is necessary to "look at the conditions of the working class in the city as a whole", the situation of cyclists in Cali illustrates how working class people struggle on the roads. To summarize, while biking as a mode of travel is an important practice among low income people in Cali, it also happens within social and physical adverse conditions. Those who use 
bicycles as transportation in Cali are informal workers, mostly men, and Afro-Colombian who see it as an economic advantage which competes with the high cost of public transportation. Users of this means of transportation do not perceive their right to use roads designated for motorized transportation. Therefore, they feel obliged to negotiate only a piece of the right side of the street, so as "not to impede" the movement of other vehicles. This perspective reinforces the idea among more elite sections of the population that cycling is not a means of transportation per se, but it makes sense for the health benefits and environmental reasons.

In addition, current cyclists easily move to different places without creating additional costs. Although it is recognized that the bicycle as mode of transportation has advantages in terms of shortening travel times, greater autonomy and reduced transportation costs, users of bikes are aware of the risks to physical safety that they face daily. These risks are mediated by self-perceived vulnerability compared to other modes of transportation. Furthermore, the assessment is that while the construction of the MIO helped to improve the quality of roads in terms of reduction of potholes and improving paving, the system reduced the physical space for other means of transportation (private cars, taxis and motorcycles). Bicyclists now "negotiate their piece of street" in less physical space.

Similarly, although it is expected that the reduction of buses and minibuses were favorable for bicycle transportation because it reduces the number of cars in circulation, 
cyclists perceive the MIO buses are more dangerous than the old vans on account of their size. It's likely that MIO drivers have limited visibility of those who cycle and that increases the latter's perception, and lived experience, of vulnerability. Neglecting urban space for workers needing mobility creates a kind of inequality of the street level. And it is, according to the environmental justice perspective, an environmental injustice because some people have more benefits than others in both the distribution of infrastructure for travel and in opportunities to influence decisions related to urban transportation. 


\section{Conclusions and Discussion}

The purpose of this dissertation has been to improve understanding of sociospatial transformation processes related to urbanization, economic development and the marginalization of utilitarian cycling in Cali, Colombia, as a particular expression of the struggle for transportation space occurring in urban areas. To do so effectively the research examined the socio-spatial processes that have contributed to constraining the use of bicycles as transportation in a large Latin American city. This research also captures the unequal environmental and economic effects of these constraints on people who currently use bicycles as their primary means of transportation in Cali. By relying on a critical perspective framework, this case study demonstrates that inequality at the street level is related to the particular multi-scale constellation of social and political forces shaping urbanization of Cali and that the resulting inequality in the investment of resources produced by that dynamic, is being consolidated through the implementation of a Bus Rapid Transit (BRT) system and a set of new construction of megaprojects that favor motorized travel, adversely affecting people who use bicycles as a principal means of transportation.

Based on an historical overview of the process of urbanization in Cali, three periods were identified and in each period spatial and social transformations responsive to capital accumulation were observed. The chronological overview reveals that in tandem with Cali's urbanization process, cycling as a means of transportation has been 
losing social and physical space over time. Transformations of the built environment, as part of capitalist urbanization, have been intentional in implementing transportation infrastructure that enables increased productivity and the accumulation of profits. In addition, planning regulations for land use, the support of certain sectors of population for promoting practices to propel urban spatial expansion, and discourses both local and global, based on modernization emulating motor vehicle ownership and use, have created adverse economic and health conditions for biking in this Latin American city. This situation needs to be understood within a context of lack of strong social organizations demanding better conditions to urban mobility on bikes in Cali.

On a more granular local level of analysis, findings of this research show that in responding to the demands of globalization, the city of Cali is reinforcing the marginalization of low-income people who commute by bike out of economic necessity. Consequently, bike commuters experience daily travel in Cali as a classed, problematic, stigmatized, and transitory activity but they also recognize individual health and economic benefits of biking. In Cali bike commuters are mostly black, of lower socioeconomic status and male. They ride their bike for economic reasons. This reality is quite the opposite in other countries, primarily in high-income economies where commuters are white, middle-class, male and ride bikes out of concern for the environment and individual health (Aldred 2014). 
The majority of the literature on utilitarian cycling in high income economies focuses on exploring factors at different levels, from individual characteristics to environmental conditions, associated with cycling. This research goes beyond these concerns, by seeking to understand physical and social urban transformations that constrain biking as a mode of travel. To do so effectively it was necessary to review the history of urbanization in Cali in order to untangle socio-spatial conditions transformations that have undermining condition for cycling. More recent experience in Cali, as is the case in many other Latin American cities, even though there are currently initiatives to promote biking (Pucher, Dill, and Handy 2010; Sarmiento O 2010), most cities face serious economic and political barriers in implementing large and sustainable projects to increase utilitarian biking.

A recent pioneering study (Baumann, Bojacá, Rambeau, and Wanner 2013) about biking in several Latin American cities reports on the deficiencies in physical infrastructure for biking and the lack of government support. Moreover, this research concludes that in those Latin America cities, even though there is the limited infrastructure for biking, there are increasing numbers of bicycle-sharing programs, loans for buying bicycles, and recreational programs such as Ciclovias. Interestingly, these programs do not represent a threat to any motorized oriented city. On the contrary, the private sector, sometimes in partnership with municipal governments, is promoting those programs and taking advantage of this new business. 
In addition to this development, around 190 medium and large cities around the world and 56 of which across Latin America are implementing BRT systems as well. However the report does not discuss biking as a part of the transportation sector. As argued earlier, adopting a critical theoretical perspective to explain the processes and interests shaping the infrastructure of the urban landscape and engaging in a detailed analysis of the historical conditions of the evolution of the transportation sector are best suited to understanding the challenges Latin American cities face in supporting and promoting non-motorized travel, particular in service of the those on the economic margins. The case study of Cali has been useful in describing and analyzing those barriers.

It is interesting to observe that in several cities in Europe, USA, Canada and Australia, biking as a travel mode is achieving greater prominence (Pucher, Buehler, and Seinen 2011), while in Latin American cities, the experience has been the opposite. The obstacles to implementation of non-motorized means of transportation have been formidable and the motorization process accelerating. In this regard, the two sets of experience are in stark juxtaposition. As Stehlin (2014) argues, in the USA "bike culture has become intertwined with accumulation strategies that capitalize on the framing of cycling as one commodity among many which make up the lifestyle of livability” (Stehlin 2014; p. 35). In others words, as Stehlin (2014) elaborates if in the USA the majority of the increase in bike riding occurs in gentrificated areas, then biking is contributing indirectly to "the reurbanization of capital investment" (p. 23). This observation supports 
the preliminary conclusion that within the capitalist system investments in the built environment in any location will only be undertaken if it is profitable, and sometimes as a secondary factor, such investment is beneficial for all society, as would be the case for building infrastructure for biking in gentrified areas.

From another angle, the social conditions for framing understanding of the value of motorization as a means of transportation may be similar to other problematic areas of public health such as with the consumption of tobacco products and health concerns in the food industry. Most wealthy countries, because of changes on the social balance of power are implementing strategies against the tobacco and food industries in order to protect people's health (Alderman J 2006; Hawkes 2007; Hyde 2008). At the same time, however, those industries relocate quickly to other countries to continue their business and production where they are free from such regulatory constraints (Sebrié and Glantz 2006). As is illustrated in this research, the automobile industry is also moving to Latin America countries. This raises a pertinent speculation: is the trajectory of the automobile industry on the same path of experience with the relocation of production and marketing of food and tobacco industries?

Moreover, this research also demonstrates from an environmental justice perspective that the interests of poor people are marginalized in the decision-making processes related to transportation planning and investment. In Colombia urban transportation planning, infrastructure and services are designed to generate profits in 
alignment with the implementation of neoliberal initiatives began since the 1990s. There is a tension in urban planning between transportation as a business and transportation to solve people needs. In Cali this tension is evident. Once the BRT was conceived as the only mass transportation system and to be operated by private agencies, all other means of travel including biking were treated as competing forms of transportation in the market. Under these conditions cyclists of lower socioeconomic status are highly unlikely to be successful, or share an equitable part of the market. Consequently, biking as a mode of travel not will be stimulated under these conditions. Even though citizens should play a key part in the decision making processes for transportation planning, or one might argue that governments have a responsibility to serve the needs of all citizens, particularly the most economically marginalized, there are currently no structures that facilitate participation.

Even though this dissertation reveals that in Cali there is an historical disdain for cycling as a means of travel which has consequences on transport equity, it is relevant to point out that the BRT system solves several mobility problems in the city. In fact, as the main mass transit service in Cali, the BRT solves transportation needs of many lowincome transit riders who depend and use this service daily. More research regarding BRT impacts on people's quality of life, air quality, traffic injuries or transit equity is necessary in order to understand the relative contributions of the BRT and biking in alleviating hardship, and the different socioeconomic sectors most affected by each mode of transportation. 
The implications of this research are four fold. First, biking as a mode of travel should be understood as a political concern that goes beyond current public health and environmental discourses for promoting biking as a way to be a healthy and an ecofriendly citizen. In Latin American cities the disdain and disregard of biking as a means of transportation should be understood as a social injustice to those on the economic margins, similar to their experience with the deprivation of parks, schools, health services, or housing. However, while parks, schools, health services and housing are increasingly gaining acceptance as crucial to social reproduction, biking as transportation and the built environment to support it are still considered a marginal concern.

Second, along with the first implication, the concept of equity needs to be included in discourse and practices to promote biking as a means of transportation from a public health and environmental perspective. As this research shows bike commuters are mostly Afro-Colombian workers, from low socioeconomic strata. Neglecting investments in infrastructure to solve their need for transportation is an issue of distributive justice because those individuals do not have the same rights that other individuals such as motorcyclists, motorists and public transit users have to use road networks to solve their mobility needs. Moreover, in comparison with motorists, cyclists have greater exposure to traffic injuries. These represent a substantial and unequal distribution of risks, as the environmental justice perspective argues. 
Third, analyzing biking as a mode of travel is a complex area of research. In Latin American biking is a historical, multi-scale, place-based and classed issue. Studies that shed light on the complexity of these conditions would sharpen and refine conceptual pathways towards emancipatory initiatives to recover rights to the city that are more equitable across socioeconomic sectors. It is ironic and regrettable that most people who travel by bicycles in Cali are workers from the construction sector since even though they are on the front lines of building the city they have only marginal rights to enjoy it.

Fourth, the complexity of travel by bicycles in urban areas in Latin America is not just an issue of the presence or absence of physical infrastructure. As this research suggests, transforming the built environment has implications on social life. The built environment oriented towards motorized travel and profits embraces certain worldviews and practices such as individualism, speed, competition, fears for physical safety and social and physical fragmentation affecting quality of life, as current cyclists expressed in this research.

Given these implications, it would be useful if the scope of future empirical research about biking in Latin American cities would address two interrelated areas: historical studies about biking in urban areas and social science research about the role of social movements in advocating for cycling. Such studies would shed light on understanding, which, if any, local social groups participate in shaping the city, what roles they play, and what instruments and discourses they use to reflect their interests and 
objectives. An examination of the processes and institutions in cities that, over time, yield more bike friendly infrastructure for utilitarian biking would also be valuable.

Reflecting on the impact of the dynamic of globalization and the resulting problems for human health caused by the food and tobacco industries, another related and interesting area of research would be an examination of the strategies used by the automobile industry to achieve automobile hegemony in Latin American cities.

In closing, some limitations in this research can be identified. First, the historical overview of urbanization process in Cali would have been even more useful had it been possible to complete a more thorough and detailed historical analysis. Unfortunately, historical information about urban transformations, transportation and biking in the city of Cali is rather scarce. In addition, the lack of expertise in historical archival research on the part of the researcher combined with time constrains restricted the historical scope of this study. Nevertheless, to overcome those potential limitations consultations with experts from history and urban studies regarding urban changes in Cali in the $20^{\text {th }}$ century were secured and a professional historian oriented the collection of information from historical archives of Cali.

Second, due to the fact that documents and literature identified on transportation and biking were extensive, it is possible that some issues were not considered or under studied. Third, the point of view from the national transportation office was not included 
in the interviews of stakeholders because the relevant public servant had administrative and time limitations that made participation in this research impossible. The research instead relied on analysis of documents from this office for the study.

Overall the results of this study are valuable because they contribute to more refined understanding of why in a large Latin American urban area there are such challenges to improving conditions for travel by bike. In particular, this case study deconstructs the social processes and transformation that resulted in the constraints placed upon utilitarian cycling in Cali as a particular expression of the struggle for transportation space occurring in urban areas. A struggle which is part of a more general and historical situation involving economic, social and political forces that have led to predominant motorization in the city of Cali, Colombia, privileging the implementation of Bus Rapid Transit, private car and motorcycle usage in the last decades. 


\section{REFERENCES}

Ahumada, Consuelo. 1996. El modelo neoliberal y su impacto en la sociedad colombiana. Bogotá: El Ancora Editores.

Alcaldía de Cali. 1979. "PIDECA: Plan Integral de Desarrollo de Cali." Cali: Alcaldía de Cali.

—. 1980. "Lineamientos para un Plan Vial y de Transporte de Cali y su área de influencia." edited by P. Municipal. Cali: Municipio de Cali.

—. 1993. "Acuerdo 13 de 1993. Plan Vial de tránsito y de transporte 1993-2008." edited by DNP. Cali: Alcaldía de Cali

—. 2010. "Contrato de concesión Megaobras." Pp. 34, edited by S. d. I. y. Valorización. Santiago de Cali: Alcaldía de Cali.

Alderman J, Daynard R. A. 2006. "Applying lessons from tobacco litigation to obesity lawsuits." American Journal of Preventive Medicine 30:82-8.

Aldred, R. Jungnickel K. 2014. "Why culture matters for transport policy: the case of cycling in the UK." Journal of Transport Geography 34:78-87.

Almandoz, Arturo. 2008. "Despegues sin madurez: Urbanización, industrialización y desarrollo en la Latinoamérica del siglo XX." EURE (Santiago) 34:61-76.

Angotti, T. 1987. "Urbanization in Latin America: Toward a Theoretical Synthesis." Latin American Perspectives 14:134-156.

Arboleda, G. and G. Vivas. 1991. Periodos historicos y transporte en Cali. Estudio Plan vial y de transporte de la ciudad de Santiago de Cali., Edited by D. A. d. P. Municipal. Santiago de Cali: AT Editores.

Archila N, M. 2002. "Colombia en el cambio de siglo: actores sociales, guerra y política." Nueva sociedad:14.

Ardila, A. and G. Menckhoff. 2002. "Transportation Policies in Bogota, Colombia: Building a Transportation System for the People." Transportation Research Record: Journal of the Transportation Research Board 1817:130-136.

Ardila, Arturo. 2008. "Limitation of Competition in and for the Public Transportation Market in Developing Countries: Lessons from Latin American Cities." Transportation Research Record: Journal of the Transportation Research Board 2048:8-15.

Attride-Stirling, Jennifer. 2001. "Thematic networks: an analytic tool for qualitative research." Qualitative Research 1:385-405.

Baer, Werner. 1972. "Import Substitution and Industrialization in Latin America: Experiences and Interpretations." Latin American Research Review 7:95-122.

Bailey D, De Ruyter A. Michie J. Tyler P. 2010. "Global restructuring and the auto industry." Cambridge Journal of Regions, Economy and Society 3:311-318.

Baumann, C., M. Bojacá, M. Rambeau, and Z. Wanner. 2013. "Biciudades 2013: Regional study on the use of the bicycle as a mode of transportation in Latin America." Inter American Development Bank.

Beyazit, E. 2011. "Evaluating social justice in transport: Lessons to be learned from the capability approach." Transport Reviews 31:117-134.

Böcker, Lars Dijst Martin Prillwitz Jan. 2013. "Impact of Everyday Weather on Individual Daily Travel Behaviours in Perspective: A Literature Review." Transport Reviews 33:71-91. 
Bonilla Sandoval, Ramiro. 2012. "Modelos urbanísticos en el siglo XX." Pp. 25-85 in Historia de Cali Siglo XX, vol. 1, edited by G. Loaiza Cano. Santiago de Cali: Programa Editorial Facultad de Humanidades, Universidad del Valle.

Bowen, Glenn A. 2009. "Document Analysis as a Qualitative Research Method." Qualitative Research Journal 9:27-40.

Brenner, Neil Theodore Nik. 2005. "Neoliberalism and the urban condition." City 9:101-107.

Broach, Joseph, Jennifer Dill, and John Gliebe. 2012. "Where do cyclists ride? A route choice model developed with revealed preference GPS data." Transportation Research Part $A$ 46:1730-1740.

Bullard, Robert D. 2007. Growing smarter : achieving livable communities, environmental justice, and regional equity. Cambridge, Mass.: MIT Press.

Burawoy, Michael. 2009. The extended case method : four countries, four decades, four great transformations, and one theoretical tradition. Berkeley: University of California Press.

Burns, C. M. and A. D. Inglis. 2007. "Measuring food access in Melbourne: Access to healthy and fast foods by car, bus and foot in an urban municipality in Melbourne." Health \& Place 13:877-885.

Caracciolo, Carlos Héctor. 2009. "Bicicleta, circulación vial y espacio público en la Italia Fascista." Pp. 20-42 in Historia Crítica. Bogotá, Colombia: Universidad de Los Andes.

Cass, Noel, Elizabeth Shove, and John Urry. 2005. "Social exclusion, mobility and access." The Sociological Review 53:539-555.

Castillo, Jairo. 2009. "21 megaobras Cali."

Cavill, N., S. Kahlmeier, H. Rutter, F. Racioppi, and P. Oja. 2008. "Economic analyses of transport infrastructure and policies including health effects related to cycling and walking: A systematic review." JTRP Transport Policy 15:291-304.

Comité automotor colombiano-Fenalco. 2013. "Informe del sector automotor a Diciembre de 2013." Fenalco, Bogotá.

Comité de Ensambladoras de Motos Japonesas. 2013. "Octavo Estudio Socio demográfico de los Usuarios de Motos en Colombia." Bogotá.

Concejo de Cali. 1970. "Plan General de Desarrollo Urbano Cali Área Metropolitana PGD." Santiago de Cali: Concejo de Cali.

CONPES 3167. 2002. "Política para mejorar el servicio de transporte público urbano de pasajeros." edited by D. N. d. Planeación. Bogotá, Colombia.

CONPES 3260. 2003. "Política Nacional de Transporte urbano y masivo." edited by D. N. d. Planeación. Bogotá, Colombia.

CONPES 3305. 2004. "Lineamientos para optimizar la política de desarrollo urbano." edited by D. N. d. Planeación. Bogotá, Colombia.

CONPES 3504. 2007. "Sistema integrado de servicio público urbano de transporte masivo de pasajeros para Santiago de Cali - Seguimiento." edited by D. N. d. Planeación. Bogotá.

CONPES 3767. 2013. "Sistema integrado de servicio público urbano de transporte masivo de pasajeros para Santiago de Cali- Seguimiento." Pp. 41, edited by DNP. Bogotá, Colombia. Corrales, J. 2009. "21 Megaobras. Cobro para todos ¿Beneficio para quién?." Revista La Palabra. Cox, P. 2011. "“'A denial of our boasted civilisation": Rear Lights, Cycle Paths and Conflicts over Road Use in Britain, 1926-1935' "Transfers 2. 
Chakraborty, J. 2006. "Evaluating the environmental justice impacts of transportation improvement projects in the US." Transportation Research Part D: Transport and Environment 11:315-323.

Chapman, L. 2007. "Transport and climate change: a review." Journal of Transport Geography 15:354-367.

Chichilnisky, Graciela and Geoffrey Heal. 1993. "Global Environmental Risks." The Journal of Economic Perspectives 7:65-86.

Davis, A., N. Cavill, H. Rutter, and H. Crombie. 2005. Making the case : improving health through transport. Holborn, London: Health Development Agency.

Davison Kk, Werder J. L. Lawson C. T. 2008. "Children's active commuting to school: current knowledge and future directions." Preventing chronic disease 5.

de Buen, O., M. Juhel, P. O'Neill, M. Plessis-Fraissard, J. Saghir, Z. Shalizi, W. Suchorzewski, and A. Wray. 2008. "Safe, Clean, and Affordable... Transport for Development " World Bank, Washinton DC.

de Carvalho M.L, de Freitas C. M. 2012. "Pedalando em busca de alternativas saudáveis e sustentáveis." Ciencia e Saude Coletiva 17:1617-1628.

de Nazelle, A., MJ. Nieuwenhuijsen, and JM. Antó. 2011. "Improving health through policies that promote active travel: A review of evidence to support integrated health impact assessment." Environment International 37:766-777.

de Roux, Gl. 2008. "Hacia un Valle del Cauca incluyente y pacífico. Informe Regional de Desarrollo Humano. Idh-Valle 2008." PNUD - Gobernación del Valle., Cali.

Delmelle, EC. and I. Casas. 2012. "Evaluating the spatial equity of bus rapid transit-based accessibility patterns in a developing country: The case of Cali, Colombia." Transport Policy 20:36-46.

Diario El País. 2014. "Demandas no frenan megaobras." Cali.

Ding, Ding and Klaus Gebel. 2012. "Built environment, physical activity, and obesity: What have we learned from reviewing the literature?" Health \& Place 18:100-105.

DNP. 2008. "En qué invierte el Estado Colombiano? Los grandes proyectos de inversión del Estado Comunitario en 2008. Sistema integrado de transporte masivo para Santiago de Cali - Mío (Masivo Integrado de Occidente)."6.

Duzán, MJ. 2013. "A los caleños se les ha subido la autoestima." Pp. 1 in Semana. Bogotá: Publicaciones Semana S.A.

Ebert, Anne-Katrin. 2012. "When cycling gets political: Building cycling paths in Germany and the Netherlands, 191040." The Journal of Transport History 33:115-137.

Eitoku, Y and S Misokami. 2010. "An Evaluation Method of Transportation Policies by the Quality of Mobility Index based on Capability Approach." Eastern Asia Society for Transportation Studies 1:12.

Espinosa R, León Darío. 2006. "El Plan Piloto de Cali 1950." Pp. 11 in Bitácora Urbano-Territorial, vol. 1.

Everett, M, A Mejia, and O Quiroz. 2009. "Building evidence to prevent childhood obesity: lessons from the Portland Healthy Eating Active Living (HEAL) Coalition." Practicing anthropology 31:21-26.

Faulkner, Guy E., P. Grootendorst, VH. Nguyen, T. Andreyeva, K. Arbour-Nicitopoulos M, C. Auld, SB. Cash, J. Cawley, and P. Donnelly. 2011. "Economic instruments for obesity 
prevention: results of a scoping review and modified delphi survey." International Journal of Behavioral Nutrition and Physical Activity 8.

Felix, D. 1989. "Import substitution and late industrialization: Latin America and Asia compared." World Development 17:1455-1469.

FES-Univalle. 2010. "Evaluación del impacto de la red de ciclo-rutas en la actividad física utilitaria en la población adulta de Cali. 2010-2013." Universidad del Valle-FES, Cali.

Figueroa P, EA. 2012. "Obras públicas y transformación urbanística de Cali, 1950-1970." Pp. 12 in Historia de Cali siglo XX, vol. 1, edited by G. Loaiza Cano. Santiago de Cali: Programa Editorial Facultad de Humanidades, Universidad del Valle.

Fraser, S. and K. Lock. 2011. "Cycling for transport and public health: a systematic review of the effect of the environment on cycling." The European Journal of Public Health 21:738-743.

Freund, P. and G. Martin. 2000. "Driving South: The globalization of auto consumption and its social organization of space." Capitalism Nature Socialism 11:51-71.

Friedman, M. S., K. E. Powell, and L. Hutwagner. 2001. "Impact of changes in transportation and commuting behaviors during the 1996 Summer Olympic Games in Atlanta on air quality and childhood asthma." JAMA 285:897-905.

Garrett-Peltier, H. 2011. "Pedestrian and bicycle infrastructure: A national study of employment impacts." Political Economy Research Institute, Amherst, MA.

Guerrero, Rodrigo. 2011. "Cali en cifras." Pp. 181. Santiago de Cali: Alcaldia de Cali.

Gwilliam, Kennet. 2002. "Cities on the move: A World Bank urban transport strategy review." The World Bank, Washington DC.

Hallal, P, LF. Gomez, DC. Parra, F. Lobelo, J. Mosquera, AA. Florindo, RS. Reis, M. Pratt, and OL. Sarmiento. 2010. "Lessons learned after 10 years of IPAQ use in Brazil and Colombia." Journal of physical activity \& health 7:259-64.

Handy, S. 2005. "Critical Assessment of the Literature on the Relationships Among Transportation, Land Use, and Physical Activity." Paper prepared for the Transportation Research Board and the Institute of Medicine Committee on Physical Activity, Health, Transportation, and Land Use Washington D.C.

Harvey, David. 1976. "Labor, Capital, and Class Struggle around the Built Environment in Advanced Capitalist Societies." Politics \& Society 6:265-295.

-. 1978. "The urban process under capitalism: a framework for analysis." International Journal of Urban and Regional Research 2:101-131.

—. 2008. "The right to the city." New Left Review 2008.

-. 2012. Rebel cities : from the right to the city to the urban revolution. New York: Verso.

Hawkes, C. 2007. "Regulating and litigating in the public interest: regulating food marketing to young people worldwide: trends and policy drivers." American journal of public health 97:1962-73.

Heinen, E., B. van Wee, and K. Maat. 2010. "Commuting by Bicycle: An Overview of the Literature." Transport Reviews 30:59-96.

Henderson, Jason Mark. 2002. "Contesting the spaces of the automobile: the politics of mobility and the sprawl debate in Atlanta, Georgia."

Hiller, Harry H. 2000. "Mega-events, Urban Boosterism and Growth Strategies: An Analysis of the Objectives and Legitimations of the Cape Town 2004 Olympic Bid." International Journal of Urban and Regional Research 24:449-458. 
Hine, Julian and Fiona Mitchell. 2001. "Better for Everyone? Travel Experiences and Transport Exclusion." Urban Studies 38:319-332.

Hyde, Rob. 2008. "Europe battles with obesity." The Lancet 371:2160-2161.

IPAQ Core Group, M Sjostrom, B Ainsworth, A Bauman, F. Bull, C Craig, and J. Sallis. "IPAQ International Physical Activity Questionnaire.": http://www.ipaq.ki.se/ipaq.htm.

Jaramillo, C., PA. Ríos, and AR. Ortiz. 2009. "Incremento del parque automotor y su influencia en la congestión de las principales ciudades colombianas." Pp. 15, Yumpu. Cali.

Jauhiainen, Jussi S. 2006. "Urbanisation, Capital and Land-Use in Cities." Pp. 179-193 in Place and Location. Studies in Environmental Aesthetics and Semiotics V, edited by V. S. Eva Näripea, Jaak Tomberg. Tallinn: Cultural Endowment of Estonia Estonian Science Foundation.

Jessop, Bob. 2008. "Post-Fordism and the State." Pp. 251-279 in Post-Fordism: Blackwell Publishers Ltd.

Kaplan, J., S. Bascom, D. Ellenbogen, and G. Gerdel. 2012. "Economic Impact of Bicycling and Walking in Vermont. Final Report." Vermont Agency of Transportation.

Kawabata, M. and Q. Shen. 2006. "Job accessibility as an indicator of auto-oriented urban structure: a comparison of Boston and Los Angeles with Tokyo." Environment and Planning B Planning and Design 33:115-130.

Khasnis, A. A. and M. D. Nettleman. 2005. "Global Warming and Infectious Disease." Archives of Medical Research 36:689-696.

Krathwohl, David R. 2009. Methods of educational and social science research : the logic of methods. Long Grove, IL: Waveland Press.

Krizek, KJ, Ann Forsyth, and Laura Baum. 2009. "Walking and Cycling International Literature Review. Final Report." vol. 2011, edited by E. Legarè. Melbourne: Department of Transport. Walking and Cycling Branch. Level 15, 121 Exhibition Street MELBOURNE VIC 3000.

Künzli, N., R. Kaiser, S. Medina, and M. Studnicka. 2000. "Public-health impact of outdoor and traffic-related air pollution: a European assessment." Lancet 356:795-801.

Litman, Todd and Marc Brenman. 2012. "A New Social Equity Agenda For Sustainable Transportation." Victoria Transport Policy Institute.

Liu, Feng. 2001. Environmental justice analysis : theories, methods, and practice. Boca Raton: Lewis Publishers.

López A, O., JC. Escudero, and LD. Carmona. 2008. "Los determinantes sociales de la salud. Una perspectiva desde el Taller Latinoamericano de Determinantes Sociales de la Salud, ALAMES." Pp. 323-335 in Taller Latinoamericano de Determinantes Sociales de la Salud, vol. 3, edited by ALAMES. Ciudad de México.

Lubans, DR., CA. Boreham, P. Kelly, and CE. Foster. 2011. "The relationship between active travel to school and health-related fitness in children and adolescents: a systematic review." Journal of Behavioral Nutrition and Physical Activity 8:5.

Lucas, Karen. 2012. "Transport and social exclusion: Where are we now?" Transport Policy 20:105-113.

Lucas, Karen and Peter Jones. 2012. "Social impacts and equity issues in transport: an introduction." Journal of Transport Geography 21.

Lupano, J. and R. Sánchez. 2009. "Políticas de movilidad urbana e infraestructura urbana de transporte." NU Cepal, Santiago, Chile. 
Marin, JA. and C. Gil. 2011. "Seguimiento a los Sistemas Integrados de Transporte Masivos SITM." Pp. 14-17 in Infraestructura \& desarrollo. Bogotá, Colombia: Camara Colombiana de la infraestructura.

Martens, K. 2012. "Justice in transport as justice in accessibility: Applying Walzer's 'Spheres of Justice' to the transport sector." Transportation 39:1035-1053.

-. 2013. "Role of the bicycle in the limitation of Transport Poverty in the Netherlands." Transportation Research Record: Journal of the Transportation Research Board 2387:2025.

Martens, K., A. Golub, and G. Robinson. 2012. "A justice-theoretic approach to the distribution of transportation benefits: Implications for transportation planning practice in the United States." Transportation Research Part A 46:684-695.

Martin, A. Suhrcke M. Ogilvie D. 2012. "Financial Incentives to Promote Active Travel: An Evidence Review and Economic Framework." American Journal of Preventive Medicine 43:e45-e57.

McCarthy, M. 2005. "Transport and health." Pp. 132-154 in Social determinants of Health, edited by M. Marmot and R. G. Wilkinson.

McMichael, Philip. 2012. Development and social change : a global perspective. Los Angeles: SAGE.

Meléndez A, M. and G. Perry R. 2009. "Industrial policies in Colombia." Fedesarrollo, Bogotá, Colombia.

Metrocali. "Descripción." Santiago de Cali.

Mitric, Slobodan. 2013. "Urban transport lending by the World Bank: The last decade." Research in Transportation Economics 40:19-33.

Molina, Patricia. 2012. "Presidenta de Metro Cali revela situación real del sistema MIO y su futuro inmediato."

Monark de Colombia S.A. 1969. La industria de las bicicletas en Colombia. Cali: Fábrica de Bicicletas Monark de Colombia S.A. \& Industria Colombiana de Bicicletas El Balin.

Moodie M, Sheppard L. Keating C. Flego A. Sacks G. 2013. "Cost-Effectiveness of Fiscal Policies to Prevent Obesity." Current Obesity Reports 2:211-224.

Morgan, D. L. 2007. "Paradigms Lost and Pragmatism Regained: Methodological Implications of Combining Qualitative and Quantitative Methods." Journal of Mixed Methods Research 1:48-76.

Morrison, D. S., M. Petticrew, and H. Thomson. 2003. "What are the most effective ways of improving population health through transport interventions? Evidence from systematic reviews." Journal of Epidemiology \& Community Health 57.

Nordbakke, S. 2013. "Capabilities for mobility among urban older women: barriers, strategies and options." Journal of Transport Geography 26:166-174.

O'Rourke, D. and Connolly S. 2003. "Just Oil? The Distribution of Environmental and Social Impacts of Oil Production and Consumption." Annual Review Of Energy And the Environment 28:587-618.

Office of the Deputy Prime Minister of Great Britain. 2003. Making the connections : final report on transport and social exclusion. London: Social Exclusion Unit.

Oja, P. Titze S. Bauman A. de Geus B. Krenn P. Reger and Nash B. Kohlberger T. 2011. "Health benefits of cycling: a systematic review." Scandinavian Journal of Medicine \& Science in Sports 21. 
Oldenziel, Ruth and Albert de la Bruhèze Adri. 2011. "Contested Spaces: Bicycle Lanes in Urban Europe, 19001995." Transfers 1:29-49.

Ospina G, J I. 2008a. "Plan de Desarrollo 2008 - 2011 "Para vivir la vida dignamente" ". Santiago de Cali.

Ospina G, Jorge I. 2008b. "Acuerdo 241 Megaobras." Pp. 23. Santiago de Cali: Alcaldía de Cali.

Parra, D. C., C. M. Hoehner, P. C. Hallal, I. C. Ribeiro, R. Reis, R. C. Brownson, M. Pratt, and E. J. Simoes. 2011. "Perceived environmental correlates of physical activity for leisure and transportation in Curitiba, Brazil." Preventive Medicine 52:234-238.

Pendola, R. and S. Gen. 2007. "BMI, auto use, and the urban environment in San Francisco." Health and Place 13:551-556.

Perfetti del C., M, D Silva A., and EE Freire D. 2013. "Encuesta Nacional de Calidad de Vida ECV." edited by DANE. Bogotá, Colombia: DANE.

Persaud, Thakour, Oscar Alvarado, and Mauricio Cuellar. 1976. "Staff Appraisal Report Colombia. Bogotá Urban Transport Project \& Loan." World Bank.

Pinto, MT. 2008. "La disputa política en torno a la alcaldía de Cali de 2007." Pp. 26 in Sociedad y Economía. Santiago de Cali: Universidad del Valle.

Powell J, Dalton A. Brand C. Ogilvie D. 2010. "The health economic case for infrastructure to promote active travel: A critical review." Built Environment 36:504-518.

Proexport. 2012. "Automotive Industry in Colombia." Proexport, Bogota, Colombia.

Pucher, J., R. Buehler, and M. Seinen. 2011. "Bicycling renaissance in North America? An update and re-appraisal of cycling trends and policies." TRA Transportation Research Part A 45:451-475.

Pucher, J., J. Dill, and S. Handy. 2010. "Infrastructure, programs, and policies to increase bicycling: an international review." Preventive Medicine 48 (S1):S106-25.

Quiroga, JP., LC. Munar, and MF Peña. 2012. "Análisis estratégico del sector automotriz en Colombia." Administración de empresas. Facultad de Administración, Universidad del Rosario, Bogotá DC.

Roberts, I., R. Wentz, and P. Edwards. 2006. "Car manufacturers and global road safety: a word frequency analysis of road safety documents." Injury prevention : journal of the International Society for Child and Adolescent Injury Prevention 12:320-2.

Robeyns, Ingrid. 2003 a. "Sen's capability approach and gender inequality: Selecting relevant capabilities." Feminist Economics 9:2-3.

Rodrigue, J.P., C. Comtois, and B. Slack. 2009. "Urban Transportation." Pp. 172-202 in The Geography of Transport Systems: Taylor \& Francis.

Rogat, J., M. Hinostroza, and K. Ernest. 2009. "Promoting Sustainable Transport in Latin America through Mass Transit Technologies." Pp. 9 in Colloque international Environnement et transports dans des contextes différents. Ghardaïa, Algérie, 16-18 fév. 2009.: Actes, ENP ed., Alger.

Rongfang Liu, Chang-Qian Guan. 2005. "Mode Biases of Urban Transportation Policies in China and Their Implications." Journal of Urban Planning \& Development 131.

Saenz, JD. 2012. "La élite política y sus decisiones sobre la espacialidad en Cali de 1958 a 1998." Pp. 296-326 in Historia de Cali Siglo XX, vol. 2, edited by G. Loaiza Cano. Santiago de Cali: Programa Editorial Facultad de Humanidades, Universidad del Valle. .

Sallis, JF., LD. Frank, BE. Saelens, and M. K. Kraft. 2004. "Active transportation and physical activity: opportunities for collaboration on transportation and public health research." 
Transportation Research Part A: Policy and Practice Transportation Research Part A: Policy and Practice 38:249-268.

Sarmiento O, Torres A. Jacoby E. Pratt M. Schmid T. L. Stierling G. 2010. "The Ciclovía-Recreativa: A mass-recreational program with public health potential." Journal of physical activity \& health 7:163-80.

Sassen, Saskia. 1996. "Whose City Is It? Globalization and the Formation of New Claims." Public culture : bulletin of the Project for Transnational Cultural Studies. 8:205.

Saunders, L., J. M. Green, M. P. Petticrew, R. Steinbach, and H. Roberts. 2013. "What are the health benefits of active travel? A systematic review of trials and cohort studies." PloS one 8.

Scott, W. 2002. "Assessment of the Non-Motorized Transport Program: Kenia and Tanzania " World Bank.

Schweitzer, Lisa and Abel Valenzuela. 2004. "Environmental Injustice and Transportation: The Claims and the Evidence." Journal of Planning Literature 18:383-398.

Sebrié, E. and SA. Glantz. 2006. "The Tobacco Industry In Developing Countries: Has Forestalled Legislation On Tobacco Control." British Medical Journal 332:313-314.

Sen, Amartya. 1989. "Development as Capability expansion." Journal of Development Planning 19:18.

Sen, Siddhartha. 2008. "Environmental Justice in Transportation Planning and Policy: A View From Practitioners and Other Stakeholders in the Baltimore-Washington, D.C. Metropolitan Region." Journal of Urban Technology 15:117-138.

Shemilt, I., G. J. Hollands, T. M. Marteau, Nakamura R., Jebb S.A., Kelly M. P., Suhrcke M., and Ogilvie D. 2013. "Economic Instruments for Population Diet and Physical Activity Behaviour Change: A Systematic Scoping Review." PLOS ONE 8.

Starkey, P. 2001. "Local transport solutions. People, paradoxes and progress 2001. Lessons arising from the spread of intermediate means of transport." World Bank.

Stehlin, John. 2014. "Regulating Inclusion: Spatial Form, Social Process, and the Normalization of Cycling Practice in the USA." Mobilities 9:21-41.

Stoffers, M. 2012. "Cycling as heritage: Representing the history of cycling in the Netherlands." Journal of Transport History 33:92-114.

Sze, Julie and Jonathan K. London. 2008. "Environmental Justice at the Crossroads." Sociology Compass 2:1331-1354.

Taylor, D. E. 2000. "The Rise of the Environmental Justice Paradigm: Injustice Framing and the Social Construction of Environmental Discourses." American Behavioral Scientist 43:508580.

Tellez, J, M Hernandez, MC Llanes, and JC Suarez. 2012. "Colombia Situación automotriz." BBVA.

Transmilenio. 2013. "Historia de Transmilenio." vol. 2013, edited by Imaginamos. Bogotá, Colombia.

U.N. 2009. "Urban and Rural Areas 2009." edited by P. Division. New York, USA: United Nations Department of Economic and Social Affairs.

UN-Habitat. 2012. "State of the World's Cities Report 2012/2013: Prosperity of Cities." UNHabitat, Nairobi, Kenia.

Ureta, Sebastian. 2008. "To Move or Not to Move? Social Exclusion, Accessibility and Daily Mobility among the Low-income Population in Santiago, Chile." Mobilities 3:269-289. 
Urrea, F. and F Murillo. 1999. "Dinámica del poblamiento y algunas características de los asentamientos populares con población afrocolombiana en el oriente de Cali." in Observatorio Socio-político y Cultural sobre "Desplazados, migraciones internas y reestructuraciones territoriales", edited by Cidse-IRD. Bogotá, Colombia: CLACSO.

Vargas da Cruz, MJ. and C.F. Camargo Rolim. 2010. "The Brazilian automotive industry in the BRICs context: the case of the Metropolitan Region of Curitiba." Cambridge Journal of Regions, Economy and Society 3:319-334.

Vasconcellos, E. A. 1997a. "The demand for cars in developing countries." Transportation research. Part $A$, Policy and practice. 31:245.

-. 1997b. "The making of the middle-class city: Transportation policy in Sao Paulo." Environment \& Planning A 29.

Vasconcellos, Eduardo Alcântara. 2001. Urban transport, environment and equity : the case for developing countries. London: Earthscan.

Vasquez B, E. 2001. Historia de Cali en el siglo 20: sociedad, economía, cultura y espacio. Santiago de Cali: Universidad del Valle.

Walker, Gordon. 2009. "Beyond Distribution and Proximity: Exploring the Multiple Spatialities of Environmental Justice." Antipode 41:614-636.

Walzer, Michael. 1983. Spheres of justice : a defense of pluralism and equality. New York: Basic Books.

Wei, Longyu, Feifei Xin, Kang An, and Yitong Ye. 2013. "Comparison Study on Travel Characteristics between Two Kinds of Electric Bike." Procedia-Social and Behavioral Sciences 96:1603-1610.

World Bank. 1972. "Urbanization. Sector working paper." The World Bank, Washington DC.

-. 1975. "Urban transport. Sector policy paper." The World Bank, Washington DC.

-. 1996. "Sustainable transport: Priorities for policy reform. Development in practice." The World Bank, Washington DC.

-. 2007. "Transport Lending Trends 1996-2007." vol. 2013. Washington: The World Bank.

-. 2011. "Support to the National Urban Transit Program Project." Washington DC.

Yago, Glenn. 1983. "The Sociology of Transportation." Annual Review of Sociology 9:171-190.

Zenk, S. N., A. J. Schulz, B. A. Israel, S. A. James, S. Bao, and M. L. Wilson. 2005. "Neighborhood racial composition, neighborhood poverty, and the spatial accessibility of supermarkets in metropolitan Detroit." American journal of public health 95:660-7.

Zhang H, Shaheen S. A. Chen X. 2014. "Bicycle Evolution in China: From the 1900s to the Present." International Journal of Sustainable Transportation 8:317-335.

Zuleta L, JE and F Bernal B. 2001. "Los VI Juegos Panamericanos en Cali: Una visión alternativa de su impacto en la ciudad y de sus gentes.", Facultad de Humanidades- Departamento de Historia, U del Valle, Santiago de Cali. 
Appendix A. Forum and journals

\section{Boletín informativo}

\section{La bicicleta, como medio de transporte en Cali, tema de discusión en Foro de Salud Pública}

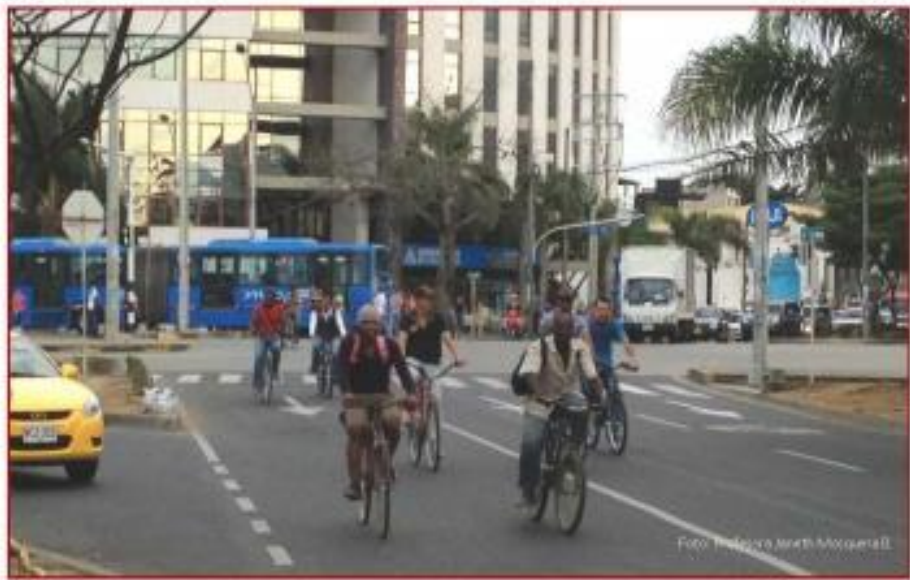

El probimo miércoles 25 de septiembre de 2013 . de $400 \mathrm{pm}$ a $7: 00 \mathrm{pm}$, en el auditcrio fves Chatain de la Facultad de Salud de la Universidad del Valle, campus San Ferrando, en Call, se realizará una nueva sesión de los forcs para la Salud Pública. El terna será "La biciclota, como medio de transporte en Call. La entrada al Foro es libre. Se debe confirmar asistencia.

Identificar las limitantes actuales que entrenta la ciudad Cali para promover el uso de la bicicleta como medio de transporte y debatir en torno a la necesidad de profundizar en el conocimiento de la relación entre transporte y salud en Colombia. son las propósitos centrales del foro que se realizará el próximo miércoles 25 de septiembre de 2013 , de $4.00 \mathrm{pm}$ a $7.00 \mathrm{pm}$, en el auditorio Ives Chatain de la Facultad de Salud de la Universidad del Valle, campus San Fernando

En Cali se vienen desarrollando varios esfuerzos con el objetivo de incentivar el uso de bicicleta entre los ciudadanos; sin embargo, estas iniciativas no parecen estar consiguiendo su objetivo. "Cali, pese a tener una tradición en el uso de bicicleta como medio de transporte también viene experimentado un proceso de incremento en el uso del transporte motorizado. Los medios de transporte no motorizados como la bicicleta. no sólo contribuyen a impactar positivamente la salud de la población sino que también mejoran las condiciones ambientales en las ciudades', explican los promotores de este Foro.

"El acelerado proceso de motorización que viven nuestras ciudades está trayendo consecuencias negativas en la salud poblacional, el ambiente y en la equidad social", explican las profesoras Janeth Mosquera Becerra y OIga Lucía Gómez de la Escuela de Salud Pública de la Universidad del Valle e 


\section{Boletín informativo}

No 27-Año 2 - Santiago de Cali, 16 de septiembre de 2013

FACULTAD DE SALUD

ESCUELA DE SALUD PÚBLICA

Dirección

investigadoras del Grupo de Investigación en Epidemiología y Salud Poblacional, GESP, de esta misma institución.

Según las expertas, el transporte es un determinante social de la salud que afecta asuntos de cohesión social, segregación espacial, acceso a servicios y a bienes, así como la salud respiratoria, lesiones de tránsito y las oportunidades para ser activo físicamente, entre otros aspectos. Por lo tanto, se recomienda implementar transportes más saludables.

A este Foro están convocados profesores y estudiantes universitarios de pre y posgrado, activistas del transporte en bicicleta, comunidad en general y representantes del sector empresarial público y privado del nivel local.

Temas centrales

El Foro se desarrollará mediante presentaciones por parte de investigadores, activistas y representantes del gobierno local y posteriormente se promoverá la participación de los asistentes a través de preguntas directas dirigidas a los presentadores y una discusión orientada por un moderador.

Durante este Foro se divulgarán también los resultados del proyecto de investigación "Evaluación del impacto de la red de ciclo-rutas en la actividad física utilitaria en la población adulta de Cali", realizado por el grupo de investigación GESP de la Escuela de Salud Pública de la Universidad del Valle, con la financiación de Colciencias y mediante convenio con la Fundación FES Social.

\section{Transmisión en línea}

Este evento hace parte de los "Foros para la Salud Pública" que realiza permanentemente la Escuela de Salud Pública de la Universidad del Valle, con el fin de promover el análisis, el conocimiento y el debate en relación con asuntos críticos que afectan la salud pública en el país.

La entrada es libre, confirmando asistencia a los correos comunicaciones.esp@correounivalle.edu.co y extensión.saludpublica@correounivalle.edu.co El Foro sobre se podrá acceder también de manera virtual, a través del sitio web de la Escuela de Salud Pública http://saludpublica.univalle.edu.co/

Más información:

Escuela de Salud Pública - Facultad de Salud - Universidad del Valle. Teléfonos: 5542480 - 5542476 Correo electrónico: comunicaciones.esp@correounivalle.edu.co Boletin Institucional Escuela de Salud Pública mmw.boletinesp-univalle.info www.forosparalasaludpublica.com

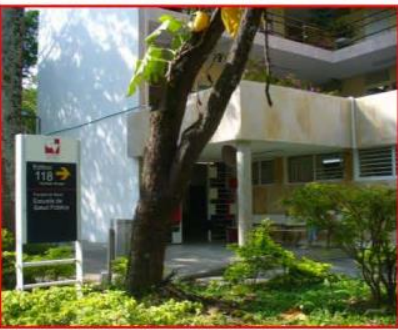

\section{Escuela de Salud Pública - Facultad de Salud Universidad del Valle}

Desde su creación en 1954 ha sido reconocida a nivel nacional e internacional por sus importantes aportes académicos, investigativos y de proyección social en beneficio del bienestar, la calidad de vida y el desarrollo social.

Misión:

Generar competencias individuales e institucionales para impactar favorablemente la salud pública y contribuir a la justicia social en la región y el pais. 
12

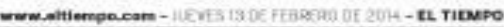

\section{Río Cauca, 'laboratorio' para estudio climático}

Imvestigadores de Univalle buscan determinar impactos en la salud de quienes habitan cuenca del río Cauca. En Bolivia analizarán cuenca del Pilcomayo.
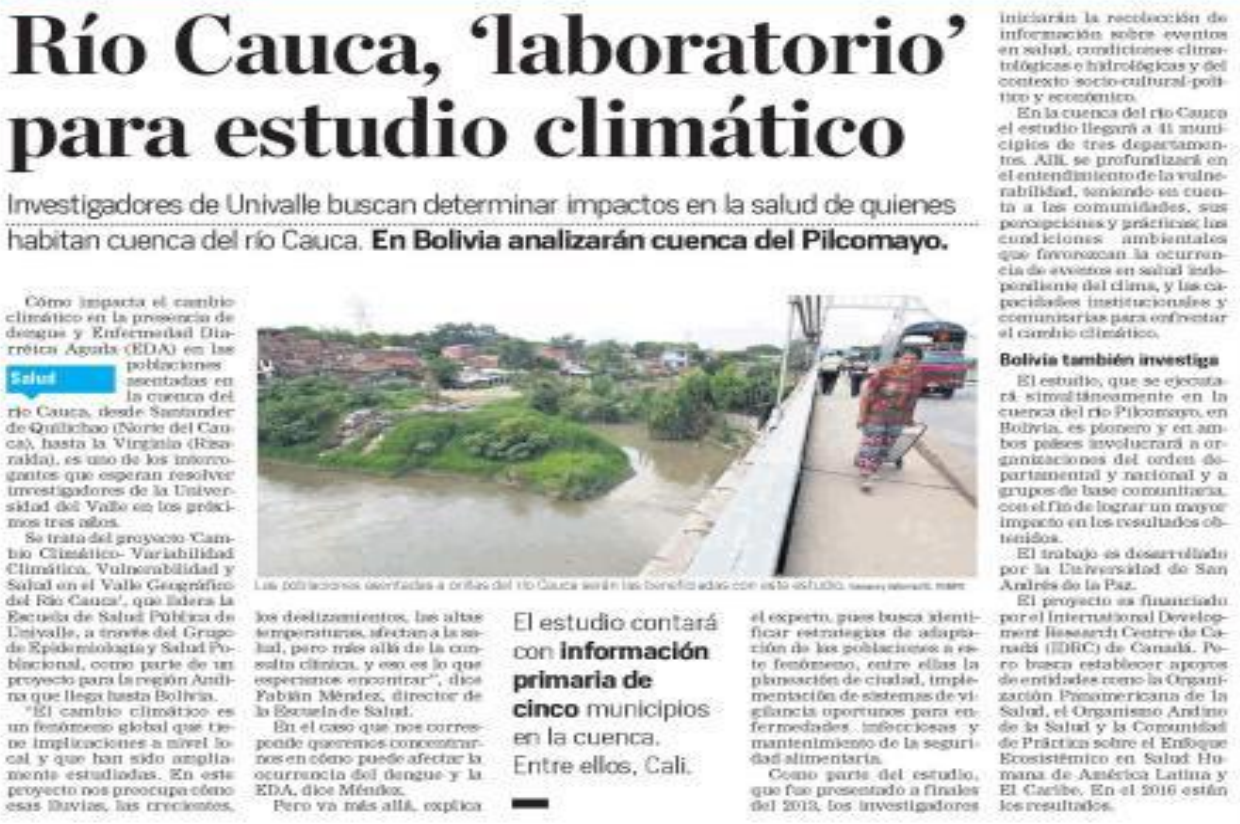

\section{Ahora el propósito en Cali es cero basuras}
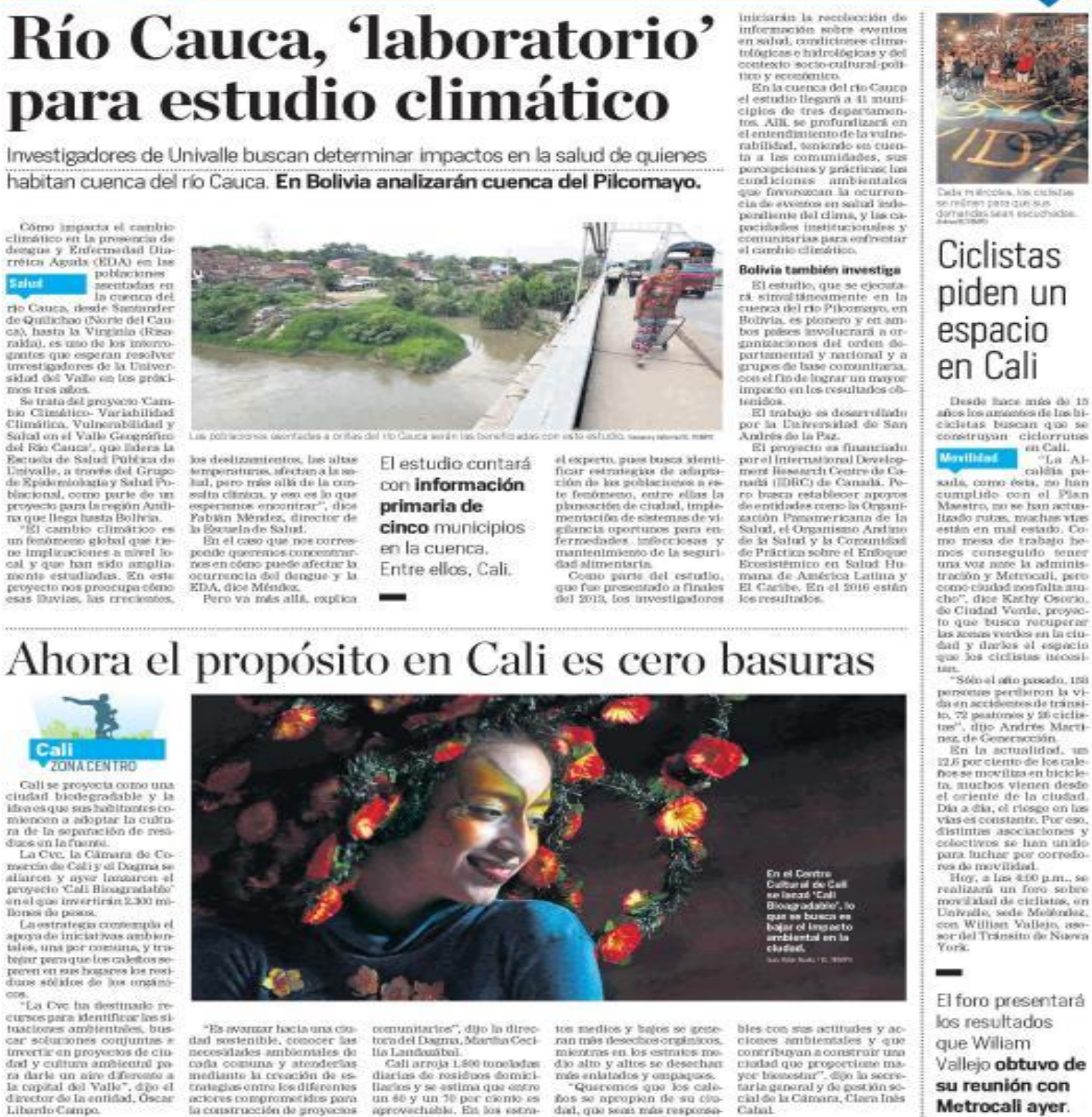

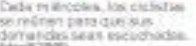

Ciclistas

piden un

espacio

en Cali

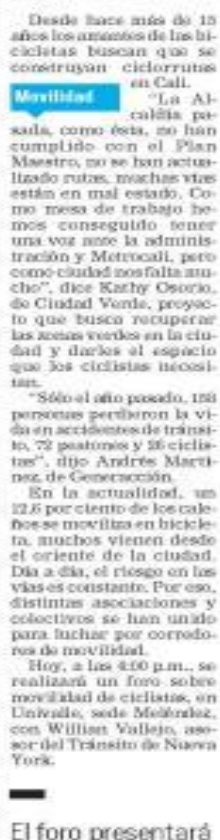

El foro presentar

los resultados

que Wiliam

Vallejo obtuvo de

su reunión con

Metrocall ayer.

Cibernautas que se

dedican a señalar

dónde hay fotomultas
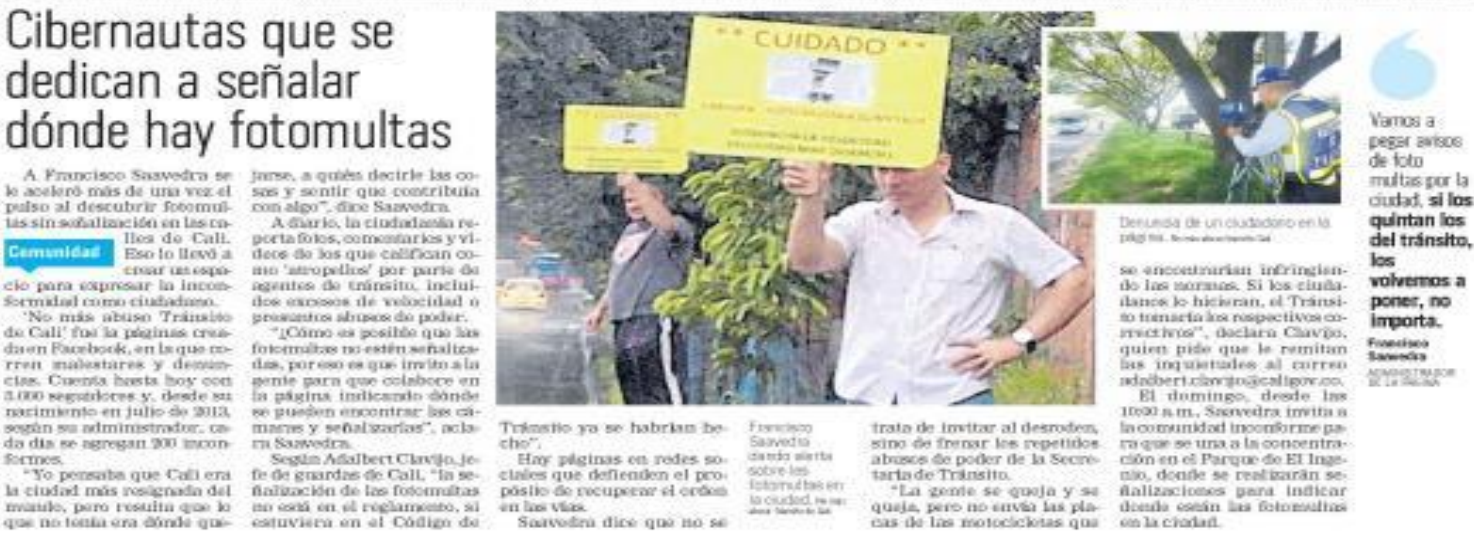


\section{Appendix B. Interview guides Individual Interview Guides}

Name:

Institution:

Position:

Time in this position:

Previous positions:

Academic degrees:

Titles:

Current address:

Gender:

Race/ethnicity

\section{Group 1: Public Officials from health and}

\section{Transportation sector and BRT officers}

1. Overall, $¿$ What is your vision of the transportation situation in Cali? (Exploring major problems, temporality, responsible, affected, solutions or alternatives)

2. What are the major challenges that currently Cali faces in terms of transportation?

3. In terms of equity, what is your vision of urban transportation in Cali?

4. In terms of health, what is your vision of urban transportation in Cali?

Compared to other cities, what advantages and disadvantages have Cali in terms of transportation?

5. What is your ideal city in terms of transportation system?

6. In general, which means of transport do officials of this organization use daily? Which means of transport do you use in your daily life?

7. In terms of transportation policy and planning of the city, what is the relationship between the national government and the local government department? (Exploring responsibilities, resources and capabilities of each level)

8. Explain or describe, please, the decision making process of building the BRT in Cali (Exploring participants, decisions, priorities, and timing)

9. What does the BRT mean to Cali (exploring mobility, access. health, equity, and accessibility)

10. In Cali, as in other Colombian and Latin American cities, building bike paths articulated to the BRT was considered, so, how was the process of defining the construction of bike paths articulated to the BRT in Cali? (Exploring timing, participants, resources, and arguments); what happened to this initiative in Cali? (Exploring resources, local and national forces for and against, and arguments)

11. From you point of view, Building a network of bike paths articulated to the BRT in Cali, How feasible (technical, social, political and economic) it is?

12. In your view, what are the biggest obstacles to implementing a multimodal transportation system in Cali (bicycling and walking as means of transportation)? (Exploring interests and stakeholders)

13. Where Colombia and Cali are going in terms of urban transportation? (Exploring interests, stakeholders and arguments)

14. Do you ride a bike regularly in Cali? (Recreational, transportation) Does anyone in your family bike ride? (Recreational, transportation)

15. Is there anything I have not asked about the BRT or transportation system and on bike paths, that you would like that we explore more? 


\section{Group 2. Bike pro activists}

1. Overall, $¿$ What is your vision of the transportation situation in Cali? (Exploring major problems, temporality, responsible, affected, solutions or alternatives)

2. ¿What are the major challenges that currently Cali faces in terms of transportation?

3. In terms of equity, what is your vision of urban transportation in Cali?

4. In terms of health, what is your vision of urban transportation in Cali?

5. In general, which means of transport do officials of this organization use daily? Which means of transportation do you use in your daily life?

6. How social organizations participated in the decision process of building mine in Cali? (participants, decisions, priorities, timing)

7. What does the BRT mean to Cali (exploring mobility, access. health, equity, and accessibility)

8. In your view, what are the biggest obstacles to implementing a multimodal transportation system in Cali (bicycling and walking as means of transportation)? (Exploring interests and stakeholders)

9. How is it defined that should build bike paths articulated mine in Cali? (timing, participants, resources, major developers and their arguments)

What happened with this initiative in Cali? (Resources, local and national forces for and against, major developers and their arguments)

10. Compared to other cities, what advantages and disadvantages have Cali in terms of bicycle use for transportation?

11. Where Cali is going in terms of urban transportation? (Exploring interests, stakeholders and arguments)

12. Do you ride a bike regularly in Cali? (Recreational, transportation) Does anyone in your family bike ride? (Recreational, transportation)

13. ¿Is there anything I have not asked about the BRT or transportation system and on bike paths, that you would like that we explore more?

\section{Group 3. Researchers}

1. Overall, ¿What is your vision of the transportation situation in Cali? (Exploring major problems, temporality, responsible, affected, solutions or alternatives)

2. What are the major challenges that currently Cali faces in terms of transportation?

3. In terms of equity, what is your vision of urban transportation in Cali?

4. What are the major challenges that currently Cali in terms of transport and health?

5. In general, which means of transport do officials of this organization use daily? Which means of transport do you use in your daily life?

6. How did this organization participate in the decision to build mine in Cali? (participants, decisions, priorities, timing)

7. What does the BRT mean to Cali (exploring mobility, access. health, equity, and accessibility)

8. In Cali, as in other Colombian and Latin American cities, building bike paths articulated to the BRT was considered, so, how was the process of defining the construction of bike paths articulated to the BRT in Cali? (Exploring timing, participants, resources, and arguments); what happened to this initiative in Cali? (Exploring resources, local and national forces for and against, and arguments)

9. In terms of health benefits, do you think that is sought or was sought with these bike paths?

10. In your view, what are the biggest obstacles to implementing a multimodal transportation system in Cali (bicycling and walking as means of transportation)? (Exploring interests and stakeholders)

11. Where Colombia and Cali are going in terms of urban transportation? (Exploring interests, stakeholders and arguments) 
12. Do you ride a bike regularly in Cali? (Recreational, transportation) Does anyone in your family bike ride? (Recreational, transportation)

13. ¿Is there anything I have not asked about the BRT or transportation system and on bike paths, that you would like that we explore more? 
Appendix C. Interview guide (cyclists)

Focus: Biking use as a means of transportation in Cali

Name

Academic level

Gender

Race/ethnicity

Age

Birth place

Family composition

\section{Topics:}

1. The experience of using bike in Cali

2. Advantages and disadvantages of using a bike as a mode of travel in Cali

3. Transportation in Cali: main problems, people affected, responsible and alternatives.

4. Relationship between equity, health and urban mobility in Cali

5. Views about who is using a bike as a mode of travel in Cali

6. Experience of participation in pro-biking organizations

7. Transportation means used by relatives, friends and coworkers

8. Barriers ad facilitators to use a bike as a means of transportation in Cali

9. MIO implementation and the experience of biking as a mode of travel in Cali of MIO (before and after) 